Linköping University Medical Dissertations

No. 1529

\title{
ASPECTS OF THE PRE-DIABETIC PERIOD IN TYPE 1 DIABETES
}

\author{
Linda Åkerman
}

\author{
Division of Pediatrics \\ Department of Clinical and Experimental Medicine \\ Faculty of Health Sciences, Linköping University \\ SE-581 85 Linköping, Sweden
}


(C) Linda Åkerman 2016

ISBN: 978-91-7685-711-3

ISSN: 0345-0082

Paper II has been reprinted with permission from the copyright holder Elsevier.

The blue circle for diabetes in the cover art was used with permission from The International Diabetes Federation (IDF), who holds all rights to it.

During the course of the research underlying this thesis, Linda Åkerman was enrolled in Forum Scientium, a multidisciplinary doctoral programme at Linköping University, Sweden.

Printed by LiU-Tryck, Linköping, Sweden, 2016 


\section{ABSTRACT}

Type 1 diabetes (T1D) is an autoimmune disease characterized by insulin deficiency, due to immune-mediated destruction of beta cells. Current knowledge regarding the period preceding disease onset comes, to a large extent, from studying risk cohorts based on relatives of T1D-patients, as they have an increased disease risk. Among T1D patients in general, however, few have the disease in their immediate family. It is therefore important to study risk cohorts from the general population as well. An ongoing autoimmune reaction can often be seen in the blood long before disease onset, by detection of autoantibodies directed towards beta cell antigens. By autoantibody screening among participants in the ABIS (All Babies in the South-east of Sweden) cohort, we could identify a group of children from the general population with increased risk for T1D, positive for multiple autoantibodies. They were enrolled in a 2-year prospective follow-up aiming to characterize the prediabetic period and to identify factors indicative of progression/non-progression to T1D. We assessed glucose homeostasis and autoantibody titers over time, and searched for risk-biomarkers by analyzing the expression of immune-related genes (Th1-Th2-Th3) in peripheral blood mononuclear cells (PBMC) from these children, in comparison to healthy children and newly diagnosed T1D patients. In the same groups we also compared serum micro RNA (miRNA) profiles, knowing that miRNA molecules have desirable biomarker properties. We found that two specific autoantibodies, IA2A and ZnT8A, were detected at higher concentrations in riskindividuals who progressed to overt T1D during or after the follow-up period, compared to those who still have not. We also observed disturbed glucose homeostasis long before onset in the progressors, but it was seen among those who remain symptom free as well. Further, we found support for the possible role of insulin resistance as an accelerator of the disease process. For gene expression and serum miRNA, few differences were observed between risk-individuals and healthy children overall. However, for PBMC gene expression and serum miRNA both, there were associations to beta cell function and glucose homeostasis, and for miRNA also to islet autoantibodies. Although specific profiles for prediction of disease onset or identification of risk-individuals could not be found, these results are interesting and deserve to be evaluated further. As part of another sub-study within ABIS, the effects of physical activity on glucose homeostasis were assessed in healthy schoolchildren. The level of physical activity, measured by pedometers, was related to insulin resistance and beta cell-stress, and decreased physical activity was associated with increased insulin resistance and load on the insulin-producing beta cells, already at school-age. 


\section{SUPERVISOR}

Rosaura Casas, Associate Professor

Division of Pediatrics, Department of Clinical and Experimental Medicine,

Faculty of Health Sciences, Linköping University, Linköping, Sweden

\section{CO-SUPERVISOR}

Johnny Ludvigsson, Professor Emeritus

Division of Pediatrics, Department of Clinical and Experimental Medicine,

Faculty of Health Sciences, Linköping University, Linköping, Sweden

\section{OPPONENT}

Susan Wong, Professor

Institute of Molecular \& Experimental Medicine

Cardiff University, Cardiff, UK

\section{COMMITTEE BOARD}

Jonas Wetterö, Docent

Autoimmunity and Immune Regulation Unit (AIR)/Rheumatology, Department of Clinical and Experimental Medicine

Faculty of Health Sciences, Linköping University, Linköping, Sweden

Daniel Agardh, Associate Professor

Unit for Diabetes and Celiac Disease, Department of Clinical Sciences,

Faculty of Medicine, Lund University, Malmö, Sweden

Xiao-Feng Sun, Professor

Division of Oncology, Department of Clinical and Experimental Medicine

Faculty of Health Sciences, Linköping University, Linköping, Sweden 
POPULÄRVETENSKAPLIG SAMMANFATTNING ….................................................... 1

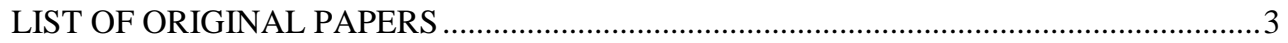

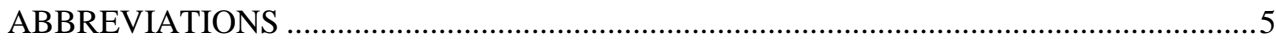

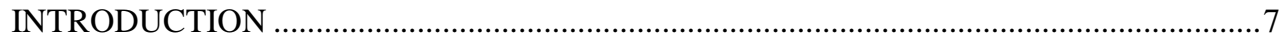

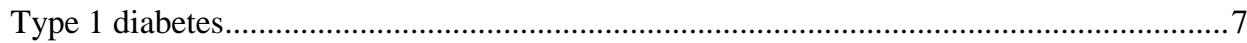

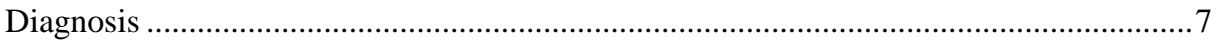

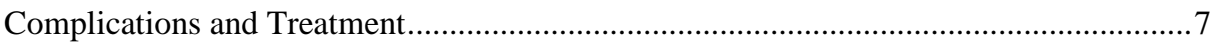

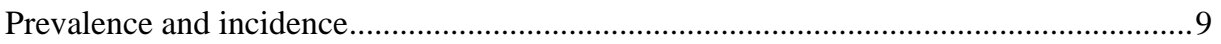

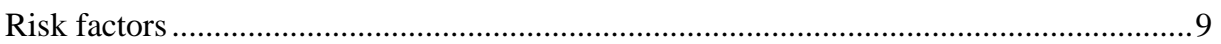

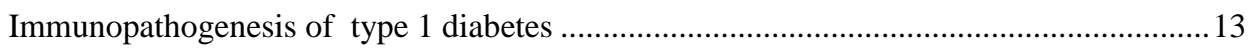

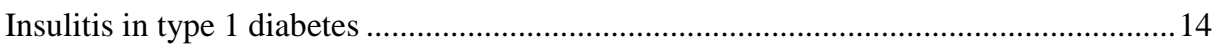

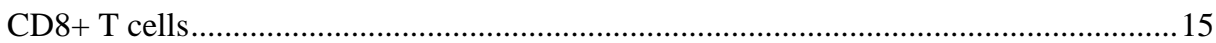

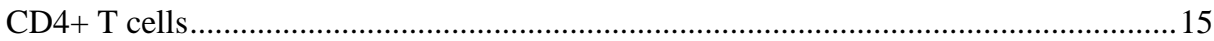

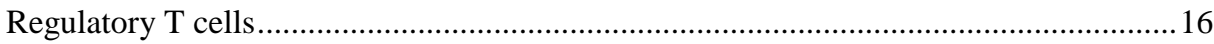

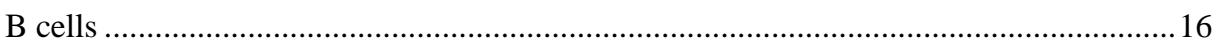

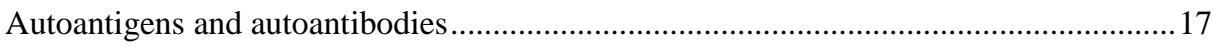

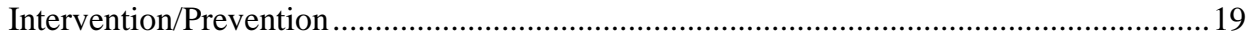

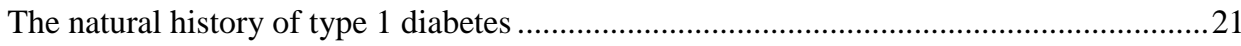

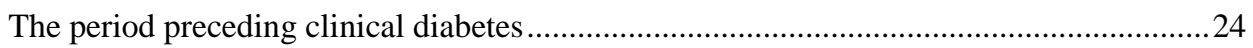

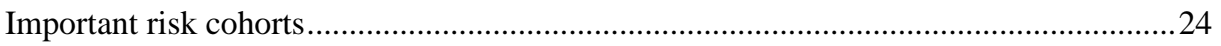

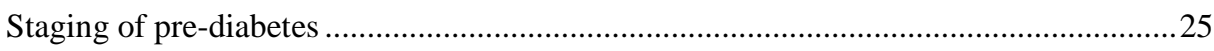

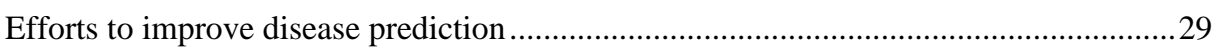

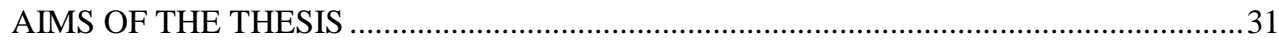

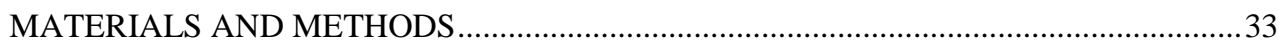

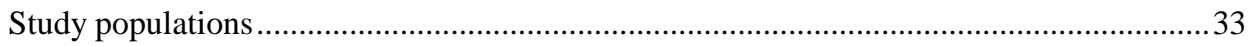




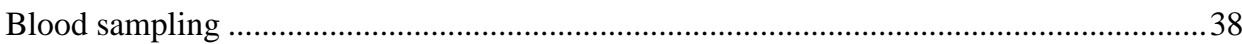

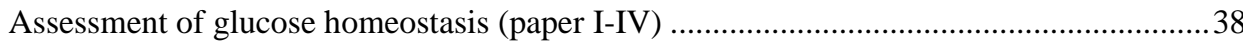

Measurement of islet autoantibodies (paper I, II and III) ...............................................39

Determination of HLA-genotype (paper I-III) ............................................................. 41

Real-time quantitative RT-PCR for analysis of mRNA and miRNA levels .......................42

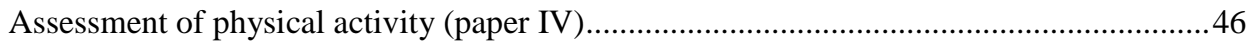

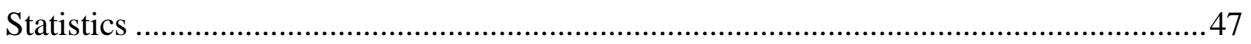

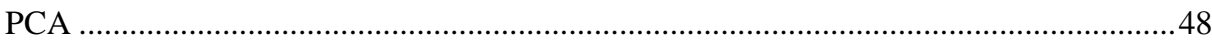

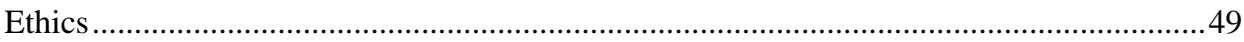

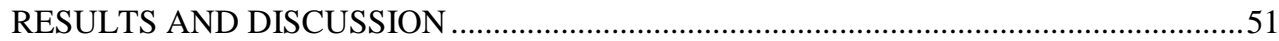

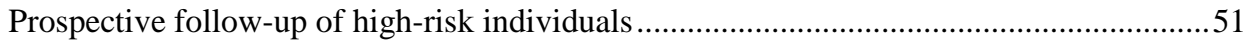

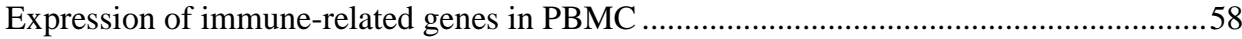

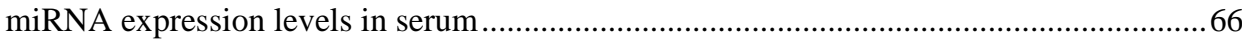

The effect of physical activity on glucose homeostasis in healthy youth ...........................75

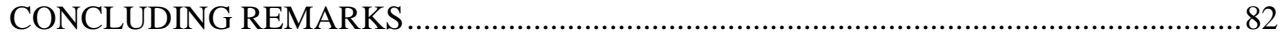

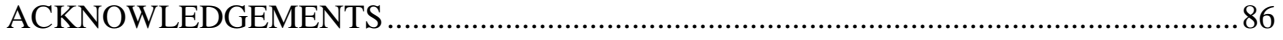

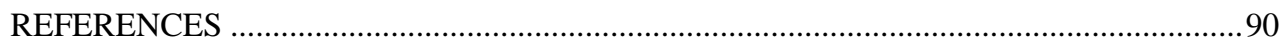




\section{POPULÄRVETENSKAPLIG SAMMANFATTNING}

Bland kroniska sjukdomar hos barn är typ 1-diabetes en av de allra vanligaste. Att leva med diabetes innebär en daglig, livslång kamp för att hålla jämna blodsockernivåer, och trots strikt behandling är komplikationer senare i livet svåra att undvika. Vi kan ännu inte bota eller förebygga sjukdomen, och vi kan inte förklara varför visa blir sjuka medan andra inte blir det.

Typ 1-diabetes är en autoimmun sjukdom där kroppens immunförsvar bryter ner betaceller, de celler i bukspottskörteln som producerar insulin. Insulin är det livsviktiga hormon som reglerar sockerhalten i blodet, och om man inte kan producera det själv måste det tillföras kroppen via injektioner. Redan innan man får diabetessymptom går det ofta att hitta tecken i blodet, autoantikroppar, som tyder på att nedbrytningen av betaceller pågår. Detta har man utnyttjat i ABIS-studien (Alla Barn I Sydöstra Sverige), en stor studie om syftar till att undersöka betydelsen av omgivningsfaktorer för utvecklingen av autoimmuna sjukdomar. Totalt ungefär 21000 barnafödande kvinnor i Blekinge, Småland, Öland och Östergötland tillfrågades om de ville delta, och nästan $80 \%$ svarade ja. Blod och andra provtyper samlades in från mor och barn vid födseln och med jämna mellanrum ifrån barnen under uppväxten. Familjerna fyllde även i omfattande frågeformulär om matvanor, boende, livsstil, sjukdomar i släkten, m.m. Analys av blodprover påvisade 46 barn som hade flera sorters autoantikroppar riktade mot de insulinproducerande cellerna, och därmed ökad risk för typ 1-diabetes. Ungefär hälften av dem hade redan insjuknat före 11 års ålder, men de som fortfarande var friska utgjorde en viktig grupp att studera, eftersom det kan ge ledtrådar om hur sjukdomen uppstår och hjälpa oss att hitta ännu bättre sätt att i förväg kunna avgöra vilka som kommer att bli sjuka. Att korrekt kunna identifiera riskindivider är en grundläggande förutsättning för att kunna testa nya metoder att förebygga sjukdomen.

Det övergripande syftet med mitt avhandlingsarbete var att öka kunskapen om sjukdomsprocessen innan typ 1-diabetes bryter ut, och en viktig del blev då att följa dessa högriskindivider med regelbundna provtagningar under två år. En del av barnen fick typ 1diabetes under studiens gång medan vissa fick diagnosen en tid efter uppföljningen. Några är fortfarande friska. Vi visade att höga koncentrationer av autoantikropparna IA2A och ZnT8A var vanligare hos de som utvecklade diabetes jämfört med de som fortfarande är friska. Förmågan att reglera blodsockret var försämrad långt innan insjuknande, men det var den även hos många individer som fortfarande är friska. Insulinresistens kan ha påskyndat den 
destruktiva processen och framkallat sjukdomsdebut. För att lära oss mer om vad som händer i immunsystemet under utvecklingen av typ 1-diabetes studerade vi nivåerna av specifika mRNA, de molekyler som agerar mellanhand i kodningen av gener till proteiner, $\mathrm{i}$ immunceller från blodet. Vi fann att det var stora likheter mellan mRNA-nivåerna hos riskindivider, friska barn och barn med diabetes. Man vet att nivåer av mRNA kan styras av små regulatoriska molekyler, så kallade mikro-RNA (miRNA). Vi mätte förekomsten av miRNA-molekyler i serum från riskindividerna, och fann att skillnaderna mot friska barn inte var stora. Däremot såg vi hos riskindividerna att flera miRNA var kopplade till förmågan att reglera blodsockret, och till koncentrationen av autoantikroppar, samt att barn som nyss fått diabetes hade starkt avvikande miRNA-profiler.

Ett delarbete rör barn ifrån ABIS-studien där fysisk aktivitet mättes med pedometer vid 8 års ålder och igen vid 12 år. Vi mätte längd, vikt och bukomfång, och blodprover togs. Fysisk aktivitet skattades också genom frågeformulär. Grad av fysisk aktivitet var kopplad till insulinfrisättning redan vid 8 år, och ännu tydligare vid 12 år, och de som rörde på sig mer behövde tillverka mindre mängd insulin och svarade även bättre på insulin (lägre insulinresistens). Detta sågs framförallt hos pojkar, som också hade en högre fysisk aktivitet än flickor. 


\section{LIST OF ORIGINAL PAPERS}

This thesis is based on the following papers, referred to in the text by their Roman numerals:

\section{Paper I}

Åkerman L, Ludvigsson J, Swartling U, Casas R

Characteristics of the pre-diabetic period in children with high risk of type 1 diabetes recruited from the general Swedish population - the ABIS study

Manuscript

\section{Paper II}

Åkerman L, Ludvigsson J, Casas R.

Low C-peptide levels and decreased expression of TNF and CD45 in children with high risk of type 1 diabetes.

Clin Immunol. 2013 Jul;148(1):4-15. doi: 10.1016/j.clim.2013.03.011. Epub 2013 Mar 29.

\section{Paper III}

Åkerman L, Casas R, Ludvigsson J, Skoglund C

Serum miRNA profile of children with high risk for type 1 diabetes

Manuscript

\section{Paper IV}

Huus K*, Åkerman L*, Raustorp A, Ludvigsson J.

Physical Activity, Blood Glucose and C-Peptide in Healthy School-Children, a

Longitudinal Study.

PLoS One. 2016 Jun 7;11(6):e0156401. doi: 10.1371/journal.pone.0156401. eCollection 2016.

* These authors contributed equally to this work 
ABBREVIATIONS

\begin{tabular}{|c|c|}
\hline HLA & Human leucocyte antigen \\
\hline BMI & Body mass index \\
\hline $\mathrm{GAD}_{65}$ & Glutamic acid decarboxylase 65 \\
\hline GADA & Autoantibodies to $\mathrm{GAD}_{65}$ \\
\hline $\mathrm{HbA1c}$ & Glycated hemoglobin A1c \\
\hline HOMA2-\%B & Homeostatic model assessment, $\%$ beta cell function \\
\hline HOMA2-IR & Homeostatic model assessment, insulin resistance \\
\hline HOMA2-\%S & Homeostatic model assessment, $\%$ insulin sensitivity \\
\hline IA 2 & Protein tyrosine phosphatase-like protein IA2 \\
\hline $\mathrm{IA} 2 \mathrm{~A}$ & Autoantibodies to IA2 \\
\hline IAA & Autoantibodies to insulin \\
\hline ICA & Islet cell autoantibodies \\
\hline IFG & Impaired fasting glucose \\
\hline IFN & Interferon \\
\hline IGT & Impaired glucose tolerance \\
\hline IL & Interleukin \\
\hline IvGTT & Intravenous glucose tolerance test \\
\hline MHC & Major histocompatibility complex \\
\hline miRNA & Micro RNA \\
\hline mRNA & Messenger RNA \\
\hline NGT & Normal glucose tolerance \\
\hline OGTT & Oral glucose tolerance test \\
\hline PBMC & Peripheral blood mononuclear cells \\
\hline PCA & Principal component analysis \\
\hline T1D & Type 1 diabetes \\
\hline $\mathrm{T} 2 \mathrm{D}$ & Type 2 diabetes \\
\hline TNF & Tumor necrosis factor \\
\hline Treg & Regulatory $\mathrm{T}$ cell \\
\hline ZnT8 & Zink transporter 8 \\
\hline ZnT8A & Autoantibodies to $\mathrm{ZnT} 8$ \\
\hline
\end{tabular}




\section{INTRODUCTION}

\section{Type 1 diabetes}

Diabetes mellitus is a collective term for disorders characterized by chronic hyperglycemia caused by either defective insulin secretion, or defects in insulin action on the target tissue, or a combination of both [1]. The term encompasses forms of diabetes with differing etiologies, where the main types can be categorized as Type 1 diabetes (T1D), Type 2 diabetes (T2D), gestational diabetes mellitus and specific types of diabetes caused by monogenetic defects, diseases of exocrine pancreas or drugs/chemicals [2]. In T1D, the hyperglycemia is caused by an absolute insulin deficiency due to destruction of insulin-producing beta cells, whereas T2D is characterized by varying proportions of insulin resistance and insulin secretory defects.

\section{Diagnosis}

Diabetes is diagnosed after laboratory tests assessing plasma glucose levels in a fasting state or after a glucose load [2]. Diagnosis can be made when any of the three following criteria are fulfilled: fasting plasma glucose $\geq 7.0 \mathrm{mmol} / \mathrm{L}$ or plasma glucose $\geq 11.1 \mathrm{mmol} / \mathrm{L}$ at 2 hours after ingestion of glucose in an oral glucose tolerance test, or a random plasma glucose $\geq 11.1 \mathrm{mmol} / \mathrm{L}$ in a patient with classic symptoms of hyperglycemia. Diagnosis of T1D in children is usually preceded by classical symptoms of hyperglycemia, like increased urinary volumes, increased thirst and weight loss, while clinical presentation can be vaguer in adult T1D patients.

\section{Complications and Treatment}

Type 1 diabetes is associated to short term complications like serious hypoglycemia or hyperglycemia with ketoacidosis or nonketotic hyperosmolar syndrome, and long-term complications such as retinopathy, nephropathy, cardio-vascular complications and peripheral/autonomic neuropathy, as reviewed in [3]. Cardiovascular complication is the leading cause of death among T1D patients, except in patients below the age of 30 where death due to short-term complications are more common [4-7].

Even though diabetes treatment has improved greatly in the past decades, leading to decreased prevalence of complications [8, 9] and improved life expectancy $[4,10]$, patients with T1D still have a higher risk of premature death compared to the general population. The 
increased mortality rate is seen both at higher age as a consequence of late complications and during early life, mainly due to the acute complications $[4,11,12]$.

A person with T1D needs life-long, continuous administration of exogenous insulin to stay alive. The severity of complications is closely related to glycemic control, why adequate treatment is of outmost importance. It was shown in the Diabetes Control and Complications Trial (DCCT) study that intensive insulin therapy, aiming to maintain glucose levels near to normoglycemia, leads to a striking reduction in the microvascular complications retinopathy, nephropathy, and neuropathy [13]. The onset of these complications was delayed and the progression of complications was slower. Later follow-ups of the cohort also showed that intensive insulin therapy resulted in a reduction of macrovascular complications [14]. The Linköping Diabetes Complications Study also demonstrated the importance of maintained glycemic control for the prevention of retinopathy and nephropathy [15], and the Vascular Diabetic Complications in Southeast Sweden (VISS ) study recently reported that proliferative retinopathy and persistent macroalbuminuria seems to be prevented when glycated hemoglobin A1c (HbA1c) is maintained below 7.6\% [16]. Intensive insulin therapy is now the mainstay treatment of T1D [17]. This careful control of blood glucose is achieved by using a combination of long-acting insulin analogues and short-acting insulin. Beside the pharmaceutical treatment, a critical part of T1D care is education and support for patient selfmanagement [17].

The DCCT study also showed that lower HbA1c is associated to lower all-cause mortality [18]. An association between glycemic control and mortality has been seen in Sweden as well [19]. Better glycemic control was clearly related to higher survival, but it should be noted that even in the most well-managed T1D, where target HbA1c values are reached, a more than double all-cause mortality and risk of death due to cardiovascular causes is seen in comparison to the general population. Furthermore, although it has been shown that intensive therapy is crucial to postpone the onset of complications, few patients actually manage to reach the highly set goals for glycemic control $[19,20]$. This shows that trying to achieve values near normoglycemia is difficult, and it highlights the importance of research in diabetes care. Maybe even more, it highlights the need to further increase the understanding of T1D pathogenesis in order to prevent or reverse the disease process. Despite the progress seen in diabetes care, T1D is still a disease difficult to live with. 


\section{Prevalence and incidence}

Sweden has, next to Finland, the highest incidence of T1D in the world [21], with approximately 44 cases per 100.000 inhabitants per year [22]. The incidence is increasing by $3-4 \%$ annually around Europe [23], and the increase is especially high in children [21]. It was shown that the general increase in incidence seemed to level off in Sweden since the year 2000 [22], and that the increase was proportionally larger among children $0-5$ years of age in Sweden too [24-26]. This was however questioned by a recent study revealing that the actual incidence among persons aged 15-34 may be two to three times higher than previously reported, which would affect the proposed left-shift in onset-age [27].

\section{Risk factors}

\section{Genetic risk factors}

It is well known that there is an important genetic component in the aetiology of T1D. The disease shows familial aggregation, and the probandwise concordance rates between monozygotic twins has been reported to range from $23 \%$ [28] to an estimated $70 \%$ [29]. Type 1 diabetes is a polygenic disease, and there are now as many as 58 genomic regions showing an association to it [30].

The most important genetic determinants for T1D risk, providing approximately half of the genetic susceptibility, are genes within the human leucocyte antigen (HLA) class II gene complex [30]. This region is located on chromosome 6 and contains genes encoding the major histocompatibility complex (MHC) proteins, including the highly polymorphic immune recognition molecules DR and DQ which are involved in presentation of exogenous antigens to CD4+ T cells [31]. Strong linkage to this region has in fact been seen for most autoimmune diseases. The composition of the HLA-DQ heterodimers, encoded by the genes HLA-DQA1 and -DQB1, has the highest impact on the magnitude of T1D risk, although HLA-DR (encoded by DRB1) is a modifying factor [32]. The full haplotype therefore gives a more complete picture of the individual risk. In the case of T1D, the haplotypes DRB $1 * 0401$ DQB1*0302 (DR4-DQ8) and DRB1*0301-DQB1*0201 (DR3-DQ2) confer the highest susceptibility and are found in up to $90 \%$ of Scandinavian children developing the disease, either one of them or both in combination [33]. At the same time, these risk-associated haplotypes are very common in the general population, and only a minority of individuals at increased genetic risk eventually develop T1D. The many occurring variants of HLA-DR-DQ haplotypes can be hierarchically arranged from very high risk to protection of disease [34]. A 
haplotype associated with protection from T1D is HLA-DRB1*15:01-DQA1*01:02DQB1*06:02, recently shown to have a protective effect during all stages of disease progression, including development of autoantibodies and metabolic abnormalities [35].

Minor genetic determinants of risk are HLA-DP in the class II locus and genes within the class I locus, and also genes in the non-classical "class III" region [34]. There are also genetic variants in non-HLA genes showing associations to T1D, like the insulin gene (INS), protein tyrosine phosphatase, non-receptor type 22 (PTPN22), cytotoxic T-lymphocyte-associated protein 4 (CTLA4) and interleukin 2 receptor alpha (IL2RA) [36].

\section{Environmental risk factors}

The dramatic increase in T1D incidence seen worldwide occurs at a rate that cannot be explained by the spread of disease-related genes. This, together with the incomplete twin concordance, clearly demonstrates that environmental factors have an influence on the etiology of T1D. In support of this are studies showing an adjustment of incidence rates as populations from low-incidence areas, like south Asia, migrate to areas with higher incidence, like the UK $[37,38]$. The incidence increases in the migrating population, reaching rates close to those observed within the indigenous population. It has also been shown in Sweden that immigrant patients appear more prone to develop T1D when they were born and live in Sweden [39].

It is likely that causative environmental factors are especially important early in life, as the disease process often starts at a very young age [40]. Illustrating this is another Swedish study, showing that children born in Sweden by parents immigrated from low-incidence areas show an increased risk to develop T1D compared with immigrant children not born in Sweden, whereas children born in low-incidence areas and then adopted by Swedish parents do not [41].

In Finland, there are indications of an increasing impact of causal environmental factors, as the relative contribution of genetic predisposition in the overall diabetes susceptibility is smaller now than it was before. The proportion of T1D-patients carrying high-risk HLAgenotypes has decreased over time, and the number of individuals developing disease despite presence of protective genotypes is increasing [42].

There is a plethora of environmental factors whose significance for T1D development has been explored during the past decades, as reviewed in [43]. The major suggested factors can 
be divided into microbial exposures, dietary exposures and factors putting extra stress on beta cells.

Microbial exposures - The role of microbial exposure in the development of T1D goes down one of two paths; either as a causative agent with specific infections leading to damage in beta cells, or as a protective agent with lack of infections during childhood preventing normal development of immunoregulatory mechanisms [44]. Several specific infections have been proposed to cause T1D, but the strongest case is made for infection by different species of enteroviruses [45]. Signs of ongoing enteroviral infection has been detected in the pancreas of live T1D patients [46] and a link between enterovirus infection and development of T1D has been seen in observational [47] and prospective cohort-studies [48, 49]. It is not all that clear exactly how enteroviruses contribute to initiation or propagation of the autoimmune process, but direct mechanisms like beta cell damage by virus-induced cytolysis or indirect mechanisms, where viruses change the microenvironment by altered expression of cytokines and chemokines, have been suggested [50]. Based on the currently available data, it seems likely that a fraction of T1D patients suffer from a viral insult of some kind, during some point of the disease process [45].

In the hygiene hypothesis, initially proposed by Strachan in the context of atopic disease [51], it is conversely a lack of infection that is suggested as a causative factor in T1D development [52]. Decreased infectious burden in the western society, as a consequence of vaccination regimes, use of antibiotics and increased hygiene, has been observed in parallel to the increased incidence of immune-mediated diseases. Even so, there is currently no robust data from prospective studies that can support this theory [43].

A rather novel area of research, also pertaining to microbial exposure, it that of the intestinal microbiota [53]. The colonization of microbes that occur in the gastrointestinal tract is important for immune regulation to develop normally, and even though there are not yet many studies to rely on, there seem to be differences in the intestinal microbiome of diabeticor pre-diabetic individuals compared to healthy individuals [54]. It should however be noted that the differences appeared after seroconversion, so if there in fact is a role of the intestinal microbiota in disease development, it is likely not during the early initiating events.

Dietary factors - The list of dietary factors suggested to have a role in T1D development is long, containing breastfeeding, introduction of solid foods, consumption of cow's milk, cereals, vitamin D, vitamin E, zink, ascorbic acid and fatty acids. Dietary exposure to toxins 
or chemicals has also been suggested. It was proposed already in the eighties that breastfeeding might have a protective role [55], and several studies have since addressed the effect of dietary habits in early infancy. Reaching a clear conclusion has however been challenging due to large variations in the obtained results, and because of the inherent difficulties in studying feeding habits. A pooled analysis including data from nearly 10.000 T1D patients indicated a weak protective effect of exclusive breastfeeding [56], and there is some evidence for a protective effect of continued breastfeeding during introduction to solid foods $[57,58]$. In all, the current evidence for a link between infant feeding habits and development of T1D can be considered inconclusive [59]. The potential role of vitamin D is interesting for several reasons. It has important roles in the immune system, and its receptor is found in beta cells, in target tissues of insulin and in all immune cells [60]. The major source is endogenous synthesis in the skin following UVB-radiation, and the apparent latitudinal gradient of T1D incidence in the Northern Hemisphere has given rise to the idea that vitamin D deficiency may be part of T1D pathogenesis. Epidemiological data has provided some support for this [60], but large-scale clinical trials assessing the effects of carefully administered vitamin D supplementation on T1D development are currently lacking. Thus, there is no conclusive evidence regarding a possible protective role of vitamin $\mathrm{D}$ in T1D.

Beta cells under increased pressure - Given that the increased T1D incidence correlates well to gross domestic product, it has been suggested that risk factors associated to wealth may be of importance [24]. Examples of such factors are rapid growth and weight development during early childhood. Large studies have reported associations between high birthweight and increased risk for T1D [61, 62], although it should be noted that an association has been shown between high relative birthweight and genotypes conferring T1D risk [63]. It is thus possible that growth in utero is independently associated with risk genotypes, and that high birthweight is an effect of HLA rather than a risk factor for T1D. Rapid growth during the first years of life has however also been associated both to elevated risk of islet autoimmunity [64] and clinical disease [65, 66], and higher body mass index (BMI) has been associated to younger age at disease onset, suggesting that increased weight gain may be a risk factor for early manifestation of T1D [67]. These associations have boiled down to differently formulated, but closely related, theories in which excessive activity of pancreatic beta cells is a central element. The extra load is suggested to either initiate or accelerate the immune-mediated destruction of beta cells, ultimately leading to insulin 
deficiency. In the overload hypothesis [68] and the beta cell stress hypothesis [69] it is hypothesized that excessive activity of pancreatic beta cells due to any reason, for example overfeeding or accelerated growth, causes or accelerates the beta cell destruction that is characteristic of T1D. The accelerator hypothesis [70] specifically points out insulin resistance as the driving factor of beta cell loss in individuals at genetic risk. The insulin resistance, in turn, is suggested to be a consequence of for example extra body weight. Increased insulin resistance is also known to be related to psychological stress, and it has been shown in the All Babies in Southeast Sweden (ABIS) cohort that that psychological stress in general (measured as psychosocial strain in the family) [71], or serious life events in the mother in particular [72], is related to increased risk to develop islet autoimmunity in early childhood, manifested by diabetes-related autoantibodies. It was also recently shown in ABIS that experience of a serious life events in the child itself is related to the risk of developing overt T1D [73]. A proposed link between beta cell stress, regardless of cause, and initiation or acceleration of beta cell loss is prolonged endoplasmatic reticulum (ER) stress (reviewed in [74]). Beta cells, together with other secretory cells, are naturally under a great deal of ER stress due to the high need of protein synthesis, but under normal conditions this stress is counteracted by regulatory mechanisms that resolve the effects of ER stress [74]. When the ER stress becomes excessive, these mechanisms may not suffice, resulting in abnormal post-translational modification of proteins produced in beta cells. These modified proteins may act as neo-autoantigens, exacerbating the already ongoing autoimmune process.

Despite numerous hypotheses and extensive efforts to identify the environmental factor(s) triggering the disease process, no conclusive evidence has yet been found. Type 1 diabetes is a complex disease and it seems likely that several different factors may be involved and may interact with each other to cause disease, primarily in genetically susceptible individuals.

\section{Immunopathogenesis of type 1 diabetes}

For the purpose of research, the pancreas is a very inaccessible organ. It is located deep inside the abdomen, surrounded by vital organs, and is penetrated by a rich capillary network, making it difficult to obtain biopsies without complications - even with the advanced laparoscopic surgical methods available today. Recently, a Norwegian research group received ethical approval to obtain biopsies from live patients with new-onset T1D, based on the recent advances in surgical techniques and the consequently lower estimated risk of complications. The study, called the Diabetes Virus Detection study (DiViD), however 
stopped recruiting patients following an unexpectedly high rate of complications [75], and obtaining pancreas samples from live patients is thus still problematic from an ethical point of view. The scientific community remains constrained to the study of post-mortem pancreata, animal models or peripheral blood samples to further elucidate the pathogenesis of T1D, awaiting novel methods that allow direct study of the pancreas in a safe way.

\section{Insulitis in type 1 diabetes}

Presence of insulitis - infiltrating immune cells in and around pancreatic islets- in patients with juvenile diabetes mellitus was reported already in 1965 by Gepts [76]. He also reported substantial beta cell loss at disease onset. The histological evidence accumulated henceforth has helped in our understanding of what is going on in the pancreas of T1D patients (reviewed in [77]), although we still have a lot to learn. We now know that the pancreas of recently diagnosed patients have varying proportions of insulin-containing islets without inflammation, insulin-containing islets showing signs of inflammation, and finally insulin deficient islets [77]. The latter are found in majority at onset and completely dominate in long-standing T1D. Characterization of the infiltrating immune cells has revealed that the most abundant cell type is CD8+ T cells, followed in decreasing order of presence by macrophages (CD68+), CD4+ T cells, B cells (CD20+) and plasma cells (CD138+). Cell types more rarely found in diabetic pancreas-specimens are regulatory $\mathrm{T}$ cells (Treg), plasma cells and natural killer (NK) cells [78]. More in-depth clues about the molecular and cellular events mediated by these cells in the development of T1D have been obtained by studying animal models of the disease, primarily the non-obese diabetic (NOD) mouse. There is also a great deal of information gained from in vitro studies analyzing peripheral blood from T1D patients at different stages of the disease, and from the use of cell lines with beta cell properties. The general idea stemming from these fields of study, very simplified, is that selfantigens are processed in the pancreas by resident antigen presenting cells (APCs), who present the antigens to autoreactive CD4+ T cells ( $\mathrm{T}$ helper cells) after migrating to draining pancreatic lymph nodes (Figure 1) [79].

Following engagement of the T cell receptor (TCR)-complex with MHC-bound antigen in the presence of co-stimulatory signals, these T helper cells become activated and expand clonally. They subsequently migrate into the islets, where they recruit other inflammatory cells, including CD8+ T cells (cytotoxic T cells). This infiltration of immune cells into the islets, termed insulitis, is destructive to the beta cells. As a consequence of APCs and T cells releasing pro-inflammatory cytokines, additional $\mathrm{T}$ cells are recruited, aggravating the 
insulitis. B cells are also involved in the process, producing autoantibodies directed toward islet antigens, and probably having a role as APCs as well.

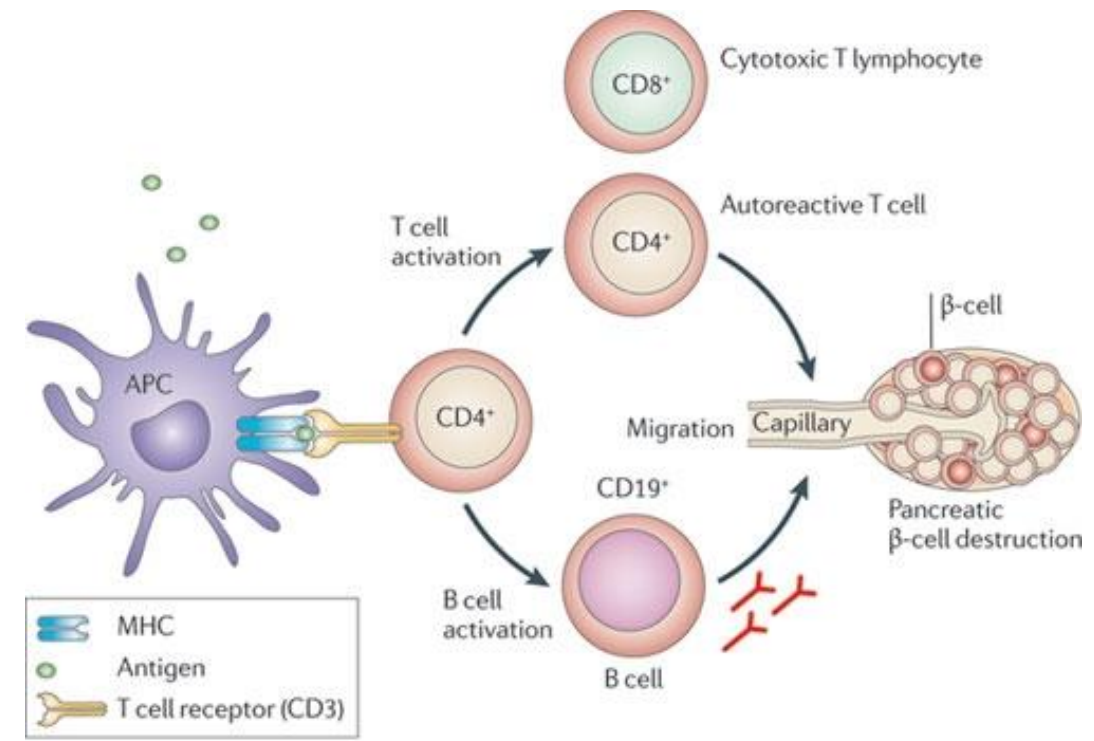

Figure 1. The involvement of T cells, antigen presenting cells (APSs) and B cells in the immunopathogenesis of type 1 diabetes. MHC, major histocompatibility complex. Illustration from [79], reproduced with permission from Nature Publishing Group.

\section{CD8+ T cells}

Cytotoxic T cells are believed to have an important role in the initial phase of insulitis [77]. When there are still plenty of remaining beta cells, CD8+ T cells are the most numerous among the infiltrating immune cells. The exact mechanisms used by CD8+ T cells to kill beta cells are not known, but experimental data suggests release of perforin and granzymes, binding of Fas Ligand to Fas receptor to induce apoptosis, and secretion of inflammatory cytokines inducing production of free radicals and evoking ER stress [80]. There is direct evidence of islet autoreactivity by CD8+ cells in human T1D islets [81].

\section{CD4+ T cells}

T helper (Th) cells, are present during all phases of insulitis, albeit in low levels [77]. It has also been shown that beta cell-antigen specific CD4+ T cells are present in islets from T1D patients [82]. Since the eighties, Th cells have been subdivided based on their different expression of surface molecules, transcription factors and distinct profiles of cytokine release 
[83]. Cells designated as Th1 are characterized by a more pro-inflammatory profile, secreting primarily interferon (IFN)- $\gamma$, while Th2 are ascribed an anti-inflammatory role, with a cytokine profile dominated by interleukin (IL)-4, IL-5 and IL-13 [84]. For a long time, the widely held belief was that Th1 cells were major contributors in the development of T1D, while Th2 instead had a protective effect [85]. With more information at hand, it is now clear that the division of CD4+ T cells into Th1 and Th2 is a simplification [84]. There are at least four different, probably more, Th subsets, including Th1, Th2, Th17, and inducible T regulatory cells (iTregs, sometimes referred to as Th3). There is also data indicating that the Th1/Th2 subsets may not have as clear roles in the development of autoimmune disease as previously thought, and although still unclear, it has been implicated that cells of the Th17 subset have some degree of involvement [86].

\section{Regulatory T cells}

Autoimmunity is loss of self-tolerance, and immune regulatory mechanisms to maintain selftolerance are to a large extent governed by Treg cells [87]. It is therefore not surprising that Tregs have been proposed to have an important role in the development of T1D. Regulatory T cells derived from the thymus, called natural Tregs (nTregs) can be phenotypically characterized by surface markers $\left(\mathrm{CD} 4^{+} \mathrm{CD} 25^{\text {hi }} \mathrm{CD} 127^{\text {low }}\right)$, and they stably express the transcription factor Forkhead box P3, FOXP3, which is important for their development and function [88]. Although this characterization is often used to identify Tregs, there are functionally distinct subsets of Tregs that differ in their expression of other surface markers and represent cells with varying suppression methods, suppression targets, homing properties etc, as reviewed in [89]. Recent results obtained using mass cytometry revealed that the Treg compartment seems much more complex than previously thought, containing a large number of sub-populations [90]. We therefore still have a lot to learn regarding the full role of Treg in T1D, but so far, extensive data from experimental animal models and a growing amount of results from studies in human T1D does indeed shown defective Treg immune regulation, in part mediated by abnormal sensitivity to Treg-mediated suppression in responding effector cells $[88,91]$.

\section{B cells}

The precise role of B cells in the process of beta cell destruction is not known, although there is substantial evidence that they indeed are important. They are commonly found in islets from T1D patients, in highest proportion during late-stage insulitis when an established decrease in beta cell mass is seen [77]. In most T1D patients, autoantibodies directed to islet 
autoantigens can be detected in the circulation before clinical presentation of the disease [92]. Although these antibodies are not in general thought to be directly pathogenic [93], they do demonstrate the presence of autoreactive B cell activity. Furthermore, it has been shown that depletion of B cells by treatment with anti-CD20 (Rituximab) gives partial beta cell preservation in human recent-onset T1D [94]. In the NOD mouse model, B cells unquestionably have a role in disease development, as extensively reviewed in [95]. It seems like several mechanisms are involved, including antigen presentation to diabetogenic $\mathrm{T}$ cells and faulty B cell tolerance. The B cell compartment also contains cells with regulatory properties (Bregs) that, much like Tregs, can be subdivided based on their functional characteristics [96]. The IL-10 producing Br1 cells $\left(\mathrm{CD} 19^{+} \mathrm{CD} 24^{\mathrm{hi}} \mathrm{CD} 38^{\text {hi }}\right)$ have been implicated in autoimmune diseases like systemic Lupus Erythematosus [97], and decreased numbers of these cells have been observed in T1D [98].

\section{Autoantigens and autoantibodies}

In analogy to the TCR on T cells, B cells are equipped with B cell receptors (BCR) that recognize antigens [95]. The components responsible for antigen-recognition in the BCR are immunoglobulins. Upon binding of antigen to the BCR, the B cells can differentiate terminally into an antibody-producing CD138+ plasma cell, after a process involving activation, co-stimulation and exposure to certain T-cell derived cytokines. The plasma cell then secretes antibodies with the same specificity as the BCR-immunoglobulin that initially recognized the antigen. In the opsonization process of the humoral immune response, these secreted antibodies mark pathogens for destruction and neutralize viruses.

The presence of islet cell autoantibodies (ICA) in sera from T1D patients was shown in the seventies, after letting sera from T1D patients incubate with frozen pancreas tissue sections $[99,100]$. By this method, the antigen-specificity of the reacting autoantibodies is not revealed, but since then several major and minor islet autoantigens have been identified. The major autoantigens, all found within the beta cell (Figure 2), include glutamic acid decarboxylase $65\left(\mathrm{GAD}_{65}\right)$ [101], the tyrosine phosphatase-like insulinoma-associated antigen-2 (IA2, also known as ICA512) [102], the zinc transporter 8 (ZnT8) [103] and (pro)insulin [104]. The frequency for autoantibody positivity to these four antigens at onset of clinical disease are $>80 \%, \geq 70 \%, \geq 65 \%$ and $>50 \%$, respectively [105]. 
Insulin or proinsulin has been suggested as the primary autoantigen in T1D [106]. It is the only islet autoantibody that is strictly beta-cell specific, and the antibodies are directed towards epitopes mapping to the B chain of human proinsulin or insulin [107].

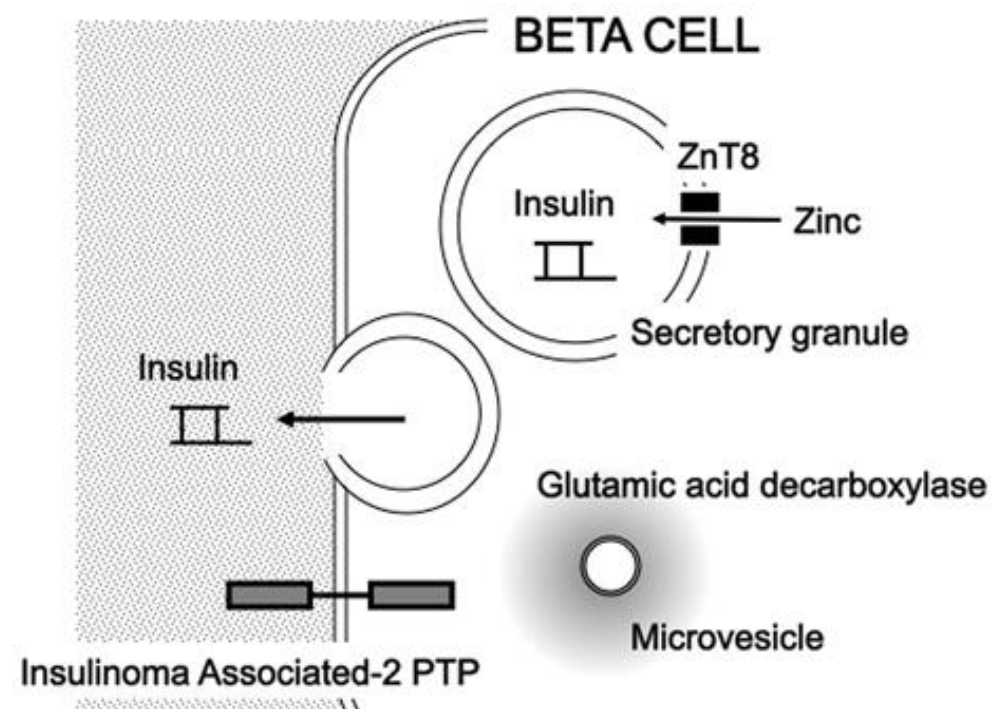

\section{Plasma membrane}

Figure 2. Cellular localization of the four major islet autoantigens within the beta cell: glutamic acid decarboxylase (GAD), tyrosine phosphatase-like insulinoma-associated antigen-2 (IA2), zinc transporter 8 (ZnT8) and (pro)insulin. Illustration from [108].

GAD was initially discovered as a $64 \mathrm{kD}$ protein to which newly diagnosed T1D patients showed immunoreactivity in immunoprecipitation studies [109]. The protein was later identified to be GAD, a neuroendocrine enzyme involved in the conversion of glutamic acid to the inhibitory neurotransmitter $\gamma$-aminobutyric acid (GABA) [101]. It is primarily found in the nervous system and in pancreatic alpha-, beta-, and delta cells [110]. In beta cells, the localization of GAD is concentrated to synaptic-like microvesicles, where its functional relevance is unclear. Two separate GAD isoforms, sharing $70 \%$ homology, have been identified; $\mathrm{GAD}_{65}(65 \mathrm{kDa})$ and $\mathrm{GAD}_{67}(67 \mathrm{kDa}) . \mathrm{GAD}_{65}$ is the predominant form in human and rat islets, whilst $\mathrm{GAD}_{67}$ is more abundant in mice.

IA2, member of the transmembrane protein tyrosine phosphatase (PTP) family, is an integral membrane protein, expressed in neuroendocrine tissues [105]. In pancreatic islets, it is found 
in alpha-, beta- and delta cells, and it has been implicated to have a role in insulin secretion, biogenesis and homeostasis of secretory granules, and beta cell expansion.

The zink transporter 8 is the most recently identified of the four major islet autoantigens. Although it can be found in other endocrine cells in the islets, it is enriched in beta cells where it is involved in zink accumulation into secretory granules [105].

In addition to these four major autoantigens, there are also minor antigens to which autoantibodies in serum from T1D patients are directed. Examples are the previously mentioned $\mathrm{GAD}_{67}$, and IA2 $\beta$ (phogrin) [111] which is highly analogous to IA2. Tetraspanin7 has recently been identified as another target of autoimmunity in T1D [112].

Autoantibodies generally appear early in life. Although rarely found in the first 6 months, the peak age of seroconversion seems to be somewhere in the span of 9 to 24 months [113-115]. Seroconversion to multiple autoantibodies often occurs within 2 years from the first autoantibody, and there is a specific order in which the different autoantibodies often appear [116]. Insulin autoantibodies are usually the first to be detected, followed by GADA, while both IA2A and ZnT8A can be regarded as "late" autoantibodies that rarely are seen at first seroconversion. The order of appearance is affected by risk-HLA, with the HLA- DR4-DQ8 haplotype associated to first positivity to IAA only, and the HLA-DR3-DQ2 haplotype instead associated with GADA only as the first autoantibody [113].

\section{Intervention/Prevention}

Even though modern diabetes treatment regimens have increased the life expectancy and quality of life for T1D patients, insulin replacement is indeed no cure. Therefore, based on what is known about the pathogenesis of T1D, numerous therapeutic strategies have been tested in clinical trials to prevent or intervene in the disease process. To date, none of the studied therapies have provided a clinical effect meeting the primary endpoint measure, together an acceptable level of side effects [117]. Although the ultimate goal is disease prevention, importance of maintaining even modest residual beta cell function after disease onset has been demonstrated. In the DCCT study, the incidence of retinopathy, nephropathy and severe hypoglycaeima was reduced in subjects with any sustained C-peptide secretion [118], and remaining, albeit low, endogenous insulin secretion has been shown to have a beneficial effect of on glycemic control and insulin dose in Swedish T1D patients [119]. 
Attempts on disease prevention can be performed in different stages. Primary prevention takes place in genetically susceptible individuals and aims to avoid that the autoimmune reaction is initiated in the first place. This can theoretically be achieved by avoiding potentially triggering factors or correcting nutritional deficiencies presumably involved in disease development. Based on epidemiological data indicating a role of early cow's milk introduction in the development of T1D, the Trial to Reduce IDDM in the Genetically at Risk (TRIGR) study aimed to assess whether weaning to a formula based on casein hydrolysate rather than cow's milk could reduce the development of autoimmunity in individuals with increased genetic risk [120]. This is an example of primary prevention. The results thus far, after 7 years, do not show a difference in the incidence of diabetes-associated autoantibodies.

Secondary prevention takes place after the appearance of autoantibodies, and aims to prevent progression to clinical disease, while tertiary prevention (or intervention) trials are performed after the onset of symptomatic disease to preserve remaining beta cell mass. Secondary and tertiary prevention can be of antigen-specific nature, or non-antigen-specific with systemic effects, including mild immunomodulation, broad immunosuppression and cellular therapies. The earliest attempt at non-specific immune intervention in T1D was the use of plasmapheresis in children with recent-onset disease, as a means to reduce circulating autoantibodies [121], showing preservation of beta cell function to some extent. Other examples of non-specific immune interventions are systemic immunosuppressive drugs like cyclosporine A or mycophenolate mofetil, characterized by low specificity and thereby often associated to severe side effects that prevent their use despite significant clinical effects [122]. Slightly more specific are approaches using monoclonal antibodies directed towards immune cell subsets like B cells, or immune molecules of relevance in T1D pathogenesis, like co-stimulatory ligands (CTLA4-Ig, Abatacept) or T-cell receptor molecules (e.g. CD3). One example is the monoclonal antibody anti-CD3 Teplizumab, targeting T cells, that failed to reach the primary outcome in a clinical phase III trial [123]. Another example is the B celltargeting monoclonal antibody anti-CD20 Rituximab, which showed promising results in a phase II trial [94], but the two-year follow-up showed that the effect initially seen was merely a short delay of decline in C-peptide [124].

Antigen-specific immunotherapy is an interesting concept, based on the thought that administration of a diabetes-related antigen in the appropriate context could divert the immunological response toward a more protective and tolerant profile. The high specificity of antigen-based treatment would also minimize the risk of serious side effects caused by a 
general response of the immune system. An example of an antigen-specific treatment is the administration of alum-formulated $\mathrm{GAD}_{65}$ (Diamyd®) in recent-onset T1D. Although there were encouraging results from a phase II trial [125], a subsequent European phase III trial failed to show clinical efficacy [126]. Antigen-specific treatment has also been evaluated for secondary prevention. In the ongoing Diabetes Prevention - Immune Tolerance (DiAPREVIT), the possibility to prevent further beta-cell loss by treatment with Diamyd ${ }^{\circledR}$ is assessed, in children with multiple islet autoantibodies [127]. In in DPT-1, administration of low-dose subcutaneous insulin has been tested in autoantibody positive first- or second degree relatives with an estimated five-year risk over 50\%. [128]. This treatment did not delay or prevent T1D. The same was true for administration or oral insulin in individuals with slightly lower estimated five-year risk, also tested within DPT-1 [129].

An example of a cellular treatment is immunotherapy using polyclonal regulatory $\mathrm{T}$ cells. Based on findings of defective T-cell mediated immune regulation in T1D, patients were treated with autologous ex vivo-expanded polyclonal Tregs (CD4+CD127lo/-CD25+) in a phase I study [130]. The treatment was safe and well tolerated, and future trials will tell whether a clinically relevant positive effect can be obtained. Another example is treatment with autologous mesenchymal stromal cells, interesting because of their immunomodulating properties $[131,132]$ and shown recently in a small pilot trial to constitute a safe treatment that potentially preserves beta cell function [133].

\section{The natural history of type 1 diabetes}

The model of T1D as a chronic progressive autoimmune disorder, proposed by Johnny Ludvigsson at a Nordic Symposium and later, more well-known, by George Eisenbarth in 1986 [134], has become the reference model to explain the natural history of the disease although it has been subject to several modifications over the years as our understanding of the disease has increased (Figure 3) [135]. The disease starts with genetic predisposition, which in the context of relevant - but yet not well defined - environmental triggers initiate the immune-mediated destruction of beta cells, perhaps as early as in utero. This destructive process, once started, can likely be subject to additional modifying factors that affect the disease course. Beta cells are silently destroyed, in a linear fashion or with a relapsingremitting pattern, during a period of time that can vary tremendously between individuals. 


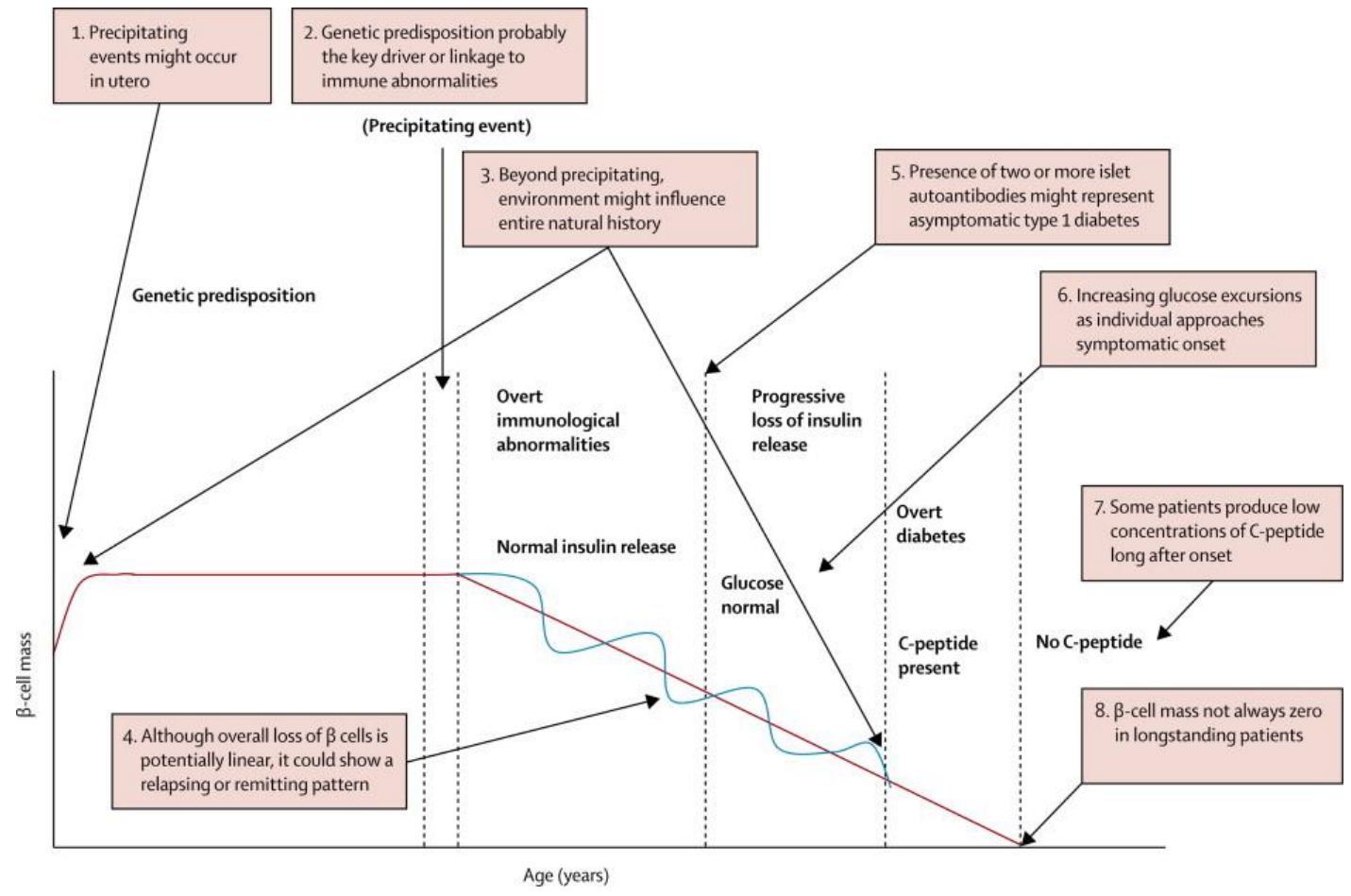

Figure 3. The natural history of type 1 diabetes, revisited. Illustration from [135], reproduced with permission from Elsevier.

In persons diagnosed at a young age the process is generally more rapid, while T1D presented in adulthood can be preceded by many years of ongoing (but presumably low-grade) autoimmunity, detectable in the circulation by the presence of autoantibodies. Nonsymptomatic dysglycemia can often be detected, sometimes temporary, long before clinical disease. When the functional beta cell mass reaches a critically low level, symptoms appear because of the inability to maintain normal glucose homeostasis. For a long time, the proportion of beta cells remaining at this point was thought to be around 10-20\% [134], but it is now less clear how much of the functional beta mass actually remains at onset of clinical disease [136]. It has also been assumed that the endogenous insulin production completely disappears after years of disease duration, but this too has been debated. It was shown already in the seventies that many patients had preserved beta cell function several years after onset [137], and as the sensitivity of the methods used for detection of residual insulin secretion has increased, persisting endogenous production has been revealed in many patients despite disease duration over 50 years [138]. In addition, examination of pancreas sections 
postmortem in long-standing patients showed presence of insulin positive beta cells in all of them.

Defining the present state of an individual progressing towards insulin deficiency is the functional mass of beta cells, together with how well the produced amount of insulin meets the body's insulin requirements at the moment. Only when the needs are no longer met does symptoms emerge. There are currently no available methods to directly measure the remaining functional beta cell mass. The ability to secrete insulin, in a fasting state or after a glucose load, can be used as a proxy. Direct measurement of insulin is however difficult, since the concentration in blood drops quickly after release due to peripheral extraction and significant first-pass metabolism by the liver [139]. Serum C-peptide, on the other hand, has a much longer half-life and its liver-extraction is negligible, giving a much more reliable measurement. C-peptide is the connecting peptide between the A- and B-chain of the insulin molecule, enzymatically cleaved from the precursor molecule and secreted by beta cells in equimolar amounts to insulin (Figure 4).

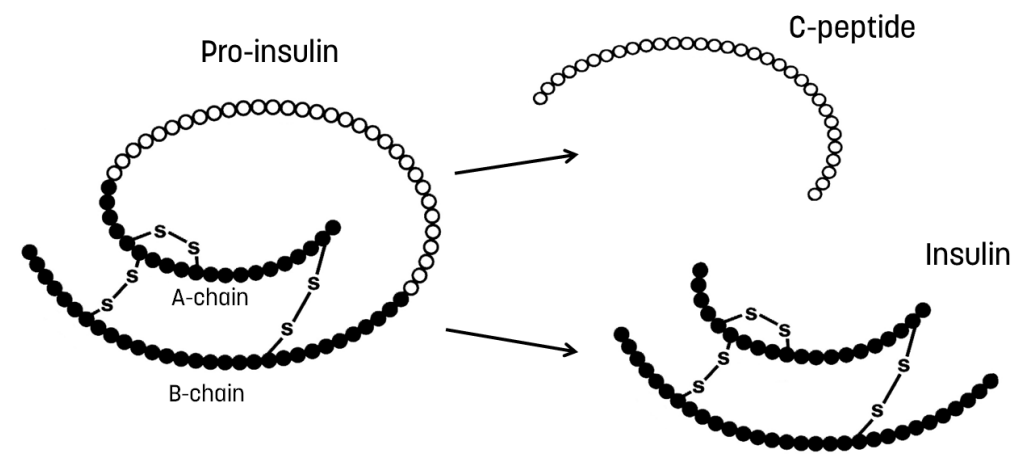

Figure 4. Proinsulin, enzymatically cleaved at two sites into insulin and connecting peptide (C-peptide).

Beside C-peptide, the concentration of plasma glucose is naturally of high relevance during the natural history of T1D. Low C-peptide does not necessarily imply high plasma glucose, and vice versa, due to complex interactions between insulin and glucose in target tissues. In the context of insulin resistance, for example, plasma glucose can be elevated despite high production of C-insulin. Therefore, assessment of plasma glucose in the fasting state and upon glucose challenge, both central measurements when diagnosing T1D, gives a more complete picture of the glucose homeostasis [140]. In addition, measurement of $\mathrm{HbA1c}$ provides an average blood glucose level over the past 2-3 few months, circumventing the high intra-individual variability seen in fasting plasma glucose. Performing a glucose 
tolerance test is important because changes in postprandial glucose often precede an increase of fasting plasma glucose.

\section{The period preceding clinical diabetes}

Accurate prediction of T1D risk is essential when performing clinical prevention trials. When an effective preventive therapy eventually is found, it will also be necessary to implement efficient and precise means of identifying individuals at risk among the general population. The significant contribution of risk genes in the aetiology of T1D, and the presence of islet autoantibodies before disease onset, enables identification of persons that suffer a greater risk of T1D than people in general. This provides an opportunity to study the pre-diabetic period in detail, which not only can contribute to improved risk assessment, but also to increased knowledge about the disease process. Increased knowledge, in turn, is instrumental in the development of novel potential preventive therapies.

Several prospective cohort studies have followed relatives of T1D patients, known to have a 10 to 100-fold higher risk of T1D compared to the general population [116]. The purpose of these studies was to explore the natural history of the disease and also to enroll these at-risk individuals to clinical trials aiming to stop or delay the disease progression at an early stage. These studies have given us a vast amount of information about the characteristics of the period preceding disease onset.

\section{Important risk cohorts}

In addition to ABIS, there are several cohort studies aiming to increase the understanding of the natural history of T1D. Two especially important studies, including relatives of T1D patients, are the TrialNet Natural History Study (NHS) and its predecessor the Diabetes Prevention Trial of Type 1 Diabetes (DPT-1). In DPT, a total of 711 autoantibody positive T1D-relatives were subject to further risk staging (genetic, immunologic, and metabolic factors) and enrolled into one of two randomized trials of low-dose insulin to try and alter the disease course [128, 129]. The subsequent, larger effort to study the natural history and identify clinical trial participants, the TrialNet NHS, screens T1D-relatives in USA, Canada, UK, Germany, Italy, Australia and New Zealand [141]. An estimated 15.000 relatives are screened annually, followed by further risk staging in individuals testing positive for islet autoantibodies. These studies have made essential contributions to the understanding of the pre-diabetic phase, and especially TriaNet NHS is expected to continue generating valuable scientific discoveries in the coming years. However, a limiting factor for the generalizability 
of the results is the fact that as few as $15 \%$ of T1D patients have a family history of the disease [142]. For this reason, there are also risk cohorts assessing the risk in the general population.

The Environmental Determinants of Diabetes in the Young (TEDDY) study, is a multinational observational cohort study involving six clinical centers in Sweden, Finland, USA and Germany [143]. The overall aim is to identify environmental factors (infectious agents, dietary factors or other environmental exposure) associated with increased risk of autoimmunity and T1D. Newborns from the general population and newborns with firstdegree relatives suffering from T1D have been screened for HLA-mediated risk genotypes, followed by detection of autoantibodies and close follow-up of risk-individuals until age 15 .

Another large risk cohort study screening individuals from the general population is the Type 1 Diabetes Prediction and Prevention Project (DIPP) in Finland [144]. The DIPP study aims to clarify the pathomechanism of T1D development, and does this by screening newborns for HLA-risk alleles. Children carrying HLA associated to moderate or high genetic risk for T1D are subject to intensive follow-up until age 15 .

\section{Staging of pre-diabetes}

Based on the collective information obtained from the studies above, and others not described here (ENDIT, TRIGR, BABYDIAB, BABYDIET, DAISY, DiPiS), a novel way to stage presymptomatic T1D has been proposed by the Juvenile Diabetes Research Foundation (JDRF, Figure 5) [116]. This staging will here be used to summarize parts of what is known about the period preceding clinical onset of T1D. 


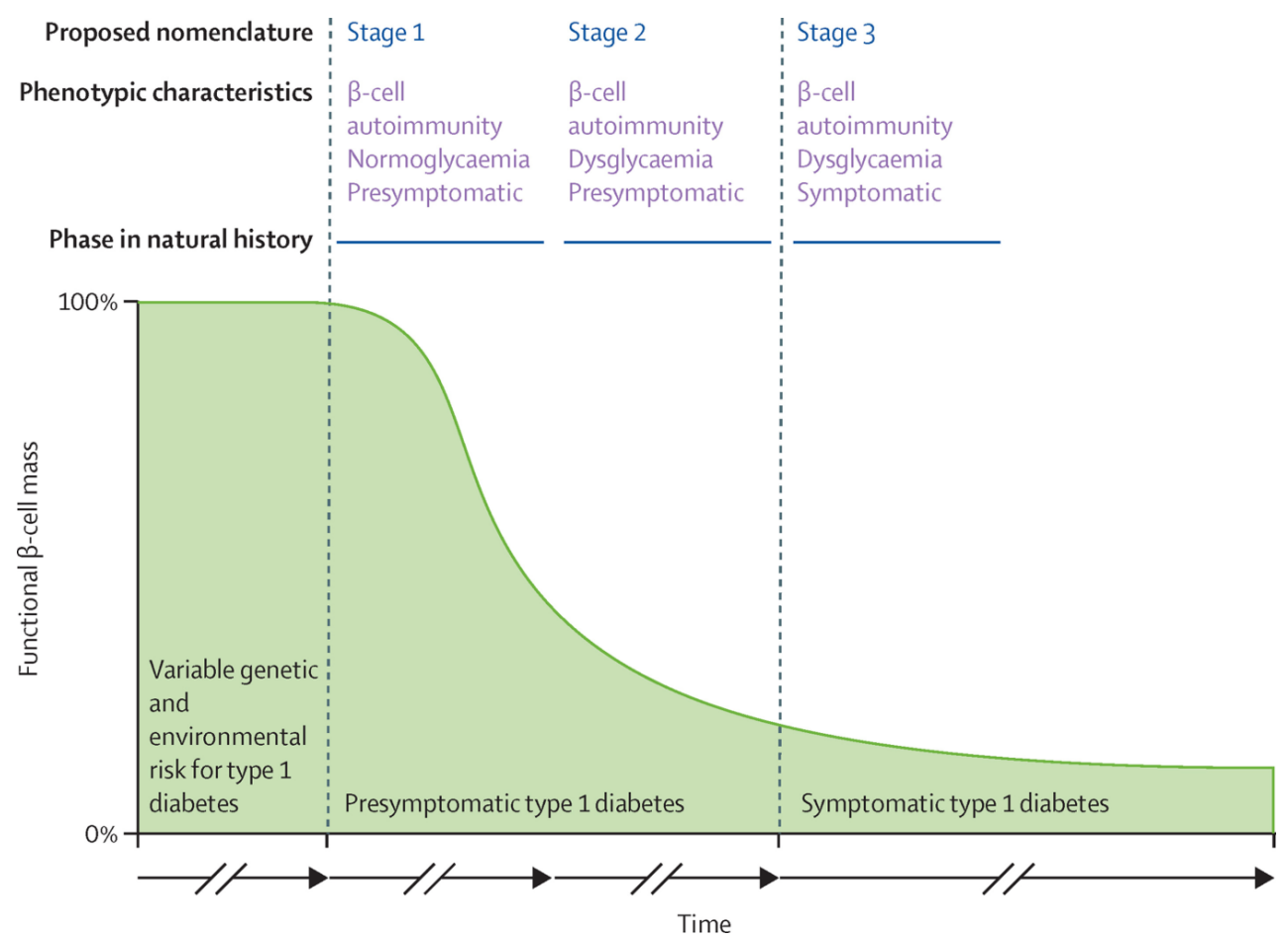

Figure 5. Staging of presymptomatic type 1 diabetes, as proposed by the Juvenile Diabetes Research Foundation, the Endocrine Society and the American Diabetes Association. Illustration from [30], reproduced with permission from Elsevier.

The first stage of presymptomatic T1D is represented by ongoing autoimmunity, shown as presence of islet autoantibodies. Regulation of blood sugar levels is still completely functional at this stage. When circulating autoantibodies to more than one major islet autoantigen can be detected, the risk to develop T1D is very high. Assessing the risk of progression to overt T1D after seroconversion to two or more autoantibodies across several risk cohorts (DAISY, DIPP BABYDIAB and BABYDIET) showed that the 10-year risk estimate is $70 \%$, and the risk during a lifetime approaches $100 \%$ [145]. For individuals positive for a single autoantibody, the 10-year risk was markedly lower, around $15 \%$. Younger age at seroconversion is associated with higher risk of progression [145], and additional factors affecting the rate of disease progression are the number, type, affinity and titer of the autoantibodies [116]. For instance it has been shown that positivity to IA2A and/or $\mathrm{ZnT} 8 \mathrm{~A}$ is related to faster disease progression [146, 147].

The second stage represents autoantibody positive individuals who have reached the point where subclinical dysglycaemia ensues, as a consequence of reduced functional beta cell 
mass. In the studies which the proposed T1D-staging is based upon, dysglycaemia has been defined as impaired plasma glucose ( $\geq 5.6$ or $\geq 6.2 \mathrm{mmol} / \mathrm{L}$ ), impaired glucose tolerance at 120 min of OGTT $(\geq 7.8 \mathrm{mmol} / \mathrm{L})$, high glucose at intermediate time-points of OGTT $(\geq 11.1 \mathrm{mmol} / \mathrm{L}$ at 30,60 or $90 \mathrm{~min}$ ) and/or HbA1c $\geq 5.7 \%$ [116]. When dysglycaemia is present, the risk of disease progression is markedly elevated, with a 5-year positive predictive value of around 95\% [148, 149]. The failure of metabolic regulation seems to occur gradually during the years preceding clinical disease. As summarized in Figure 6, representing the collective data from DPT-1, TrialNet NHS, DAISY, DiPiS, TEDDY and DIPP, the first metabolic change detected is a decrease in first-phase insulin secretion (FPIR) in IVGTT [150]. It can be seen many years before onset, but accelerates in the last two years prior to diagnosis. Increased $\mathrm{HbA} 1 \mathrm{c}$ is also seen at an early stage, followed by random plasma glucose and glucose at $120 \mathrm{~min}$ of OGTT. Fasting plasma glucose has limited predictive value, as it appears very close to clinical presentation of T1D. The collective data from these studies indicate that insulin resistance is not altered during the period preceding onset, although there are some studies indicating that it may be a useful predictive factor of progression among risk-individuals $[151,152]$.

In the third and last stage, the gap between the body's insulin need and the insulin secretory capacity becomes too large, because of the progressive decline in functional beta cell mass. Diabetes symptoms appear, and the patient needs administration of exogenous insulin to maintain glucose homeostasis.

Importantly, a large proportion of the information available about the pre-diabetic period comes from studies on first- or second-degree relatives of T1D patients, since they are easy to find and have an increased disease risk compared to the general population. However, T1D patients in general rarely have familial disease, and the generalizability of the results to T1D patients at large may therefore be an issue. Some of the more recent risk-cohorts are instead based on genetic screening among the general population. This kind of cohorts are more representative for T1D patients in general, although it should be noted that individuals developing disease despite the absence of classical risk-conferring HLA-alleles are not included in such studies. This may be even more important considering the results from Finland, showing an increasing proportion of patients with HLA-genotypes associated to low risk [42]. Very recently, the German Fr1Da study was initiated, applying a universal childhood population-based screening for multiple autoantibodies, instead of using genetic screening as a first step [153]. The identified risk-individuals will be invited to clinical trials 
aiming to halt the disease progression at an early stage. This study is expected to give important results that truly are generalizable to T1D patients at large.
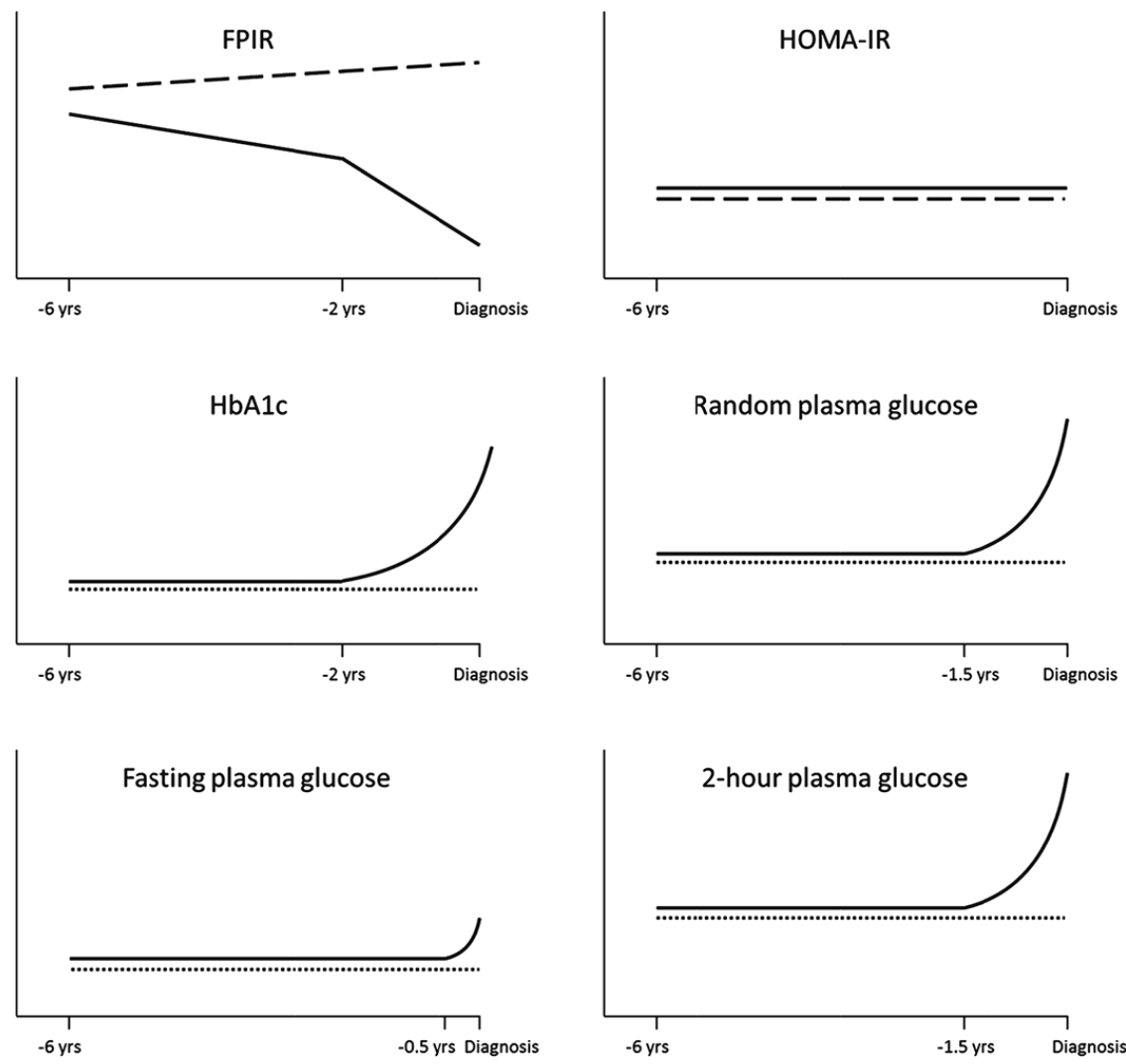

Figure 6. Development of dysglycemia during preclinical type 1 diabetes. Schematic illustration of first phase insulin response (FPIR) measured in intravenous glucose tolerance test (IVGTT), insulin resistance index (HOMA-IR), glycosylated hemoglobin A1c (HbA1c), randomly measured plasma glucose, fasting plasma glucose and 2-h plasma glucose values in oral glucose tolerance test (OGTT). Black lines: progressors, long dashed lines: non-progressors with islet cell autoantibodies only, dotted lines: non-progressors positive for multiple islet autoantibodies. The dotted and dashed lines in HOMA-IR are on the same level as the solid, but drawn separately for clarity. Figure reproduced from [150], under the creative commons license. 


\section{Efforts to improve disease prediction}

As implied by the proposed staging discussed earlier, the tools we currently have at our disposal for reliable risk stratification mainly pertain to determination of genetic risk, assessment of islet autoantibody profile and different measures of glucose homeostasis. There are extensive past and present efforts to characterize the pre-diabetic period further, in order to fully explain the pathogenesis and to find alternative surrogate markers of risk which may contribute to early and highly specific risk estimates. There have been wide efforts to measure circulating immune cells (CD4+ or CD8+ T cells) with reactivity to autoantigens, as reviewed in [154]. This has proven difficult despite the use of peptide MHC-tetramers, in part due to low precursor frequency in blood, demanding the use of large sample volumes. Different "omic" approaches, including transcriptomics, metabolomics and proteomics, can be expected to shed more light on the underlying disease process and hopefully provide novel disease markers.

Several kinds of blood based signatures have been evaluated in the context of T1D and prediabetes, based on modern technologies to measure RNA and proteins in the circulation. Transcriptional profiling has been fruitful in autoimmune disease, as reviewed in [155], revealing the presence of a type I IFN-signature in SLE and enabling disease classification and prediction of treatment response in rheumatoid arthritis, based on PBMC gene expression. A type I IFN transcriptional signature has now been detected in several studies in T1D as well, both in PBMC [156] and whole blood [157] before the development of autoantibodies, in T1D relatives with HLA-conferred risk and T1D relatives with autoantibody-positivity, respectively. Furthermore, a type I IFN-regulated signature was observed to be preferentially expressed in pre-diabetes when whole-blood microarray analysis was performed in T1D subjects, autoantibody-positive T1D relatives and healthy controls [158]. Transcriptomic profiling has also revealed an early suppression of immune response pathways in pre-diabetic children from the DIPP study, with down-regulation of networks involved in antigen presentation, T-cell receptor signaling and insulin signaling [159]. It was recently shown in the DAISY study that expression levels of genes implicated in lymphocyte activation and function were associated with progression rates to T1D [160]. A set of genes (BACH2, IGLL3, EIF3A, CDC20, and TXNDC5) were validated and shown to consistently stratify high- and low-risk subsets of autoantibody-positive individuals at genetic risk, when included in multigene models. Proteomic approaches too, have recently indicated that disease progression may be predicted. 
By applying a proteomic approach on longitudinal serum samples from participants in the DIPP study, classification of individuals that seroconverted and progressed to clinical disease could be achieved with high accuracy, among children carrying HLA-alleles conferring increased risk [161]. In the progressors, a set of proteins consistently showed different levels of abundance before the appearance of autoantibodies.

In what can be called "reverse proteomics ", incubation of healthy PBMC with sera from T1D patients is followed by assessment of induced gene-expression in the PBMC. By this method, an expression signature involving members of the IL-1 cytokine family, together with chemokines involved in chemotaxis of monocytes/macrophages and neutrophils, has been observed [162]. The signature was only seen when using sera from recent-onset patients, but not after long-standing disease. Interestingly, the signature was observed years before clinical disease, as assessed by follow-up of individuals at increased risk.

An additional layer of regulation in protein synthesis is provided by the small, non-coding, single-stranded RNA molecules called micro RNA (miRNA) [163]. They regulate gene expression post-transcriptionally by partly complementary binding to mRNA sequences [164]. The binding primarily causes repressed expression, by inhibition of translation or increased mRNA degradation, but increased expression can also occur. Each miRNA can bind to multiple mRNAs, creating a complex regulatory network affecting many physiological and pathological processes [165-167]. In T1D, there are reports on differentially expressed miRNAs in PBMCs [168-171], and specific immune cell subsets like regulatory T cells [172]. There is also experimental data showing altered levels of miRNAs within the islets of NOD-mice during the pre-diabetic phase, and the expression of specific miRNAs was affected when exposing both murine- and human islets to pro-inflammatory cytokines [173]. In addition, distinct miRNA profiles have been detected in the circulation of recent onset T1D patients compared to healthy controls, and the identified miRNAs were related to apoptosis and beta cell function [174]. Analyses of circulating miRNA expression profiles with regard to the pre-diabetic period have not yet been reported.

Despite the interesting findings coming from transcriptomics, proteomics and other fields assessing blood-based signatures, many of these early "omics" studies are based on very few individuals, and validation in larger, independent cohorts is still lacking, as noted in [175]. In addition, to be suitable as biomarkers, the signatures need to be sufficiently strong and last for a long enough time to allow them to be detected. 


\section{AIMS OF THE THESIS}

The general aim of the thesis work was to further elucidate the natural history of the period preceding disease onset, in high-risk children selected from the general population based on positivity for multiple islet autoantibodies.

The specific aims were:

$\circ$ To characterize the pre-diabetic period during a 2-year follow-up and to identify factors indicative of progression/non-progression to T1D.

○ To identify biomarkers of disease risk or disease progression in the same group of risk-individuals, by assessing the PBMC expression of genes related to the Th1, Th2 and Th3 arms of the immune system.

- To explore serum miRNA expression profiles in the risk-individuals, in order to identify deviations preceding disease onset.

○ To analyze the relationship between physical activity and several risk factors associated to the development of diabetes (glucose, C-peptide and obesity) in a group of healthy children from the ABIS study. 


\section{MATERIALS AND METHODS}

\section{Study populations}

\section{The ABIS study (paper I-IV)}

All Babies in Southeast Sweden (ABIS) is a prospective, longitudinal cohort study with the overall aim to study the etiology of immune mediated diseases, especially T1D, but also allergies, celiac disease etc [176]. All mothers in the South-east of Sweden giving birth between October 1st 1997 and October 1st 1999 were invited to participate in ABIS, and $78,6 \%$ (17055) accepted. Blood and other biological materials have been collected at birth and at age 1, 2.5-3, 5-6 and 8. In addition to the biological samples, parents and children have repeatedly completed extensive questionnaires regarding environmental factors such as eating habits, living conditions, infections, familial disease history etc.

\section{The high-risk group (paper I-III)}

Autoantibody screening was performed on samples collected throughout the ABIS study to identify individuals at high risk of T1D development. Measurement of GADA and IA-2A was performed at all time points, IAA at 5-6 and 8 years of age and ZnT8R/W/Q at age 8. All participating children did not leave samples at all time points, and the number of children screened for autoantibodies is presented in Table 1 . The screening identified $46^{*}$ children considered at high risk, defined as testing positive for 2 or more different autoantibodies on at least two sampling occasions. During the subsequent sampling at 11 years of age, it was found that 22 of them had already been diagnosed with T1D. In 2009, families of the 24 highrisk children that remained healthy were contacted and informed about the increased risk. They were invited to participate in a two year long prospective follow-up, including blood sampling every 6 months and oral glucose tolerance test (OGTT) every 12 months. The study design of the high-risk follow-up is outlined in Figure 7. All of the families accepted to participate in the follow-up, although one family dropped out before the first visit.

*Two children were invited to participate in the follow-up even though they presented with multiple autoantibodies only once and single autoantibodies at the other time points, thus not adhering strictly to our definition of high risk. These are not included in high-risk data. 
Table 1. The total number of children tested for each autoantibody (GADA, IA2A, IAA and ZnT8R/Q/W) at the first 4 sampling occasions in the ABIS study (1, 2.5, 5 and 8 years of age), and the number of children positive for each autoantibody.

\begin{tabular}{llllll}
\hline Sampling age (years): & $\mathbf{1}$ & $\mathbf{2 . 5}$ & $\mathbf{5}$ & $\mathbf{8}$ \\
\hline GADA & Analyzed samples (positive samples) & $8590(552)$ & $7455(330)$ & $4007(202)$ & $2011(86)$ \\
IA2A & Analyzed samples (positive samples) & $8472(475)$ & $7492(460)$ & $4008(42)$ & $2008(26)$ \\
IAA & Analyzed samples (positive samples) & - & - & $2576(66)$ & $604(24)$ \\
ZnT8R & Analyzed samples (positive samples) & - & - & - & $293(3)$ \\
ZnT8Q & Analyzed samples (positive samples) & - & - & - & $321(3)$ \\
ZnT8W & Analyzed samples (positive samples) & - & - & - & $262(3)$ \\
\hline
\end{tabular}

The families were first contacted by telephone, receiving information about the increased disease risk from a specialized diabetes research nurse. They were also informed about the prospective follow up of high-risk individuals and invited to a first visit at the Diabetes outpatient department, with a specialized diabetes clinician and a research nurse. Following the oral information, the families also received written information by mail.

At the first visit, blood samples were drawn for assessment of autoantibodies, C-peptide, HbA1c and HLA-genotype, and for isolation of PBMC for immunological analyses. Hair samples were collected for cortisol analyses, as a somatic sign of stress. Oral glucose tolerance test was performed, and parents and children were interviewed and asked to complete questionnaires regarding attitudes towards screening, high-risk identification and preventive measures.

\section{2-year prospective follow-up of T1D high-risk individuals}

$\begin{array}{lllll} & & \end{array}$

Figure 7. Study design of the prospective follow-up of T1D high-risk individuals. Children from the general population, positive for multiple autoantibodies $(n=21)$, were included to a 2 -year prospective follow-up with regular blood samplings, OGTT and questionnaires/interviews on psychological/psychosocial data. 
The families also received more information about T1D from a clinician and more detailed information about the follow up from members of the research team. The baseline characteristics are presented in Table 2. For the assessments at 6 and 18 months, the families were sent a blood sampling kit containing tubes for blood samples, anaesthetic numbing cream, adhesive labels, padded envelopes and instructions. The kit was brought to their local primary care clinic where blood samples were drawn. Samples were sent by post to the Paediatric Research Laboratory in Linköping, and were received and processed within 24 hours. At the 12 and 24 month follow-up, the research team visited the families at their local diabetes outpatient clinics for blood draw, OGTT and completion of questionnaires.

\section{Healthy children (paper II-IV)}

A large number of sub-studies pertaining to different areas of research have been performed within ABIS. One sub-study was performed to assess the relationship between physical activity and several risk factors for development of diabetes in children. In this prospective study, a group of healthy schoolchildren within ABIS participated at two time points, approximately 4 years apart. The children wore pedometers to measure the average number of daily steps, and blood samples were collected to determine fasting plasma glucose, Cpeptide and $\mathrm{HbAlc}$, and to estimate insulin resistance and beta-cell function using the homeostatic model assessment (HOMA). In addition, weight, height and waist circumference were recorded. All data collection was performed at the schools. Self-reported data on variables connected to physical activity, from parents and from the children themselves, were available from questionnaires at the same time points.

Inclusion to the pedometer study was performed by inviting school classes from two cities within the ABIS region, Linköping and Kalmar. The school nurse asked the children and both their parents to give written informed consent before participation. All children who were asked wanted to participate. The chosen schools were shown to be representative for ABIS children in the same area, with regard to relevant factors reflecting physical activity. 
Table 2. Baseline characteristics of all participants in paper I-III.

Gender Paper Baseline- Weight $\begin{gathered}\text { peptide } \\ \text { HbAlc }\end{gathered}$

\begin{tabular}{|c|c|c|c|c|c|c|c|c|c|c|c|c|c|c|c|c|}
\hline \multirow{2}{*}{\multicolumn{2}{|c|}{ High-risk }} & \multirow[b]{3}{*}{ I, II, III } & \multirow{2}{*}{ age years } & \multirow[t]{2}{*}{$\mathrm{kg}$} & \multirow[t]{2}{*}{$\mathrm{nmol} / \mathrm{L}$} & \multirow[t]{2}{*}{$\%$} & \multirow{2}{*}{\multicolumn{2}{|c|}{$\mathrm{mmol} / \mathrm{l}$}} & & _ & \multirow{2}{*}{\multicolumn{2}{|c|}{ Tryp }} & \multirow[t]{2}{*}{ Arg } & \multirow[t]{2}{*}{ Glut } & \multirow[t]{2}{*}{ * } & \\
\hline & & & & & & & & & & & & & & & & \\
\hline 1 & Male & & 11.5 & 33 & 0.34 & 4.2 & 5.6 & 9.1 & 32860 & 2.7 & 13.2 & 5 & 5 & 5 & SN & Moderate \\
\hline 2 & Female & I, II, III & 11.7 & 45.2 & 0.32 & 4.3 & 5.3 & 10.6 & 262.5 & 2.8 & 5.3 & 5 & 5 & 5 & SP & Low \\
\hline 3 & Male & I, II, III & 10.5 & 39.6 & 0.27 & 4.6 & 4.9 & 6.9 & 53.6 & 444.5 & 11.9 & 416.8 & 396.7 & 215.7 & $\mathrm{SP}$ & Low \\
\hline 5 & Male & I, II, III & 10.2 & 35.4 & 0.33 & 4 & 5.3 & 6 & 200.8 & 6930 & 0.1 & 2832 & 5 & 5 & SN & Moderate \\
\hline 6 & Male & I, II, III & 11.6 & 58.7 & 0.32 & 4.5 & 5.4 & 8.1 & 161 & 1128 & 11.9 & 324 & 1967 & 347.6 & SS & Moderate \\
\hline 7 & Male & I, II & 11.1 & 51.1 & 0.26 & 4.2 & 4.1 & 6.4 & 7490 & 1364 & 11.6 & 470 & 1398 & 393.6 & SN & \\
\hline 9 & Female & I, II, III & 10.0 & 50.8 & 0.91 & 4.2 & 5.2 & 6.1 & 8730 & 2.7 & 17.6 & 787.8 & 220.3 & 68.6 & SN & Moderate \\
\hline 10 & Male & I, II, III & 10.0 & 32.6 & 0.32 & 4.5 & 5.2 & 8.3 & 140.4 & 329.5 & 0.1 & 5 & 468 & 5 & SS & Moderate \\
\hline 11 & Male & I, II, III & 9.9 & 39.2 & 0.39 & 4.3 & 5 & 6.2 & 3782 & 2.7 & 3.6 & 5 & 1620 & 5 & SS & Moderate \\
\hline 12 & Female & I, II, III & 10.9 & 35.8 & 0.34 & 3.8 & N/A & $\mathrm{N} / \mathrm{A}$ & 768 & 346 & 3.9 & 45.3 & 23400 & 38.6 & SS & Moderate \\
\hline 13 & Male & I, II, III & 10.4 & 44.4 & 0.20 & 4.2 & 5.1 & 5.8 & 94.7 & 272.5 & 6.7 & 33.6 & 1237 & 45.8 & $\mathrm{SP}$ & Low \\
\hline 14 & Male & I, II, III & 10.3 & 56 & 0.44 & 4.4 & 5.1 & 5.8 & 4540 & 2.7 & 6.7 & 5 & 5 & 5 & SS & High \\
\hline 19 & Female & I, II, III & 9.6 & 26.7 & 0.25 & 4.4 & 4.3 & 6.2 & 80.9 & 18.9 & 0.1 & 34 & 242.5 & 22.5 & Ss & High \\
\hline 20 & Female & I, II, III & 10.5 & 34.5 & 0.31 & 4.5 & 5.9 & 11.1 & 8770 & 12.7 & 3.7 & 5 & 5 & 5 & SS & High \\
\hline 21 & Female & I, II, III & 10.6 & 43.7 & 0.46 & 4.5 & 5.7 & 6.2 & 8120 & 2.7 & 6.2 & 5 & 5 & 5 & SN & Low \\
\hline \multicolumn{17}{|c|}{ Type 1 diabetes } \\
\hline 22 & Female & I, II, III & 13.7 & 48.2 & 0.04 & 7.8 & $\mathrm{~N} / \mathrm{A}$ & $\mathrm{N} / \mathrm{A}$ & 44.5 & 167.1 & 2.1 & 33.2 & 127.6 & 23.6 & SS & Moderate \\
\hline 23 & Female & I, II, III & 10.9 & 49.0 & 0.30 & 9.5 & N/A & $\mathrm{N} / \mathrm{A}$ & 20.5 & 1332 & 5.2 & 76.1 & 77 & 59.2 & $\mathrm{SP}$ & Moderate \\
\hline 24 & Female & I, II, III & 9.9 & 39.9 & 0.17 & 9 & N/A & $\mathrm{N} / \mathrm{A}$ & 29.6 & 108.9 & 0.1 & 43.2 & 54.6 & 29.2 & $\mathrm{SP}$ & Moderate \\
\hline 25 & Female & I, II & 10.0 & 33.7 & 0.17 & 7 & N/A & $\mathrm{N} / \mathrm{A}$ & 180.7 & 841 & 6.7 & 416.1 & 1101 & 323.7 & $\mathrm{SP}$ & Moderate \\
\hline 26 & Male & I, II & 10.0 & 33.7 & 0.10 & 8 & N/A & $\mathrm{N} / \mathrm{A}$ & 219.9 & 661 & 0.1 & 8390 & 11040 & 9150 & SN & Low \\
\hline 27 & Female & I, II, III & 12.1 & 30.4 & 0.17 & 9.1 & N/A & $N / A$ & 8100 & 787 & 13.4 & 2011 & 49.7 & 30.4 & SS & High \\
\hline 28 & Female & I, II, III & 11.2 & 46.2 & 0.26 & 8.1 & N/A & N/A & 1427 & 834 & 0.1 & 1026.5 & 1307 & 965 & SS & Moderate \\
\hline 29 & Female & I, II, III & 12.4 & 34.4 & 0.07 & 7.2 & $\mathrm{~N} / \mathrm{A}$ & $\mathrm{N} / \mathrm{A}$ & 1410 & 44.5 & 0.1 & 25.8 & 27.2 & 19.6 & SS & Low \\
\hline
\end{tabular}

Healthy controls

\begin{tabular}{|c|c|c|c|c|c|c|c|c|c|c|c|c|c|c|c|c|}
\hline 32 & Male & I-IV & 11.9 & 30.5 & 0.60 & $\mathrm{~N} / \mathrm{A}$ & $\mathrm{N} / \mathrm{U}$ & $\mathrm{N} / \mathrm{A}$ & 12.7 & 2.7 & 0.1 & 5 & 5 & 5 & SS & Moderate \\
\hline 35 & Male & I-IV & 12.0 & 40.9 & 0.35 & $\mathrm{~N} / \mathrm{A}$ & $\mathrm{N} / \mathrm{U}$ & N/A & 8.6 & 2.7 & 0.1 & 18.6 & 5 & 5 & NN & Low \\
\hline 37 & Male & I-IV & 12.4 & 35 & 0.69 & $N / A$ & $N / U$ & N/A & 5 & 2.7 & 0.1 & 7.9 & 5 & 5 & $\mathrm{NN}$ & Low \\
\hline 38 & Male & I-IV & 12.1 & 42.8 & 0.32 & $\mathrm{~N} / \mathrm{A}$ & $N / U$ & $\mathrm{~N} / \mathrm{A}$ & 9.6 & 2.7 & 0.1 & 5 & 5 & 5 & NN & Low \\
\hline 39 & Male & I-IV & 12.2 & 43 & 0.39 & $\mathrm{~N} / \mathrm{A}$ & $\mathrm{N} / \mathrm{U}$ & N/A & 10.6 & 2.7 & 0.1 & 15.1 & 5 & 5 & PN & Low \\
\hline 42 & Male & I-IV & 12.3 & 54.6 & 0.55 & $\mathrm{~N} / \mathrm{A}$ & $\mathrm{N} / \mathrm{U}$ & N/A & 8.2 & 2.7 & 0.1 & 5 & 5 & 5 & PN & Low \\
\hline 43 & Female & I-IV & 11.5 & 35.2 & 0.57 & $\mathrm{~N} / \mathrm{A}$ & $\mathrm{N} / \mathrm{U}$ & $\mathrm{N} / \mathrm{A}$ & 24.2 & 2.7 & 0.1 & 21.7 & 5 & 5 & $\mathrm{SP}$ & Low \\
\hline 44 & Female & I-IV & 11.5 & 50.7 & 0.41 & $\mathrm{~N} / \mathrm{A}$ & $N / U$ & N/A & 17.9 & 2.7 & 0.1 & 24.7 & 24 & 5 & $\mathrm{SN}$ & Low \\
\hline 45 & Female & I-IV & 11.6 & 45.3 & 0.89 & $\mathrm{~N} / \mathrm{A}$ & $N / U$ & $\mathrm{~N} / \mathrm{A}$ & 5 & 2.7 & 0.1 & 10.6 & 18.5 & 5 & PN & Low \\
\hline 46 & Male & I-IV & 11.7 & 36.3 & 0.47 & $\mathrm{~N} / \mathrm{A}$ & $\mathrm{N} / \mathrm{U}$ & $\mathrm{N} / \mathrm{A}$ & 10.8 & 2.7 & 0.1 & 16.6 & 5 & 5 & PN & Low \\
\hline 47 & Female & I-IV & 12.3 & 50.8 & 0.56 & N/A & $\mathrm{N} / \mathrm{U}$ & N/A & 8.5 & 2.7 & 0.1 & 16.8 & 5 & 5 & SN & Low \\
\hline
\end{tabular}

Single/Transient autoantibodies

\begin{tabular}{|c|c|c|c|c|c|c|c|c|c|c|c|c|c|c|c|c|}
\hline 49 & Female & I, IV & 11.8 & 40.7 & 0.38 & N/A & $\mathrm{N} / \mathrm{U}$ & N/A & 17.8 & 2.7 & 6.2 & 5 & 5 & 5 & SN & Low \\
\hline 50 & Male & I & 11.4 & 72.4 & 0.68 & 4.2 & 5.7 & 6.1 & 45.2 & 2.7 & 0.1 & 5 & 5 & 5 & PN & Low \\
\hline 51 & Female & I & 11.4 & 38 & 0.47 & 4.2 & 5.1 & 6.2 & 20.1 & 2.7 & 3.8 & 5 & 5 & 5 & PP & Low \\
\hline
\end{tabular}

Autoantibody titers are expressed in in Units/ml. HLA* refers to the HLA classification used in paper II, HLA** to the classification in papers I and III. OGTT refers to the 2 hour plasma glucose value. N/A: not available. N/U: available but not used for group comparisons in papers I-III. C-peptide refers to fasting fasting values. 
Study participation is outlined in Figure 8. At age 8, 199 children participated in the assessment (100 girls, 99 boys, mean 7.8 years, range 6.5-8.9), 130 from schools in Linköping and 69 from schools in Kalmar. The second assessment had 107 participants (51 girls, 56 boys, mean 11.9, range 10.6-12.6), this time only from Linköping, for practical reasons. Of these 107, 104 belonged to the initial group of 199 children, and in addition 3 class-fellows who absolutely wanted to participate. At age 8, 154 of the parents answered the questionnaire, while 90 parents and 90 children answered the questionnaire at 12 years.

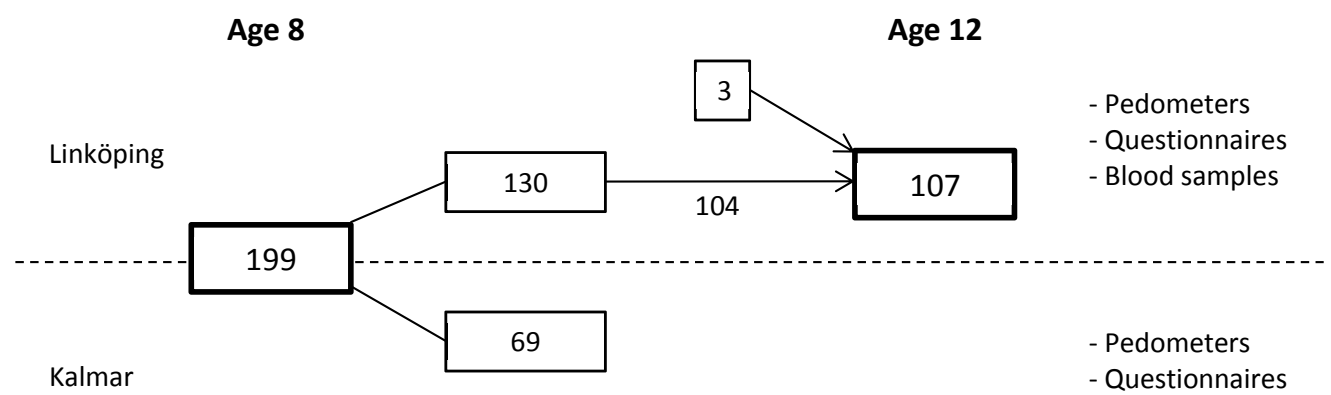

Figure 8. Outline of participation in the longitudinal pedometer study, as part of ABIS.

\section{Healthy reference group (paper II and III)}

At the second data collection of the pedometer study, the participants were around the same age as the high-risk individuals, and they therefore constituted an ideal healthy control group Table 2). Based on information in the ABIS questionnaires, a group of children fulfilling the criteria to be considered healthy controls for the studies with the high-risk group was selected from the participants in the pedometer study. The criteria to be regarded as healthy were as follows: no diabetes type 1 or 2, or any autoimmune disorders, no asthma, eczema or allergies, and no first-degree relatives with diabetes or autoimmune disorders.

\section{Diabetes patients (paper II and III)}

Samples from recently diagnosed T1D patients were obtained from the paediatric clinic at Linköping University Hospital, Sweden (Table 2). Blood samples, including serum and whole blood for isolation of PBMC, are drawn from all newly diagnosed diabetic patients at the clinic. For paper II and III, we picked samples from a group of diabetes patients that were around the same age as the high-risk individuals when they received their diagnosis. All samples were taken 1 month after disease onset. 


\section{Blood sampling}

All samples were collected in a fasting state, and always during the morning hours to avoid diurnal variations. Since ABIS-participants in the high-risk follow-up study (papers I-III) were spread out in the south-east of Sweden, it was often not possible to process the samples immediately after sampling. The samples were either drawn by our research nurse or in the children's local primary care center, depending on the type of visit (see Figure 7, study design). In samples shipped by post, processing of the blood was delayed until the day after blood draw. Therefore, this procedure was used for all samples taken in the study.

For papers I-IV, venous blood from the cubital vein was collected into sodium-heparinized tubes for isolation of peripheral blood mononuclear cells (PBMC), into serum gel tubes for analysis of autoantibodies and C-peptide, and into EDTA-tubes for measurement of HbA1c. When samplings within the high-risk follow-up were performed at local primary care centers, blood was also collected into FC mixture tubes ( $\mathrm{Na}_{2}$ EDTA, sodium fluoride, citric acid and sodium citrate) for measurement of fasting plasma glucose.

In paper IV, blood sampling was performed by research nurses during the same week as measurement of physical activity, for the data collection point at age 8 . At age 12, blood draws were performed by research- and school nurses, around the time when pedometers were worn $( \pm 1$ week).

For samples from T1D patients (paper II-III), we only used samples that had been processed at the day after blood-draw, since this was the case also for samples from the high-risk individuals.

\section{Assessment of glucose homeostasis (paper I-IV)}

\section{Fasting plasma glucose}

In papers papers I-III, fasting glucose was either measured as fasting capillary plasma glucose by use of a point-of-care glucose meter, or measured centrally at the hospital laboratory after blood collection into FC Mixture tubes.

In paper IV, fasting plasma glucose was measured using Bayer's BREEZE®2 (Bayer, Sweden). The measurement was performed on venous blood samples, producing 7-9\% higher values compared to capillary blood, and the results were adjusted accordingly. 
Fasting plasma glucose values were categorized as normal $(4.0-6.0 \mathrm{mmol} / \mathrm{l})$ or impaired fasting glucose ( $\geq 6.1 \mathrm{mmol} / \mathrm{l})$ according to the definitions established by WHO [177].

\section{Oral glucose tolerance test}

All OGTT's were performed at diabetes outpatient departments. Ingestion of $1.75 \mathrm{~g}$ glucose per kg body weight (GLUCOMEDICS®, Lablemon, Finland) up to maximally 75, was preceded by measurement of fasting capillary plasma glucose. After 120 minutes, glucose was measured again. The resulting values were categorized as normal glucose tolerance (OGTT $120 \mathrm{~min}<7,8 \mathrm{mmol} / \mathrm{l})$, impaired glucose tolerance $(\geq 7,8 \mathrm{mmol} / \mathrm{l})$ or diabetes $(\geq 11,1 \mathrm{mmol} / 1)$ again using WHO definitions [177].

\section{C-peptide}

Fasting C-peptide was measured in serum samples using a time-resolved fluoroimmunoassay (AutoDELPHIATM C-peptide kit, Wallac, Turku, Finland), in a VICTOR3 ${ }^{\mathrm{TM}}$ multilabel plate reader (Perkin Elmer LS, Wallac Oy, Finland). A C-peptide control module containing low-, medium- and high-level controls was included to validate each assay (Immulite, Diagnostic Products Corp., UK). Wallacs’ 1224 MultiCalc ${ }^{\circledR}$ program was used for automatic measurement and calculation of results, with concentrations expressed in $\mathrm{pmol} / \mathrm{ml}$.

\section{HbA1c}

HbA1c was measured with an immunological method, calibrated against the Swedish Standard Mono-S and continuously controlled against the Swedish EQUALIS reference method (External Quality Assurance in Laboratory medicine in Sweden).

\section{HOMA-assessment}

The Homeostasis Model Assessment (HOMA), first published in 1985 [178] and later updated 1998 with refined algorithms [179], can be used to obtain model-derived estimates of steady state beta cell function $(\% \mathrm{~B})$, insulin sensitivity $(\% \mathrm{~S})$ and insulin resistance (IR) as the reciprocal of $\% \mathrm{~S}$, based on fasting plasma glucose and insulin (or C-peptide) concentrations. The HOMA2 Calculator Version 2.2.3 @ Diabetes Trials Unit, University of Oxford was used, available from http://www.dtu.ox.ac.uk/homa.

\section{Measurement of islet autoantibodies (paper I, II and III)}

Levels of GADA, IA2A and ZnT8 ZnT8 (R-, W- and Q variants) were determined in serum (or whole blood for GADA and IA2A at age 1 and 2.5) by radiobinding assays described in detail elsewhere [180, 181]. Human recombinant 35S-labeled GAD65, IA-2ic, and 
ZnT8(R/W/Q) was produced by in vitro transcription/translation of complementary DNA cloned into plasmid vectors (modified pCDNA2 pEx9-GAD65 for GAD65 until 2008, pThGAD65 for GAD65 after 2008, pSP64-PolyA-IA-2ic for IA-2ic and modified pCDNA3.1 pThTnT8-R/W/Q for ZnT8R/W/Q, all kindly provided by Prof. Åke Lernmark, Lund University, Sweden). Sepharose protein A precipitation was used to separate free labelled antigen from antibody bound labelled antigen, and each plate included a standard curve, a blank (wells with only buffer), as well as positive and negative controls. A Wallac 1450 Microbeta Liquid Scintillation Counter (Perkin Elmer Life and Analytical Sciences) was used to count the immunoprecipitated radioactivity, and concentrations were extrapolated from the standard curves, expressed in Units/ml.

Measurement of IAA was performed using a competitive radiobinding assay [182] with modifications [183]. Serum samples were incubated with 125I labeled human recombinant insulin (Amersham Biosciences, Buckinghamshire, Great Britain) or with 125I insulin and an excess of unlabelled human recombinant insulin (Sigma-Aldrich, St. Louis, MO, USA). Radioactivity was measured using a gamma counter (1282 CompuGamma, Wallac, Turku), after Sepharose protein A precipitation. Each plate included a standard curve, and positive and negative controls. To calculate specific antibody binding, the mean counts per minute (cpm) of duplicate samples incubated with an excess of unlabelled insulin was subtracted from the mean cpm of duplicate samples incubated with labelled insulin. Concentrations were expressed as Units $/ \mathrm{ml}$ in relation to the standard curve.

Cut-off levels for autoantibody positivity at 1 and 2.5 years were based on the combined results from measurements in serum from children participating in the ABIS controls at 1 year $(n=1000)$ and 2,5 years $(n=1000)$. Cut-off levels for 5 years and onward were based on the analysis of samples from the ABIS cohort at the 5 year control (GADA $n=4007$, IA2A $\mathrm{n}=4007$, IAA $\mathrm{n}=2481$ ). The percentiles and corresponding concentrations (U/ml) used as cutoffs for all autoantibodies from 5 years and on were as follows: GADA $63.8\left(95^{\text {th }}\right)$, IA2A 5.8 $\left(99^{\text {th }}\right)$, IAA $4.1\left(98^{\text {th }}\right)$, ZnT8A(Arg) $34.2\left(99^{\text {th }}\right)$, ZnT8A(Gln) $23.9\left(99^{\text {th }}\right)$ and ZnT8A(Trp) 28.6 $\left(99^{\text {th }}\right)$. Sensitivity and specificity for the autoantibody assays has been evaluated through participation in the Diabetes Autoantibody Standardization Program (DASP) workshop (laboratory number 221). As seen in Table 3, where the range of sensitivity and specificity during the years 2002-2013 are presented, the results have varied considerablyover time. 
Table 3. Range of sensitivity and specificity for the autoantiody assays during the years 2002-2013 (including ZnT8A from 2010 and on), as assessed through participation in the Diabetes Autoantibody Standardization Program (DASP) workshop. The values are calculated based on the $98^{\text {th }}$ percentile for GADA and IAA, and the $99^{\text {th }}$ for IA2A and ZnT8A.

\begin{tabular}{lcccccc}
$\mathbf{2 0 0 2 - 2 0 1 3}$ & $\begin{array}{c}\text { Sensitivity } \\
(\%)\end{array}$ & $\begin{array}{c}\text { Specificity } \\
(\%)\end{array}$ & & $\mathbf{2 0 1 0 - 2 0 1 3}$ & $\begin{array}{c}\text { Sensitivity } \\
(\%)\end{array}$ & $\begin{array}{c}\text { Specificity } \\
(\%)\end{array}$ \\
\hline GADA & $54-80$ & $95-100$ & & ZnT8AR & $50-56$ & $90-99$ \\
IA2A & $48-72$ & $98-100$ & & ZnT8AW & $36-46$ & $89-93$ \\
IAA & $24-42$ & $97-100$ & & ZnT8AQ & $18-28$ & 100
\end{tabular}

\section{Determination of HLA-genotype (paper I-III)}

For determination of HLA-genotype, DNA was extracted from whole blood or PBMCs according to availability, using Maxwell@16 Blood DNA Purification Kit (Promega). The gontyping was performed by Labmedicin Skåne (Clinical Chemistry in Malmö, Sweden), using a method developed by Lavant et al [184] with the addition of a DRB $1 * 04$ restriction endonuclease [185] and a specific primer for DQB $1 * 0602$. Sequence specific primers were used to identify polymorphic regions of DQB1, DQA1 and DRB1. Presence of the following alleles was assessed: DQA1: *01, *02, *03, *04, *05, *06, DQB1: *02, *03 (subtypes $* 0301 / * 0302 / * 0303 / * 0304), * 04, * 05, * 06$ (subtypes *0601/*0602/*0603), and DRB1: *03, *04 (subtypes *0403/*0407), *07, *09.

In paper II, the haplotypes were categorized into susceptibility associated $(\mathrm{S})$, neutral $(\mathrm{N})$ and protective $(\mathrm{P})$, based on the haplotype classification used in a previous study on ABIS children [186]. Haplotypes associated to susceptibility were DR4-DQ8 (DRB1*0401/2/4/5DQB1*0302) and DR3-DQ2 (DQA1*05-DQB1*02), while protective haplotypes included DR2-DQ6 (DQB1*0602), DR11/12/1303-DQ7 (DQA1*05-DQB1*0301), DR7DQ3(DQA1*0201-DQB1*0303), DR14-DQ5(DQB1*0503), DR403-DQ8 (DRB1*0403DQB1* 0302) and DR1301-DQ6 (DQB1*0603). Haplotypes not falling into any of these categories were regarded as neutral. Genotypes associated to susceptibility were those with two susceptibility-associated haplotypes, or with one associated to susceptibility and one neutral.

In paper I and III, we instead classified the full HLA-genotypes into the risk categories low, moderate and high. The lower number of different risk-categories by this classification enabled statistical analysis despite the limited number of participants. High risk was defined as heterozygosity for DRB1*04:01/2/4/5/8-DQA1*03-DQB1*03:02/4 and DRB1*03DQA1*05-DQB1*02, moderate as homozygosity for any of the above risk haplotypes or 
DRB1*04:01/2/4/5/8-DQA1*03-DQB1*03:02/4 with a neutral haplotype, or the genotype DRB1*03-DQA1*05-DQB1*02/DRB1*09-DQA1*03-DQB1*03. Genotypes outside any of these two categories were regarded as low risk genotypes. The HLA risk-classification was based on [187] and [188].

\section{Real-time quantitative RT-PCR for analysis of mRNA and miRNA levels}

\section{Sample preparation and purification of RNA (paper II and III)}

In paper II, gene expression was analysed in PBMC. Blood was drawn into 9ml sodiumheparin tubes (Vacuette, Greiner Bio-One) and PBMCs were then isolated by Ficol Paque density gradient centrifugation or in 50ml Leucosep ${ }^{\circledR}$ tubes (Greiner Bio-One). Separated PBMCs were washed three times in RPMI 1640 medium (Gibcoß) and re-suspended in cool freezing media (10\% dimethyl sulfoxide, 50\% human AB serum, 40\% RPMI 1640) before they were put in a Mr. Frosty ${ }^{\mathrm{TM}}$ in $-70^{\circ} \mathrm{C}$ to achieve a cooling rate of one degree per minute down to $-70^{\circ} \mathrm{C}$. After the freezing procedure, the cells were stored in liquid nitrogen.

Just before RNA purification, PBMCs were quickly thawed in a $37^{\circ} \mathrm{C}$ water bath, washed once in RPMI 1640 and twice in sterile PBS. The cells were then immediately lysed (buffer RLT, Qiagen), homogenized (QIAshredder columns, Qiagen) and further processed with Qiagens RNeasy Mini Kit RNA. RNase-Free DNase Set (Qiagen) was used to eliminate contaminating DNA rests. To assess the quantity and purity of the purified RNA, we used a NanoDrop® ND-1000 spectrophotometer (NanoDrop Technologies), and RNA integrity was examined using the Agilent 6000 chip on an Agilent 2100 bioanalyzer (both from Agilent Technologies).

In paper III, miRNA expression was analyzed in serum samples. Serum was collected in Z Serum Clot Activator tubes (Vacuette, Greiner Bio-One), divided into smaller aliquots and stored frozen until use. Serum was in kept in $-70^{\circ} \mathrm{C}$, except for the serum obtained from newly diagnosed T1D patients. Serum samples are routinely collected from all newly diagnosed diabetic patients at the paediatric clinic in Linköping, and these samples are all stored at $-20^{\circ} \mathrm{C}$. RNA was extracted from serum samples using miRCURYTM RNA Isolation Kit for Biofluids (Exiqon). Due to the low abundance of miRNA in serum, carrier RNA (MS2 bacteriophage RNA, Roche) was added to avoid loss of small RNAs during the purification procedure. A protein precipitation- and DNAse digestion step was also included. Before extraction, the serum samples were thawed at room temperature and centrifuged for 5 $\min$ at $3000 \mathrm{xg}$, and only the uppermost part was used to avoid inclusion of cell debris. 
Since the concentration of miRNA in serum is low, and because carrier RNA was present, it was not possible to assess the quality and integrity of the extracted RNA samples by the commonly used NanoDrop ${ }^{\circledR}$ spectrophotometer and Agilent bioanalyzer. PCR-based QC panels were used instead (miRCURY TM microRNA QC PCR Panel, Exiqon), before proceeding to the miRNA profiling. The QC panel evaluates the major steps of the sample processing: RNA purification, cDNA synthesis and qPCR. It also evaluates whether biologically relevant miRNAs can be detected in the samples and whether there are signs of haemolysis, which might affect the results.

\section{Relative quantification of gene expression in PBMC (paper II)}

The method of choice for quantification of RNA is quantitative real-time RT-PCR (qPCR). The purified RNA is reverse transcribed into complementary DNA (cDNA), and sequencespecific primers together with polymerase are then used to amplify the targets of interest. The amount of amplicon is monitored in each amplification cycle, through detection of fluorescence emitted either by non-specific fluorochromes that and bind to any doublestranded DNA, like SYBR-green (Figure 9), or by specific hybridization probes like TaqMan probes. Regardless of the source of fluorescence, the emission intensity is proportional to the amount of amplicon present, and therefore inversely proportional to the input amount of cDNA.

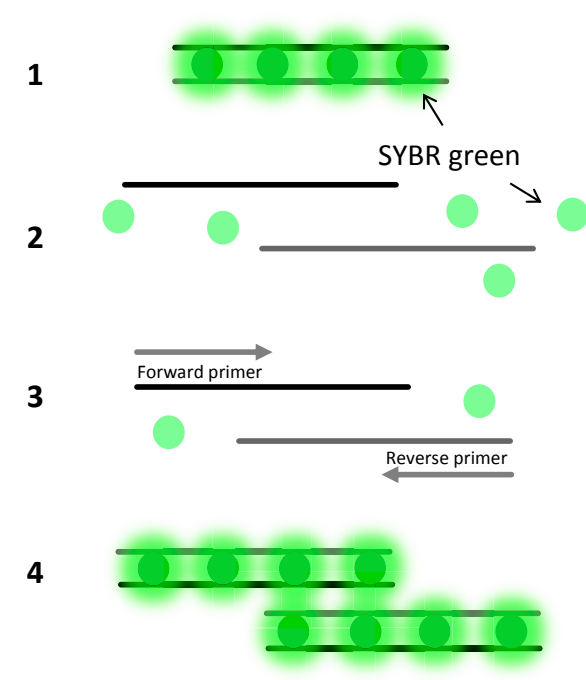

Figure 9. Schematic illustration of qPCR with SYBR-green chemistry. SYBR-green is an intercalating dye that preferentially binds to double-stranded DNA and emits green light once bound. A doubling in fluorescence intensity is proportional to a doubling in the amount of amplicon. 
In paper II, qPCR was used to assess the relative expression of genes related to immune cell function and different arms of the immune system in PBMC samples. The panels, Human Th1-Th2-Th3 PCR Arrays from SABiosciences, contained pre-dispensed primers designed to amplify 88 different targets sequences related to Th1, Th2 and Th3. The original gene setup of the panels was modified to also include FOXP3, STAT5, RORC and IL-1 $\beta$, to get a better impression of regulatory and pro-inflammatory signals. Reverse transcription of $0.5 \mu \mathrm{g}$ thawed RNA in RNase-free water was performed using the RT ${ }^{2}$ First Strand Kit (SABiosciences) and the GeneAmp® PCR System 2700 (Applied Biosystems). RT ${ }^{2}$ SYBR® Green/ROX ${ }^{\mathrm{TM}}$ qPCR Master Mix (SABiosciences) was added to the cDNA and the reaction mix was dispensed in $25 \mu \mathrm{l}$ aliquots into array wells. The 7900HT Fast Real-Time PCR System (Applied Biosystems) was used for sequence detection, and threshold cycle (Ct) values were obtained from sequence detection systems (SDS) version 2.3 (Applied Biosystems). Baseline adjustment was performed automatically and a common threshold was used for all plates in the study. Transcripts were considered detectable at $\mathrm{Ct}<35$, and only genes for which the majority of samples had detectable levels were included in subsequent data processing.

The arrays included a reverse transcription control, a positive PCR control, a genomic DNA control and five housekeeping genes: B2M, HPRT1, RPL13A, GAPDH and ACTB. Raw Ct values were normalized to HPRT1 and B2M, found by NormFinder [189] (in GenEx software) to be the most stable housekeeping genes among the five. The normalized expression of each gene was relatively quantified to the sample with the lowest expression (i.e., the sample with the lowest expression was set to 1), and $\log 2$ was applied. Data were mean centred for principal component analysis and for visualization in box plots. The mean centering removes the dependence of the average expression of the genes, but retains the magnitude of the fluctuations.

\section{Relative quantification of circulating miRNA levels (paper III)}

There are a number of different methods that can be used to study the abundance of circulating miRNAs. The most thorough way is to sequence every miRNA present in a sample, giving a genome-wide miRNA (miRnome) signature at single-base resolution. This provides an opportunity to identify novel miRNAs or specific sequence variants that may be associated to the disease of interest. The method is however very expensive and the vast amount of generated data makes result interpretation complex. A less expensive method is microarray, which is more suitable for large-scale experiments. All currently identified 
miRNAs can then be analysed in one single chip, but the sensitivity is limited and this can become a problem with low-abundant miRNAs. Considering the pros and cons of these methods, real-time quantitative RT-PCR (qPCR) is a good trade-off. It has high sensitivity and accuracy, and a relatively large number of miRNAs can be analysed in each sample to a reasonable cost.

In paper III, qPCR was used to assess the relative quantities of circulating miRNA in serum. The Serum/Plasma Focus Panels from Exiqon (miRCURY LNA ${ }^{\mathrm{TM}}$ Universal RT microRNA PCR) contain 179 different LNA ${ }^{\mathrm{TM}}$ microRNA primer sets with special focus on human miRNAs relevant in serum/plasma samples. Using this approach, there is indeed a risk to miss identification of novel disease-related miRNAs that are not commonly found in serum, but a whole-miRNome approach was not possible. The panels use Locked nucleic acid (LNA ${ }^{\mathrm{TM}}$ ) technology to overcome an inherent problem of multiplex miRNA analysis; the greatly varying melting temperatures due to the small size and the varying GC-content (Figure 10). They are high-affinity RNA analogues with a "locked" ribose ring conferring

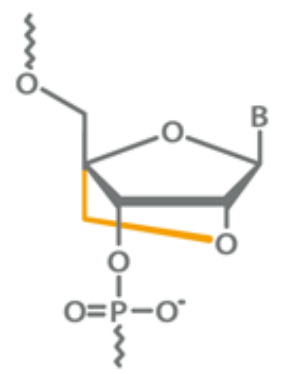

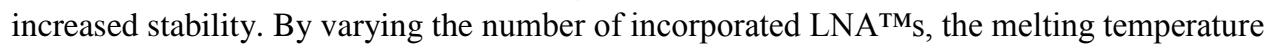
of the duplex can be adjusted, facilitating multiplex assays.

Figure 10. Primers with Locked nucleic acid (LNA $\left.{ }^{\mathrm{TM}}\right)$ technology to allow multiplex quantification of miRNA expression. The figure shows the "locked" ribose ring. Figure from [190]

The panels further include candidate reference microRNAs and spike-in control primer sets that are used together with the RNA Spike-in kit to monitor the technical quality of RNA isolation, cDNA synthesis and presence of PCR inhibitors in each sample. To obtain cDNA, RNA was reverse transcribed using Universal cDNA Synthesis Kit (Exiqon). Again, because of the low concentration of miRNA in serum and the presence or carrier RNA, it was not possible to quantify the purified RNA and base each reaction on a pre-specified amount of input RNA. Instead, a fixed volume of serum was used for each sample (200 $\mu 1)$, and cDNA was produced from the entire volume of eluted RNA. Each serum sample was analysed in 
duplicate on two separate plates, using cDNA from two different RT-reactions. Samples were dispensed into the 384-well plates manually, using a single channel electronic pipette. The 7900HT Fast Real-Time PCR System from Applied Biosystems was used for sequence detection, and threshold cycle $(\mathrm{Ct})$ values were obtained using sequence detection systems (SDS) version 2.3 (Applied Biosystems). Cycling conditions were set as specified by Exiqon, including a dissociation step to allow identification of non-specific reactions. Automatic baseline adjustment was used, and a common threshold was set for all reactions in the study. To establish individual detection cut-off values for each miRNA, cDNA-samples from a mock-RNA purification on a clean water sample was run in duplicate for all primer sets.

Before proceeding to data pre-processing and statistical analysis, genes for which $<60 \%$ of the samples had detectable levels were excluded. Dissociation curves were inspected for each reaction, and wells showing signs of non-specific reactions or primer-dimer formation were also excluded. Raw Ct values were normalized to the global mean, and the normalized expression of each miRNA was converted to relative quantities on the linear scale by assigning the normalized Ct-values as $\mathrm{N}$, according to: $\mathrm{N}=2^{(\mathrm{Ctrel-} \mathrm{Ct})}$, where Ctrel was $0 . \log 2$ was then applied. Data were mean centred for principal component analysis.

\section{Assessment of physical activity (paper IV)}

Reliable measurement of physical activity is difficult. Subjective measurement (self-report or parent proxy-report) of physical activity/sedentary behavior is commonly used because it is simple and cost effective, but such methods often suffer from poor validity and reliability, and high variability due to subject bias and difficulties in accurate recalling [191, 192]. In our study, parents and children answered questions regarding physical activity/sedentary behavior as a complement to objective measurement of physical activity.

\section{Objective assessment of physical activity using pedometers}

The average number of daily steps was record using pedometers (Yamax SW-200, Tokyo, Japan). The devices were worn during four consecutive weekdays and an assurance survey was used to control for wear time, which is a standard procedure in pedometry. The participants were instructed to wear them during the entire day until bedtime, and to put them on again in the morning, immediately after getting dressed. In the first assessment of physical activity, at age 8 , step data was collected and the pedometer reset with a 24 hour interval. The children were then also asked to complete a brief survey to verify that the pedometers had been worn according to instructions. At age 12, the sealed pedometers were instead worn for 
four consecutive weekdays without daily data recording, and the pedometers were collected and read on the morning of the fifth day. The total number of steps was then divided by the number of days the pedometer was worn. At the day of data collection, each child was interviewed according to the questions in the survey, asking whether the child had forgot to wear the pedometer at any occasion or had been ill during the period.

\section{Subjective assessment of physical activity/sedentary behavior}

In addition to the objective assessment of daily steps, questionnaire data was evaluated as a subjective estimate of physical activity/sedentary behavior. In the questionnaires filled in by parents at 8 years, there were 4 items relating to the child's daily level of physical activity, regarding hours spent in front of TV/video/DVD/computer and hours spent in physical activity or in more sedentary activities such as reading. There was also a question about the time spent in a car weekly. The answers were of multiple choice-type, with different timeintervals to choose from. Each question required a separate answer for weekdays and weekends. In the questionnaire at age 12, parents were again asked to estimate their child's time spent in physical activity on weekdays and weekends, and weekly hours spent in a car. The questions concerning hours spent in front of TV/Video/DVD/computer and hours spent with more sedentary activities were instead asked to the children, still divided into separate answers for weekdays and weekends.

\section{Statistics}

In papers I-IV, statistical analyses were performed in IBM SPSS Statistics for Windows, and graphs were prepared with GraphPad Prism 5 for Windows. In papers II-III, GenEx Enterprise (MultiD Analyses $\mathrm{AB}$ ) was used for was used for pre-processing of raw data and additional statistical analysis of miRNA and mRNA expression data.

In paper I, non-parametric tests were applied for group comparisons and analyses over time, due to the lack of Gaussian distribution in the majority of the variables and presence of outliers in otherwise normally distributed data. Because of the low number of participants with complete data sets over the entire follow-up period, Kruskal-Wallis test was performed instead of paired analyses when assessing changes over time. P-values $<0.05$ were considered statistically significant.

In paper II, data normality was assessed by Shapiro-Wilk's test and visual inspection of plotted data. Normally distributed data were analyzed by parametric tests, while non- 
parametric tests were used for data that substantially deviated from Gaussian distribution. False discovery rate (FDR)-corrected p-value (q-value) was used to compensate for multiple comparisons when determining statistical significance of differences in gene expression between groups, with differences considered significant at $\mathrm{q}<0.1$. Differences were also considered significant at Bonferroni corrected p-value keeping the type 1 error below 0.05 .

In paper III, we instead used non-parametric tests for all analyses, when parts of the data set deviated from Gaussian distribution as assessed by Shapiro-Wilk's test. When comparing groups, q-values were used to adjust for multiple comparisons. Differences were considered statistically significant at q-value $<0.05$.

In paper IV, normality of data distributions was assessed for all objectively measured variables, by D'Agostino \& Pearson omnibus normality test and visual inspection of plotted data. Since some variables deviated from Gaussian distribution, non-parametric tests were performed for analyses performed separately in boys and girls because of smaller group sizes. Correlation analyses performed on the entire group were performed with parametric tests. Pvalues $<0.05$ were considered statistically significant. Questionnaire data was processed by non-parametric tests because of its ordinal nature. The threshold of significance was lowered to $\mathrm{p}<0.01$ to compensate for multiple comparisons when correlating questionnaire data with objectively measured variables. No such compensation was made for comparisons of only objectively measured data, since the measurements were repeated in the same individuals on two different time points. Linear regression analyses were performed with Fasting C-peptide (nmol/l) and BMI Z-score as dependent variables at age 8 and 12.

\section{PCA}

In paper II and III, unsupervised principal component analysis (PCA) was performed to visualize the difference in expression patterns between groups. This is a method commonly used to reduce data dimensionality in large datasets, and it is incorporated in the GenEx Enterprise software. In PCA, the parameters that give rise to the largest variations in the data set are identified and used to create new composite variables, called principal components (as reviewed in ref [193]). Each sample/gene can then be plotted in a multidimensional space, based on the principal components, helping to visualize the underlying data structures. 


\section{Ethics}

All the work described has been performed in accordance with the Declaration of Helsinki. The Research Ethics Committee of the Faculty of Health Science at Linköping University gave ethical approval for the study of T1D patients (Dnr 02-483), for the entire ABIS study (Dnr 36287 and Dnr 03-092) and for the study of high-risk individuals within ABIS (Dnr M13-09 and Dnr M52-05). For the high-risk follow-up, the responsible guardians were thoroughly informed and asked to consent before participation. They were also encouraged to discuss the information and invitation with their children prior to signing the consent form as the children had reached an age where it was appropriate to involve them. The families were informed that participation was entirely voluntary and that they could opt out at any given time. 


\section{RESULTS AND DISCUSSION}

\section{Prospective follow-up of high-risk individuals}

Following islet autoantibody screening among children from the ABIS study, 21 children repeatedly testing positive for multiple autoantibodies were followed prospectively for two years. Three of them developed clinical disease during the follow-up period, and another nine some time after the end of the study period (all referred to as progressors). The remaining nine had still not been diagnosed with symptomatic T1D when this thesis was written (referred to as non-progressors). Based on data from previous risk cohorts, it is highly likely that these asymptomatic individuals eventually will progress to overt T1D, given that the lifetime risk of developing T1D approaches $100 \%$ when two or more islet autoantibodies are present [145].

Glucose homeostasis and autoantibody dynamics were characterized longitudinally in samples obtained throughout the study (paper I). Baseline samples (PBMC and serum) have been used to assess the PBMC expression of genes related to the Th1, Th2 and Th3 arms of the immune system (paper II) and to explore serum miRNA profiles (paper III).

The autoantibody status of these individuals before inclusion into the high-risk follow-up study was difficult to assess in detail, due to incomplete sample series and testing only for GADA and IA2A during the first years (Figure 11). From the available data, none of the high-risk individuals were positive for multiple autoantibodies at age 1 and 2.5, despite the fact that the peak seroconversion age is around two years [113-115]. However, it is now well known that IAA is usually the first autoantibody to appear in young children [116], and it is therefore likely that some of these individuals would have tested positive for multiple autoantibodies already at this young age, had IAA been in the test panel at the earlier visits of ABIS. Analysis of IAA could not be performed ad hoc due to unavailability of appropriate samples. 


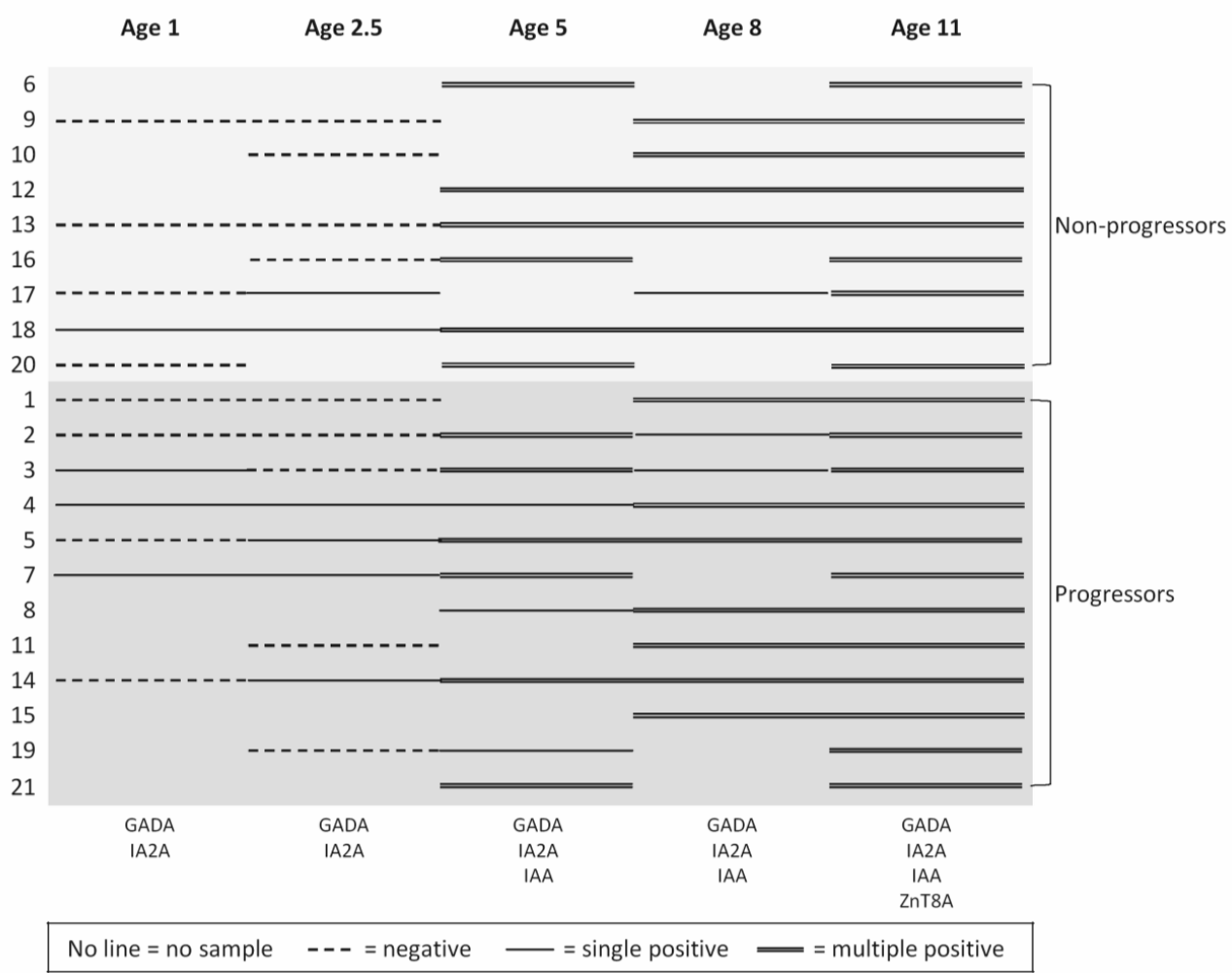

Figure 11. Autoantibody status of high-risk individuals $(n=21)$ before inclusion in the follow-up study, at the ABIS controls performed at age 1, 2.5, 5, 8 and 11. The group is divided into those who developed T1D (progressors, $n=12$, bottom segment) and those who did not (non-progressors, $n=9$, top segment). It is stated below the figure which autoantibodies were tested at each age. The subjects are labeled 1-21, in agreement with the order in Supplementary Table 1 in paper I.

\section{Baseline characteristics at inclusion to the prospective High risk follow-up study}

The baseline characteristics at the time of inclusion into the follow-up (Table 4) show that a history of T1D in the immediate family was seen in three individuals, all of them progressors. The prevalence of FDR's could not be compared statistically between the groups due to low numbers, but finding them only among progressors goes in line with unpublished observations from the TEDDY study, indicating increased risk for early onset of disease in risk-children with FDR's compared to risk-children from the general population [127].

Determination of HLA-genotype showed that few individuals were classified as having high risk, while the vast majority had a moderate or low risk (Table 4). The relatively high presence of low-risk HLA in this cohort highlights the fact that many individuals at risk are excluded in screening programs that use HLA-typing as the first screening step. It should 
however be noted that HLA-risk of higher magnitude is associated to lower age at disease onset [145], and our cohort only included children who were still healthy at an age around 11 years. The cohort could therefore be skewed towards inclusion of persons with HLAgenotypes conferring lower risk. On the other hand, the risk of developing T1D despite lowrisk HLA-genotype is reportedly increasing [42], as discussed before.

\section{Dysglycaemia was not predictive of progression in this high-risk cohort}

Already at inclusion into the follow-up, several individuals showed signs of dysglycaemia, with impaired fasting glucose or impaired glucose tolerance in OGTT (Table 4). Based on previous results regarding the predictive value of stimulated glucose for progression of disease) [116], we expected to find dysglycaemia more often in progressors. This was however not the case in this specific group; impaired glucose tolerance or impaired fasting glucose was seen to the same extent regardless of progression (Table 4). In progressors, dysglycaemia was seen 9 to 36 months before disease onset.

Table 4. Baseline group characteristics of all the high-risk children included in the prospective follow-up, and in progressors and non-progressors separately.

\begin{tabular}{lccc}
\hline & All subjects & Progressors & Non-progressors \\
& $n=21$ & $n=12$ & $n=9$ \\
\hline Gender: male $n$ (\%) & $14(67)$ & $8(67)$ & $6(67)$ \\
Age, median years (range) & $10.8(9.7-11.8)$ & $11(10.1-11.8)$ & $10.7(9.7-11.6)$ \\
First degree relative $n$ (\%) & $4(19)$ & $3(25)$ & $1(11)$ \\
HLA-DQ risk (\%) & & & \\
High & $4(19)$ & $2(17)$ & $2(22)$ \\
Moderate & $8(38)$ & $6(50)$ & $2(22)$ \\
Low & $9(43)$ & $4(33)$ & $5(56)$ \\
Autoantibody positivity $n$ (\%) & & & $9(100)$ \\
GADA & $19(90)$ & $10(83)$ & $4(44)$ \\
IA2A & $13(62)$ & $9(75)$ & $7(78)$ \\
IAA & $15(71)$ & $8(67)$ & $3(33)$ \\
ZnT8WA (Trp) & $9(43)$ & $6(50)$ & $5(56)$ \\
ZnT8RA (Arg) & $13(62)$ & $8(67)$ & $2(22)$ \\
ZnT8QA (Glt) & $7(33)$ & $5(42)$ & $4(44)$ \\
Signs of dysglycaemia* $n$ (\%) & $9(43)$ & $5(42)$ & \\
\hline
\end{tabular}

* Impaired fasting glucose or impaired glucose tolerance in OGTT 


\section{Increased insulin resistance preceded clinical disease in the progressors}

Even though we did not detect significant deviations during OGTT in progressors, we did note increasing fasting blood glucose and especially HbA1c (Figure 12) as they approached clinical disease. These difficulties to maintain blood glucose levels were seen in parallel to a progressive rise in fasting C-peptide in the progressors (Figure 12). This raised a suspicion of elevated insulin resistance in these subjects.

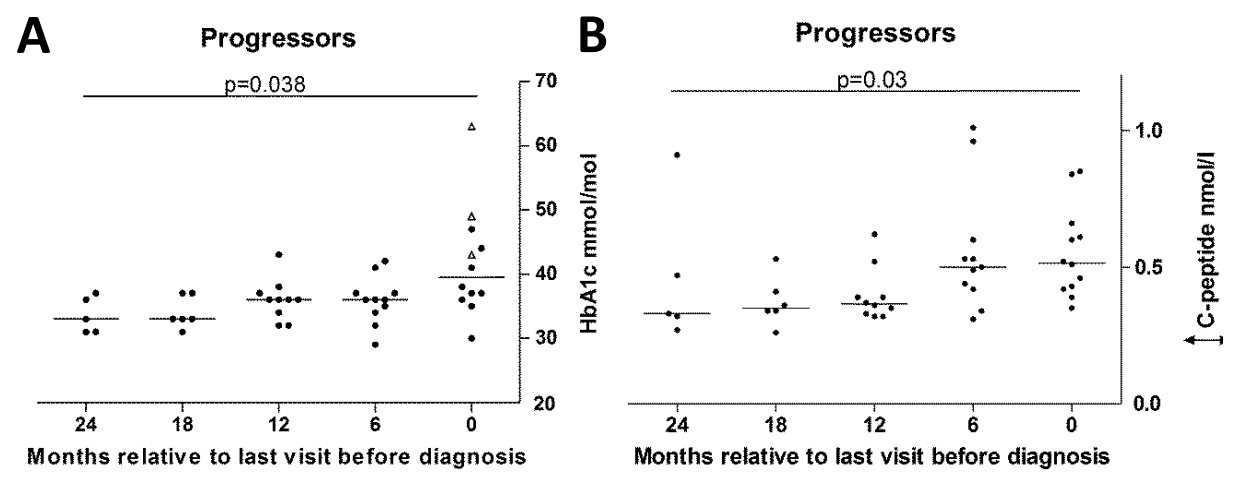

Figure 12. HbA1c (A) and C-peptide (B) in high-risk individuals who developed T1D (progressors $n=12$ ) during the follow-up period. The lines represent median values and $\mathrm{p}$-values $<0.05$ are considered statistically significant.

There is evidence of an association between insulin resistance and progression to T1D [151, 152], and when calculating the estimated insulin resistance by homeostatic model assessment (HOMA2) we did indeed observe that it increased in progressors during the follow-up (Figure 13). Looking also at the weight gain during the same period, it was apparent that progressors had a larger difference from baseline to 12 months compared to non-progressors (Figure 13), and further analysis showed that C-peptide at 12 months was strongly correlated to the weight gain during the preceding 12 months in the entire group (Spearman rho $=0.619$, $\mathrm{p}=0.006$ ). Although we lack information on Tanner stage to confirm pubertal stages, the increase in body weight likely represents the onset of a puberty-related growth spurt. It is reasonable to believe that the subsequent demand on the beta cells to increase their insulin production may be an important accelerator of immune-mediated beta cell loss in these prediabetic individuals, as suggested by the previously discussed accelerator hypothesis [70] and the beta cell stress hypothesis [194]. Excessive endoplasmatic reticulum stress caused by increased secretory load in beta cells may increase abnormal post-translational modification 
of beta cells proteins [43]. These could, in turn, act as neo-autoantigens and exacerbate the ongoing autoimmune reaction.
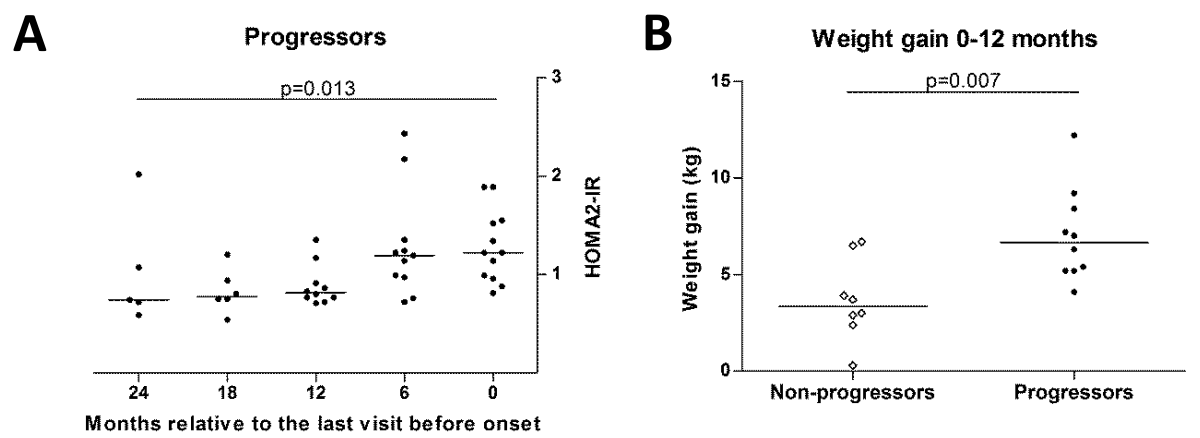

Figure 13. Insulin resistance (HOMA2-IR, A) in high-risk individuals who developed T1D (progressors n=12) during the follow-up period, and weight gain $(\mathbf{B})$ in progressors and non-progressors. The lines represent median values and $p$-values $<0.05$ are considered statistically significant.

\section{Higher titers of IA2A and ZnT8A were found in the progressors}

Analysing autoantibodies during the follow-up revealed two interesting findings. First, we observed that progressors had higher titers of IA2A and ZnT8A compared to non-progressors (Figure 14). This came as no surprise since it has been shown that IA2A is an indicator of higher risk of progression, both in first-degree relatives [146, 147] and in high-risk individuals from the general population [195]. Our results support the idea that screening for only IA2A and ZnT8A may be a feasible option for identification of high-risk individuals rapidly progressing to T1D [147]. Secondly, we found that the titers of IA2A and ZnT8A correlated to each other, and furthermore that IA2A was negatively associated to GADA. A high overlap between IA2A and ZnT8A has been seen before [196], and the inverse relation between IA2A and GADA could be explained by the fact that different HLA-genotypes are related to different autoantibody profiles. In line with the observed inverse relationship between them, it has been shown that GADA is associated with HLA-DQ2 and IAA with HLA-DQ8, while IA-2A is negatively associated with HLA-DQ2 but positively with HLADQ8 [197]. 
A

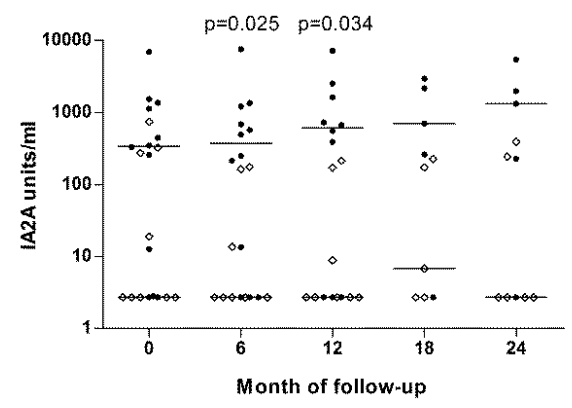

- Non+progressors

- Progressors

B

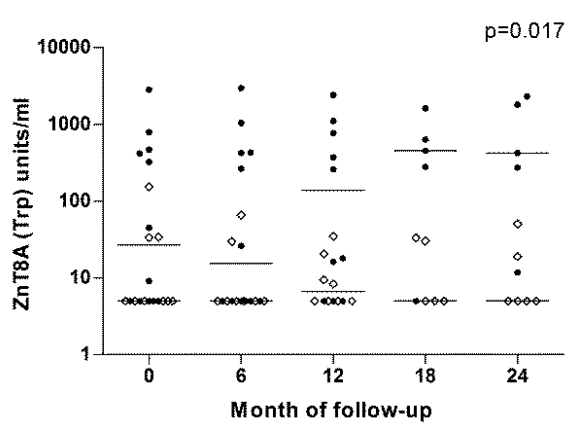

C

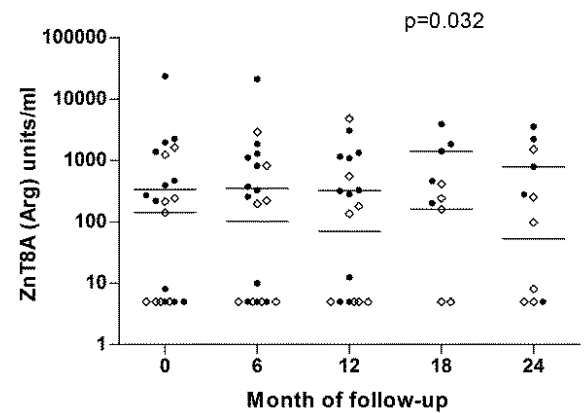

Figure 14. Ttiters of IA2A and ZnT8A in high-risk individuals who developed T1D (progressors $n=12$ ) or not (non-progressors, n=9) during the follow-up period. A) IA2A, B) ZnT8A(Trp), C) ZnT8A(Arg). The lines represent median values and p-values $<0.05$ are considered statistically significant.

To conclude, the prospective follow-up of the high-risk individuals suggests that IA2-and ZnT8 autoantibodies seem to be valuable discriminators for T1D progression in autoantibody-positive children from the general Swedish population. Disturbed glucose metabolism was observed long before diagnosis in those who developed clinical disease, but it was also seen in non-progressors. The difficulty to maintain glucose homeostasis despite the increased insulin secretion observed in the progressors suggests that insulin resistance may be an important accelerator of disease. 


\section{Ethical aspects of enrolling high-risk subjects in prospective follow-ups}

It has been shown in previous prospective risk cohort studies that being part of an organized follow-up where disease onset can be detected at an early stage is related to better metabolic control and better health at disease onset $[198,199]$. Despite this, it is not clear whether the potential advantages of participation outweighs the psychological burden of being aware of the increased risk of a serious, chronic disease. For this reason, it was important for us to study the ethical and psychological aspects of participation in this high-risk follow-up.

An ethical/psychological follow-up of the individuals included in our study was performed, assessing the levels of anxiety in parents and children upon first receiving information about the increased risk, and later on during the follow-up. Preliminary results indicate slightly elevated anxiety scores in the mothers initially, but the levels decreased as the study progressed (manuscript under preparation). Anxiety scores were not elevated in the children. A majority of the parents reported that they were doing things to try and prevent disease development in the child, and this behavior in the parents was confirmed by many of the children. An important consideration in any high-risk cohort is that risk awareness can cause this type of preventive behavior that in fact might affect the study results. As many as $67 \%$ of mothers to children at increased risk report prevention behavior [200]. Most often this refers to monitoring of symptoms, but in many cases it also refers to changes in dietary habits and the level of physical exercise, especially when the mothers have a family history of T1D. 


\section{Expression of immune-related genes in PBMC}

Given the results from several studies showing immunological deviations in peripheral blood of T1D patients, including Th1/Th2 imbalance [201], circulating autoreactive CD8+ and CD4+ T cells with islet antigen specificity [202], and functional impairment of T cell regulation [203, 204], we sought to elucidate immunological deviations preceding disease onset using a transcriptomic approach. We decided to analyze the expression of a broad array of genes related to immune cell function and different arms of the immune system (Th1-2-3). The assessment was performed in PBMCs from the participants in the prospective follow-up of high-risk individuals, and included were also age-matched recent-onset T1D patients and healthy controls from the ABIS cohort (Table 2).

\section{High degree of similarity in expression levels between high-risk children, T1D subjects and healthy controls, with a few exceptions}

The analysis revealed that the high-risk individuals and the healthy controls overall had very similar expression of the immune-related genes included in the array. There were however two exceptions, TNF and PTPRC (encoding protein tyrosine phosphatase CD45, essential for antigen receptor signaling), which were clearly lower in the high-risk group (Figure 15). They both have dual roles in the immune system, with TNF showing primarily pro- but also anti-inflammatory effects [205], and with CD45 regulating immune function positively and negatively through control of the $\mathrm{T}$ cell receptor signaling threshold, regulation of cytokine responses and regulation of lymphocyte survival [206]. Less TNF mRNA has been shown in whole blood from autoantibody-positive relatives of T1D patients compared to healthy controls, with near-normal expression in new-onset T1D [207]. Decreased expression of CD45 on peripheral lymphocytes been observed in patients with systemic lupus erythematosus [208], and point mutations in CD45 have been implicated in other autoimmune diseases, but not in T1D [209, 210]. The conflicting roles seen for TNF and CD45 make it difficult to evaluate the significance of reduced levels in high-risk individuals. However, altered expression of these two genes with important roles in immune function could be a reflection of impaired regulation of immune responses during the pre-diabetic period, resulting in sustained inflammation and autoimmunity. Once diabetes becomes overt, the autoimmune and inflammatory responses to beta cell tissue may subside due to the presumably smaller amount of remaining beta cells, maybe in combination with the intensive insulin treatment. This may explain why the T1D group had normal expression one month after disease onset. 
A

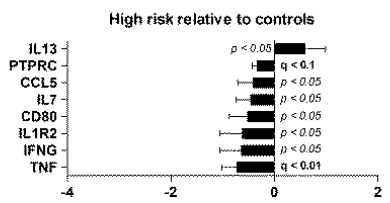

T1D relative to controls

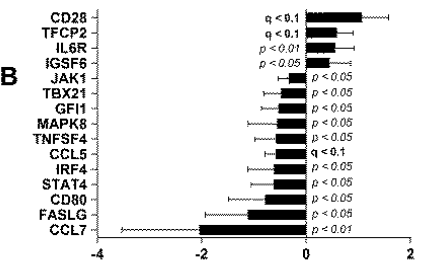

Tho relative to high risk

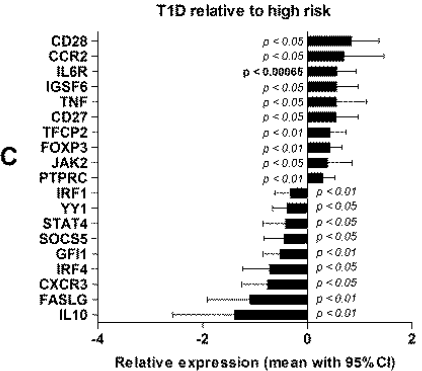

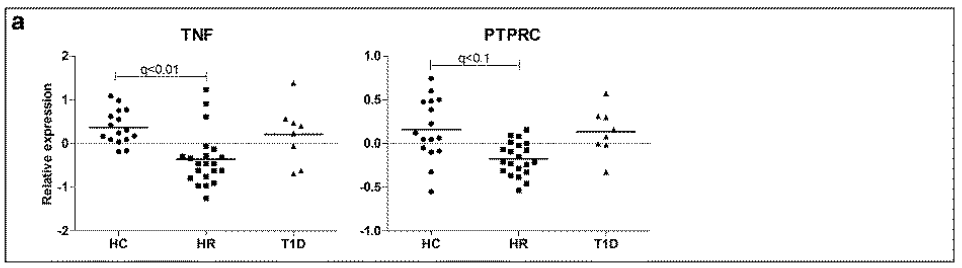
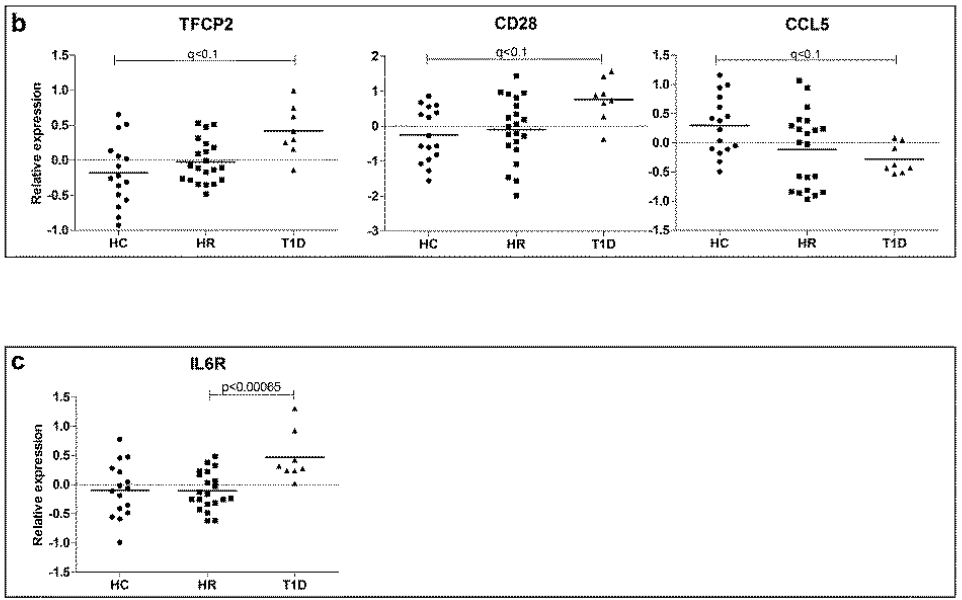

Figure 15. Relative gene expression in resting mononuclear cells from peripheral blood, comparing A) children with high risk of type 1 diabetes $(\mathrm{HR}, \mathrm{n}=21)$ and healthy controls $(\mathrm{HC}, \mathrm{n}=16$, mean expression of controls set to $0)$, B) children with type 1 diabetes (T1D, $n=8)$ and $\mathrm{HC}(\mathrm{n}=16$, mean expression of controls set to 0$)$ and C) T1D ( $n=8)$ and HR ( $=21$, mean expression of high risk children set to 0$)$. Genes with uncorrected $p<0.05$ are included in the figures, but difference in gene expression between groups was considered significant (marked in bold) only at FDR-corrected $\mathrm{p}$ value (q value) $<0.1$, or at $\mathrm{p}<0.00065$ (Bonferroni correction keeping the type 1 error below 0.05). A1-C1) Individual plots for the relative expression of genes with significantly different expression between any two groups. Differences in gene expression are considered significant at $\mathrm{q}<0.1$, or at $\mathrm{p}<0.00065$. Values are centered round the global mean (set to 0 ), marked by a dotted line, and mean expression level in each group is indicated by a full line.

The expression profile in the T1D group was also rather similar to healthy controls, although with increased expression of TFCP2 and CD28, and lower expression of CCL5 (Figure 15). Interestingly, the Th1-associated chemokine CCL5 also tended to be decreased in high-risk individuals compared to healthy controls. Studies assessing CCL5 in sera of ICA positive T1D first-degree relatives [211] and recent onset T1D patients [212] compared to healthy controls have not found any differences in CCL5 levels. CCL5 levels were however found to be inversely associated to beta cell function and positively associated to HbAlc in a study by Pfleger et al., and patients going into clinical remission had lower CCL5 [213]. In addition, 
genetic variants of CCL5 have been associated to lower circulating levels of CCL5 and protection from type 1 diabetes [214]. These findings speak of a deleterious role of CCL5, one that we cannot confirm, seeing the highest CCL5 expression in healthy children. It is however interesting that genes expressed differently in diabetic individuals compared to healthy children also deviate to some extent in high risk children compared to controls (as seen for CCL5 and also CD80).

High-risk individuals and T1D patients also showed very similar expression patterns, and only IL6R was significantly different, with higher levels in T1D. The expression of IL6R was seemingly higher in T1D than in healthy controls as well, but without significance after correction for multiple comparisons (Figure 15).

No differences were found in gene expression when subjects from all the three groups were divided based on detection or not of individual autoantibodies.

\section{Decreased C-peptide levels in high risk individuals}

When C-peptide levels were compared between groups, lower levels were seen in high-risk individuals $(0.37 \mathrm{nmol} / \mathrm{l}$, Figure 16$)$ compared to healthy controls $(0.50 \mathrm{nmol} / \mathrm{l})$, but higher than in the T1D group $(0.18 \mathrm{nmol} / \mathrm{l})$. Further analysis showed that children positive for 1-3 autoantibodies (when considering the ZnT8A variants as separate autoantibodies) had lower C-peptide than autoantibody negative children $(0.35 \mathrm{nmol} / 1$ and $0.51 \mathrm{nmol} / \mathrm{l}$, respectively, fig), and that the difference was even more evident in children positive for 4-6 autoantibodies $(0.28 \mathrm{nmol} / \mathrm{l})$.
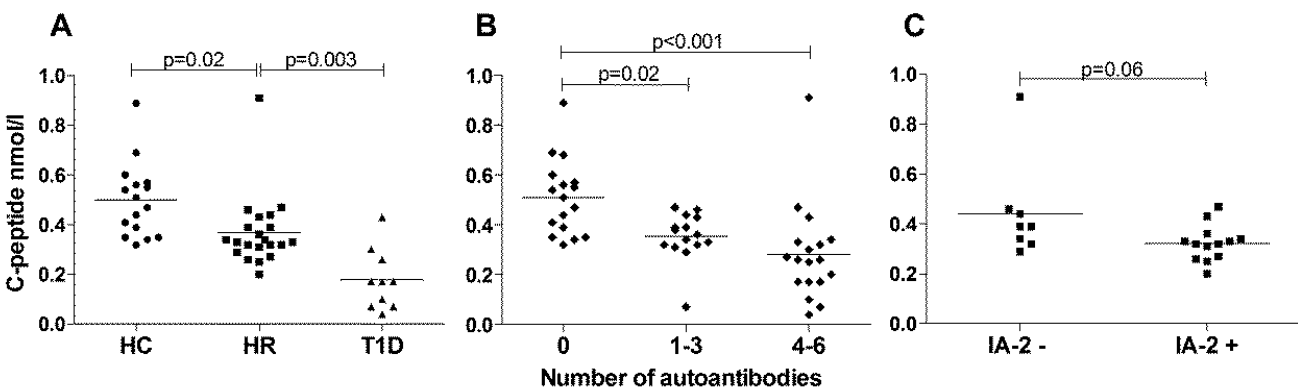

Figure 16. Fasting C-peptide in serum samples from $\mathbf{A}$ ) healthy controls (HC, $n=16)$, children with high risk for type 1 diabetes $(H R, n=21)$ and children with recent onset type 1 diabetes $(T 1 D, n=10)$, B) children grouped by the number of different autoantibodies present in serum $(0, n=17 ; 1-3, n=15 ; 4-6, n=18)$. C-peptide is expressed in $\mathrm{nmol} / \mathrm{l}$ and the horizontal lines represent the group means. Significant differences and trends are indicated by their p-values, calculated by Student's t-test for two groups and ANOVA followed by Bonferroni post-test for three groups. Differences are considered significant at p-values below 0.05, and trends at p-values below 0.1, and $\mathbf{C})$ high risk individuals negative $(n=8)$ or positive $(n=13)$ for IA2A. 
Lower C-peptide in high-risk individuals than in healthy children may support the notion of a gradual decline in metabolic function, starting long before the appearance of symptoms. Decrease levels in comparison to healthy peers has to our knowledge not been shown previously in a high-risk group from the general population, although the question of Cpeptide fluctuations during disease progression has been addressed in other risk-groups, mainly those based on first-degree relatives, who may in fact represent an entirely different stratum of individuals at risk for T1D. For instance, it was shown in the DPT-1 study, including relatives of T1D patients, that fasting C-peptide levels were maintained or even increased in participants during the 30 months preceding disease onset, while stimulated Cpeptide declined gradually during the same period [215]. The low C-peptide found by us high risk individuals highlights the importance of introducing prevention or intervention strategies at an early stage, to ensure that a clinically relevant amount of beta cells remains.

Another finding of importance for future prevention- or intervention trials is a tendency toward lower C-peptide among IA2A-positive high-risk children (Figure 16). Positivity to IA2A has previously been associated to a more aggressive or later stage of the disease process, with lower C-peptide levels and higher insulin demand in patients positive for IA2A [216]. Our results suggest that this association can be seen already during the pre-diabetic phase, and IA2A levels should thus perhaps be taken into consideration when designing novel trials.

\section{Gene expression seems related to C-peptide levels}

The marked difference seen in C-peptide levels between the groups prompted us to look at gene expression in relation to C-peptide. All study subjects (high-risk, healthy controls and T1D, plus the additional 3 children with single or transient autoantibodies) were stratified into two groups based on fasting C-peptide level above (high C-peptide, $n=26$ ) or below (low C-peptide, $\mathrm{n}=22$ ) $0.35 \mathrm{nmol} / \mathrm{l}$. This cut-off was chosen based on available C-peptide measurements $(n=92)$ from the age-matched healthy schoolchildren participating in ABIS pedometer study, of whom $75 \%$ had fasting levels over $0.35 \mathrm{nmol} / 1$. When comparing children with high or low C-peptide, it was found that the group with low C-peptide had increased expression of the transcription factors TFCP2 and JAK2, and decreased expression of JAK1, GFI1, MAF, TMED1, TNFRSF9, MAPK8, STAT4, STAT5A, CD80, CCR4, MAP2K7 and CCL7 (Figure 17). 
It was interesting that differences in gene expression were far more evident when comparing children with regard to C-peptide than when samples were stratified into groups based on autoantibody positivity. The association between gene expression and residual beta cell function could however not be seen when assessed in the three groups separately, probably due to the smaller number of subjects in each group and the relatively small range of $\mathrm{C}$ peptide values within the groups. It is worth noting that the only sign of a gene expression profile skewed toward a Th1- or Th2 type immune response was the decreased expression of several Th2 associated genes like GFI1, MAF, TMED1, STAT5A and CCR4 in the group with low C-peptide.

A Gene expression in children with $C$-peptide $<0.35 \mathrm{nmol} / \mathrm{l}$ - relative to children $w$ ith $C$ peptide $>=0.35 \mathrm{nmol} / \mathrm{l}$

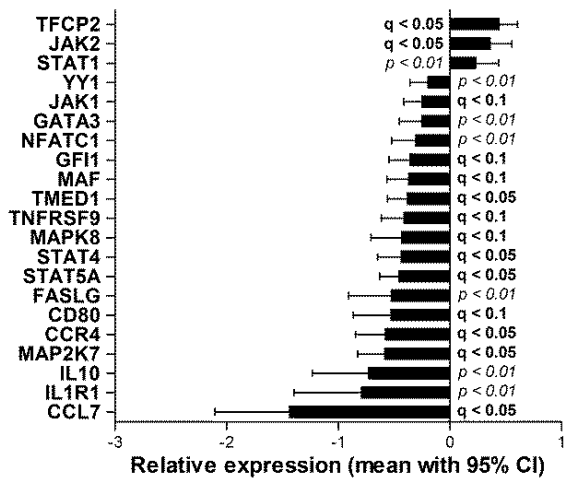

C

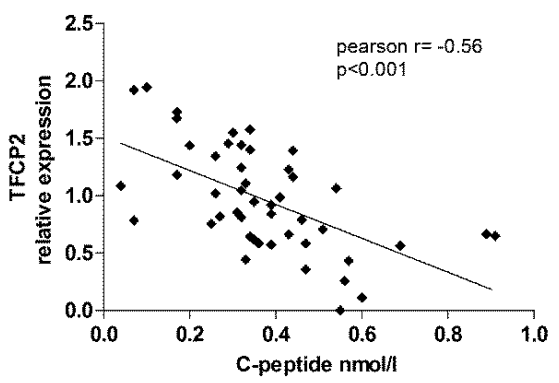

B

\begin{tabular}{lcc}
\multicolumn{3}{r}{$\begin{array}{c}\text { Correation betw een } \\
\text { expression of individual genes }\end{array}$} \\
\hline Gene & $\mathbf{r}$ & $\mathbf{p}$ \\
\hline TFCP2 & -0.56 & $<0.001$ \\
JAK2 & -0.37 & 0.009 \\
CD28 & -0.36 & 0.01 \\
GF1 & 0.36 & 0.01 \\
IL6R & -0.36 & 0.01 \\
CD27 & -0.35 & 0.02 \\
IRF4 & 0.33 & 0.02 \\
IL10 & 0.33 & 0.02 \\
STAT5A & 0.29 & 0.04 \\
\hline
\end{tabular}

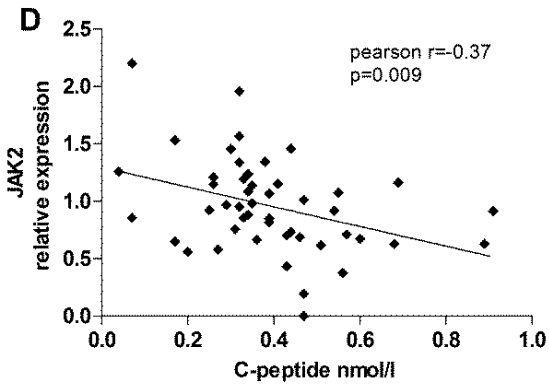

Figure 17. A) Gene expression in peripheral blood mononuclear cells from children with low C-peptide $(<0.35$ $\mathrm{nmol} / \mathrm{l}, \mathrm{n}=22)$, relative to children with high C-peptide $(\geq 0.35 \mathrm{nmol} / \mathrm{l}, \mathrm{n}=26)$. Genes with uncorrected $\mathrm{p}<0.05$ are included in the picture, but difference in gene expression between groups was considered significant (marked in bold) at FDR-corrected $\mathrm{p}$ value (q value) below 0.1, or at $\mathrm{p}<0.00065$ (Bonferroni correction keeping the type 1 error below 0.05). B) Pearson correlation coefficients and p-values of C-peptide and individual genes (number of XY pairs=48, including high risk children, healthy controls, children with recent onset type 1 diabetes and 3 children with single or transient autoantibodies). Pearson correlation between C-peptide level and the expression of C) TFCP2 and D) JAK2. 
When assessing the degree of association between individual genes and C-peptide in all children, TFCP2 and JAK2, together with CD28, IL6R and CD27, were negatively associated to C-peptide level, while GFI1, IRF4, IL10 and STAT5A instead correlated positively (Figure 17). The association was especially evident for TFCP2 and JAK2, both inversely correlated to C-peptide (Figure 17). The TFCP2 gene encodes the Late SV40 transcription factor, ubiquitously expressed and involved in fundamental biological events such as cell cycle progression, cell survival and cell growth, alongside more lineage-specific roles in for example T- and B cells (reviewed in [217]). JAK2 is the second member of the Janus kinase family, part of the JAK/STAT pathway which is a major downstream signaling pathway for cytokine-, chemokine- and growth factor receptors [218]. Other genes associated to C-peptide in our study include JAK1, STAT4 and STAT5A, suggesting that the JAK/STAT pathway, with its role in growth factor signaling, could be associated to low insulin secretion. The two genes that were higher in T1D compared to healthy children, TFCP2 and CD28, were also inversely associated to C-peptide levels. The co-stimulatory molecule CD28 is essential for T cells, both in antigen-specific activation and important biological processes like differentiation and cell cycle progression [219]. CD28 also plays an important role in development and homeostasis of Treg cells [220], and is necessary for Th2 differentiation [221]. It is difficult to speculate upon the significance of the above findings in association to T1D, but it is interesting that there seemed to be a connection between C-peptide levels and expression of genes, some related to growth signaling, while very limited associations were seen between gene expression and markers of ongoing autoimmunity. One concern in transcriptomic studies in T1D is that hyperglycemia per se could have an effect on gene expression, rather than the autoimmune process. This is exemplified in a study showing coexpression of several genes in type 1 and type 2 diabetes, suggesting that hyperglycemia indeed has a role [222], and our results could be interpreted in a similar direction.

\section{Gene expression was not related to the HLA-conferred risk}

As expected, the majority of high risk individuals carried risk-associated haplotypes $(90 \%)$ or genotypes $(71 \%)$, while they were significantly less frequent among healthy controls, showing corresponding numbers of $37.5 \%$ and $31 \%$. The frequency of protective haplotypes/genotypes did not differ between the groups. We found no association between HLA risk and gene expression when comparing all the children divided into groups based on the risk conferred by their haplotype combination $(1=\mathrm{P} / \mathrm{P}$ or $\mathrm{P} / \mathrm{N}, 2=\mathrm{N} / \mathrm{N}, 3=\mathrm{S} / \mathrm{P}, 4=\mathrm{S} / \mathrm{S}$ or $\mathrm{S} / \mathrm{N})$. 


\section{Gene expression provides a moderate separation of high-risk individuals by PCA}

We use PCA in an attempt to classify the individuals according to their gene expression profiles. To improve the possibility to detect multivariate responses, the significance threshold for PCA inclusion was lowered to uncorrected $\mathrm{p}<0.05$. Inclusion of all differentially expressed genes across the groups failed to separate high-risk, healthy and T1D samples into distinct expression clusters. The best separation possible was achieved by including TFCP2, PTPRC, TNF, CCL5 and IL6R (Figure 18). When including only high-risk and healthy subjects, a moderate separation was achieved using genes under the uncorrected 0.05 threshold: PTPRC, TNF, CD80, IL7, IL1R2 and IFNG (Figure 18). Gene expression profiles could not distinguish samples with regard to C-peptide level or positivity to individual autoantibodies.
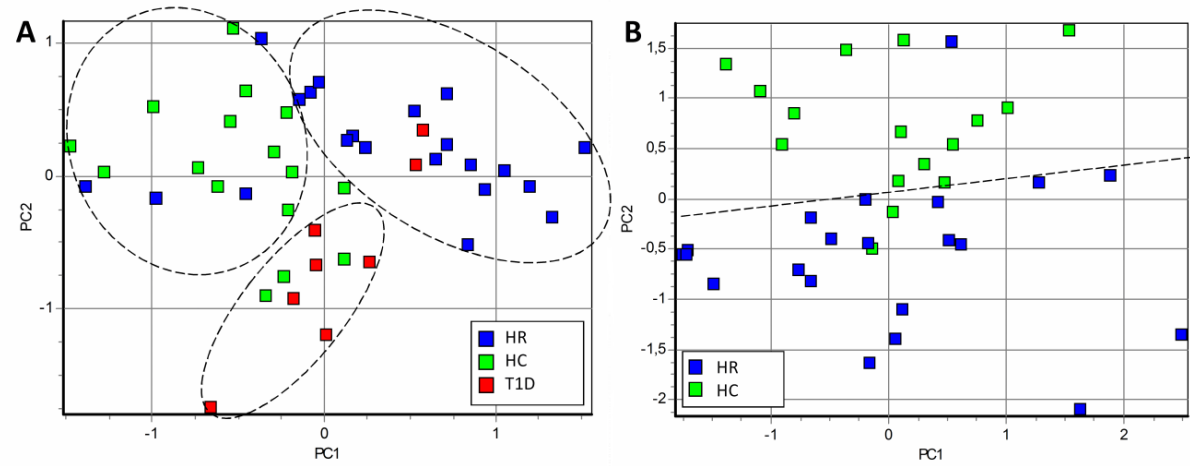

Figure 18. Principal component analysis (PCA) score plots. A) Plot visualizing the best possible separation of samples from children with high risk of type 1 diabetes (HR, blue squares, $n=21)$, healthy controls (HC, green squares, $n=16$ ) and children with recent onset type 1 diabetes (T1D, red squares, $n=8$ ), based on gene expression profiles. Inclusion of all genes differing between the groups with uncorrected $\mathrm{p}<0.05$ provided a poor separation, while CCL5, IL6R, PTPRC, TFCP2 and TNF together achieved the moderate separation seen in the plot. B) PCA score plot of high risk individuals (HR, blue squares, $n=21$ ) and healthy controls (HC, green squares, $\mathrm{n}=16$ ), based on all genes differing between the groups with uncorrected $\mathrm{p}<0.05$ (PTPRC, TNF, CD80, IL7, IL1R2 and IFNG).

A valid concern in transcriptomic studies like the one described here is the possible discrepancy between mRNA levels and corresponding translated protein levels. It would hence be of great value to experimentally confirm our results in this and other risk cohorts, and if possible also to assess the gene expression in different immune cell types. Sample volume is however a limiting factor, which is common in studies performed on pediatric 
cohorts. This transcriptomic approach, in spite of its limitations, however provides the ability to simultaneously study a broad range of markers representing different parts of the immune response in a relatively small sample volume.

In summary, whereas the overall expression of immune-related genes in PBMC of at-risk individuals, patients with new-onset diabetes and healthy controls was quite similar, children with high risk of T1D had deviating expression of TNF and CD45. It remains to be seen whether the expression of these genes can be of any use in disease prediction or risk stratification. The expression of immune related genes seems to be related not only to the autoimmune process but rather to residual beta cell function, which in turn seems to be decreased already during the pre-diabetic phase. 


\section{miRNA expression levels in serum}

Knowing that miRNAs are involved in a long list of physiological and pathological processes, and that there are indications of altered miRNA profiles in T1D patients, we were interested in exploring whether deviations could be detected in serum before diagnosis. Identification of a serum miRNA profile specific for at-risk individuals would be very useful, especially considering the extreme stability of miRNA molecules in cell-free body fluids [223]. We therefore assessed the relative expression of 129 different miRNAs commonly found in serum/plasma, in baseline samples from the high-risk individuals. Samples from healthy age-matched children from ABIS and recent onset T1D patients were included for comparison (Table 2).

\section{Similar serum miRNA profiles in high-risk individuals and healthy controls}

The analysis showed that miRNA expression was very similar in high-risk individuals and healthy controls, without any significant differences after correction for multiple comparisons. This resembles our results regarding expression of immune-related genes in PBMC, showing overall similar expression in individuals at risk and healthy controls, with few exceptions.

\section{miRNAs associated to glucose homeostasis within the high-risk group}

Interestingly, within the high-risk group we observed several highly significant correlations between miRNA expression and measures of glucose homeostasis, especially HbA1c and glucose at $120 \mathrm{~min}$ of OGTT (Figure 19). This is interesting in itself, but also in relation to the associations we previously observed between gene expression in PBMC and C-peptide in the same individuals. In many instances the variation in the measured parameters, be it mRNA in PBMC or miRNA in serum, seem to be influenced by factors related to glucose homeostasis. Among the many miRNAs correlating to HbA1c were miR-140-3p, miR-29a-3p and let-7f-5p. They have all previously been associated to different types of diabetes [224], and members of the let-7 family are known to be involved in regulation of glucose metabolism [225]. Of particular interest was the positive association observed between miR29a-3p and HbA1c. Members of the miR-29 family are abundant in the pancreas and liver, and it was recently shown that miR-29a-3p works as a positive regulator of insulin secretion, with a protective role in disease development in a mouse model for beta cell stress-induced diabetes [226]. Moreover, upregulation of miR-29a has been shown in islets of pre-diabetic NOD mice [173], likely as a compensatory mechanism attempting to restore insulin secretion 
A C-peptide

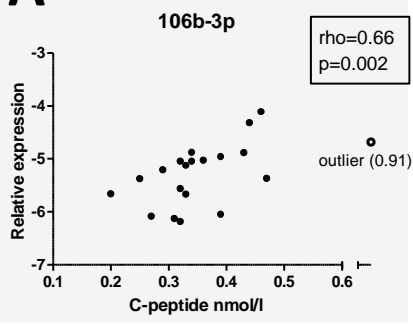

B OGTT
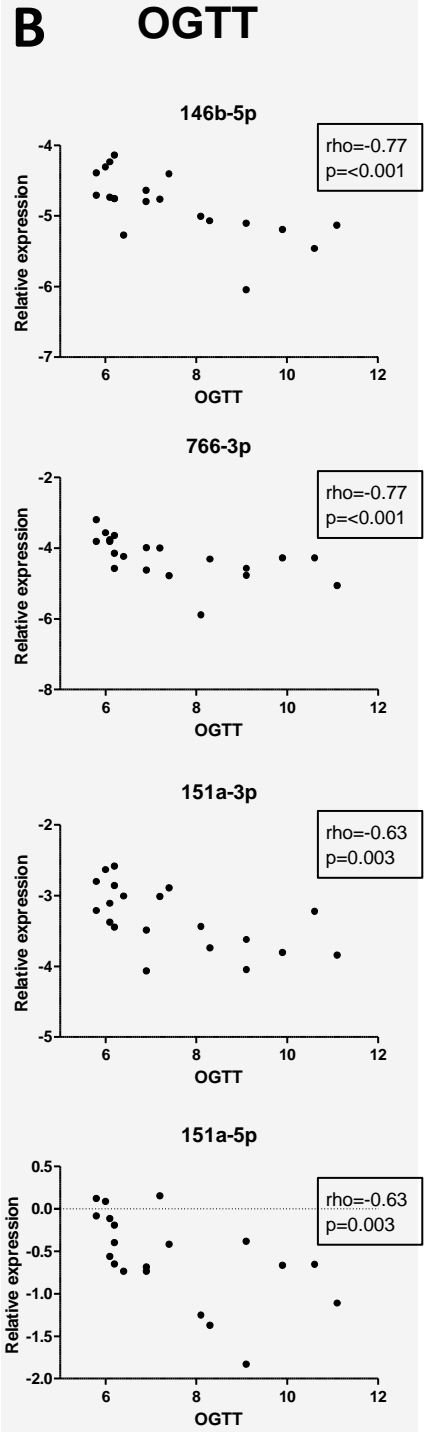

Figure 19. miRNAs correlating with $\mathrm{p}<0.01$ to parameters related to glucose homeostasis within the high-risk group. A) C-peptide, B) $\mathrm{HbA} 1 \mathrm{c}$ and C) glucose at $120 \mathrm{~min}$ of OGTT.
C HbA1c pos
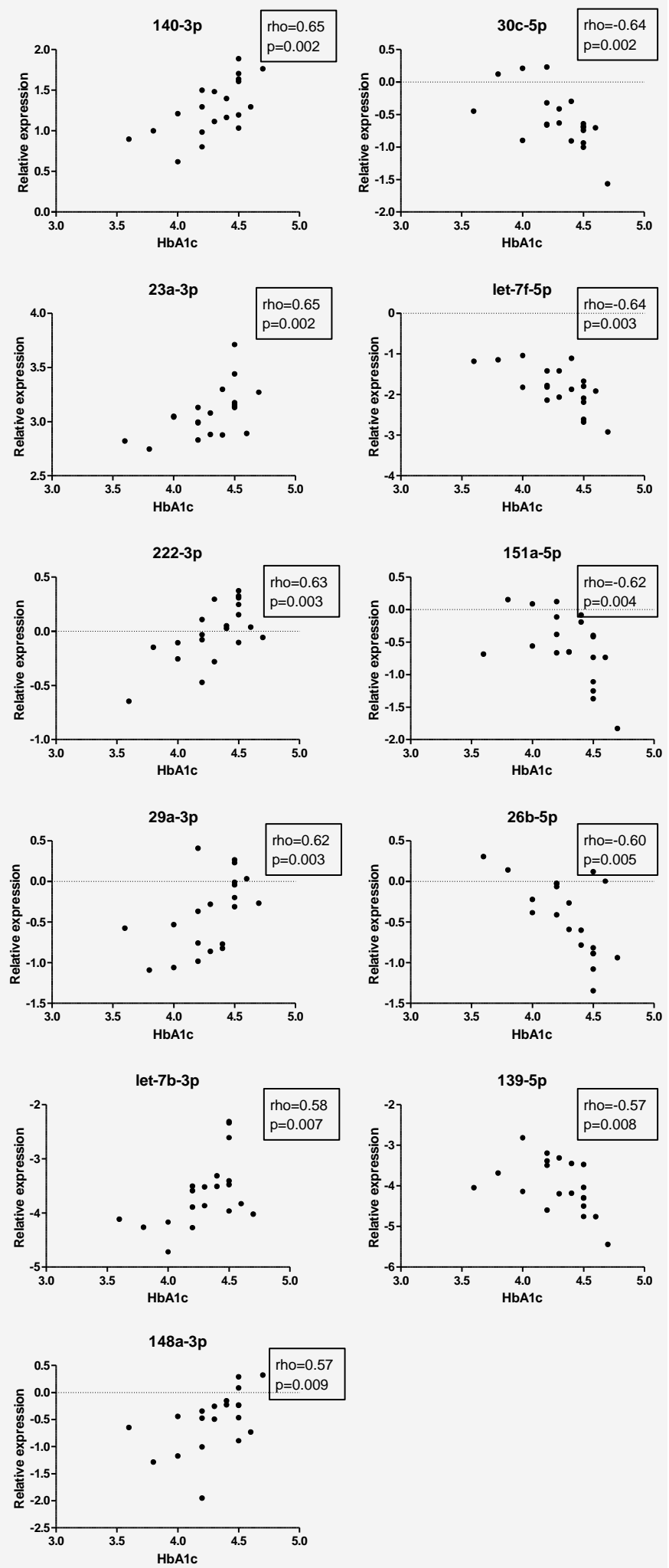

\section{HbA1c neg}


after beta cell loss [226]. The association between miR-29a-3p and HbA1c in high-risk individuals could be interpreted as a reflection of such compensatory mechanisms.

The four miRNAs most significantly associated to glucose at $120 \mathrm{~min}$ of OGTT were miR146b-5p, 766-3p, miR-151a-3p and -5p, all showing a negative correlation (Figure 19). Downregulation of miR-146b-5p in PBMC from T1D patients has been described before [168], but we did not detect a deviation of miR-146b-5p in serum from T1D patients, and to our knowledge it has not been reported by any other another study. For miR-151, it seems likely that this miRNA has a relation to metabolic processes, since it has been connected to mitochondrial activity [227], and decreased serum levels of both miR-151a-3p and $-5 p$ have been demonstrated after exercise [228]. When these four miRNAs were included in a PCA, a separation of high-risk individuals with $(n=11)$ and without $(n=9)$ impaired glucose tolerance was achieved, as illustrated in a PCA score plot (Figure 20). Given this apparent relation between serum miRNA expression and glucose levels in OGTT, it might be valuable to further explore the feasibility of their use to distinguish pre-diabetic individuals with abnormal glucose tolerance based on miRNA expression profile.

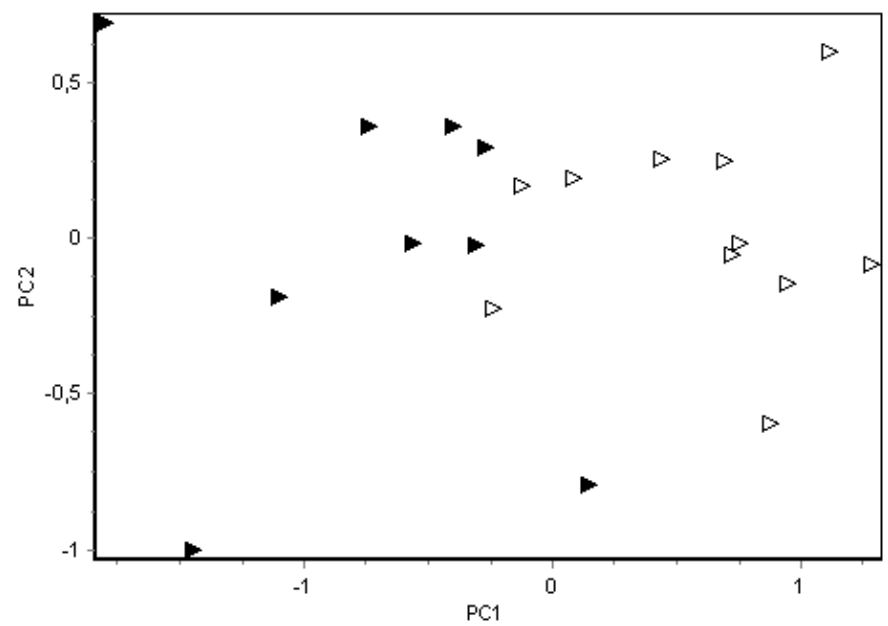

Figure 20. Principal component analysis (PCA) visualization (score plot) illustrating the separation of high-risk individuals with impaired glucose tolerance (IGT $\geq 7.8 \mathrm{mmol} / 1$ at $120 \mathrm{~min}$ of OGTT, $\mathrm{n}=11$ ) or normal glucose tolerance (NGT, $n=9$ ). The PCA is based on the four miRNAs correlating negatively to glucose at $120 \mathrm{~min}$ of OGTT, with $\mathrm{p}<0.01$. 
The only association observed between microRNA expression and C-peptide was the positive correlation to miR-106b-3p (Figure 19). To our knowledge, there are no previous reports of possible associations between miR-106b and insulin secretion in either risk individuals or T1D patients. It has however been reported that this miRNA induces mitochondrial dysfunction and insulin resistance in muscle cells [229], and that it is highly expressed in skeletal muscle tissue from T2D patients [230].

Taken together these results suggest that serum miRNAs may indeed be related to glucose homeostasis during the pre-diabetic period. Circulating miRNAs seem to reflect both causes and consequences of disturbed glucose homeostasis; i.e. disturbed insulin secretion locally in the pancreas and altered glucose metabolism in peripheral tissues like muscle and liver.

\section{miRNAs associated to islet autoantibodies within the high-risk group}

Analysis of the associations between miRNA expression and titers of islet autoantibodies among the high-risk individuals revealed several highly significant correlations (Figure 21). Of particular interest was the negative correlation seen between miR-342-3p and IA2A. It has recently been shown that certain miRNAs directly regulate the expression of T1D autoantigens, and it has been confirmed that miR-342-3p directly targets IA2- and IA2 $\beta$ mRNA [231]. The same study found that high-glucose stimulation resulted in increased expression of miRNAs associated to autoantigen regulation. Since levels of autoantigens like IA2, IA $2 \beta$ and $\mathrm{GAD}_{65}$ are also known to increase in response to high glucose [232, 233], the authors hypothesized that these miRNAs play a role in keeping balanced levels of these T1D autoantigens when glucose levels are altered. It is difficult to discern the relevance of deviating miR-342-3p levels in serum, in relation to the hypothesized role of this miRNA and others in the islets. A majority of the high-risk individuals in our study showed signs of dysglycemia at the baseline sampling (Table 2), with elevated fasting glucose or impaired glucose tolerance, regardless of autoantibody profile or whether they later progressed to T1D. Therefore, elevated glucose cannot explain the observed pattern for miR-342-3p. On the other hand, we also showed that the progressors in fact had higher IA2A titers (Figure 14A), and individuals with higher IA2A were the ones showing lower levels of miR-342-3p. This could perhaps reflect a failure to increase miR-342-3p in order to prevent higher levels of autoantigen, consequently leading to higher autoantigen levels that accelerate the autoimmune process, ultimately leading to clinical disease. This specific miRNA is just a small part of a large regulatory network, and its individual effect can only be expected to be marginal. Nevertheless, it was interesting that serum levels of a miRNA known to target islet 
A GADA
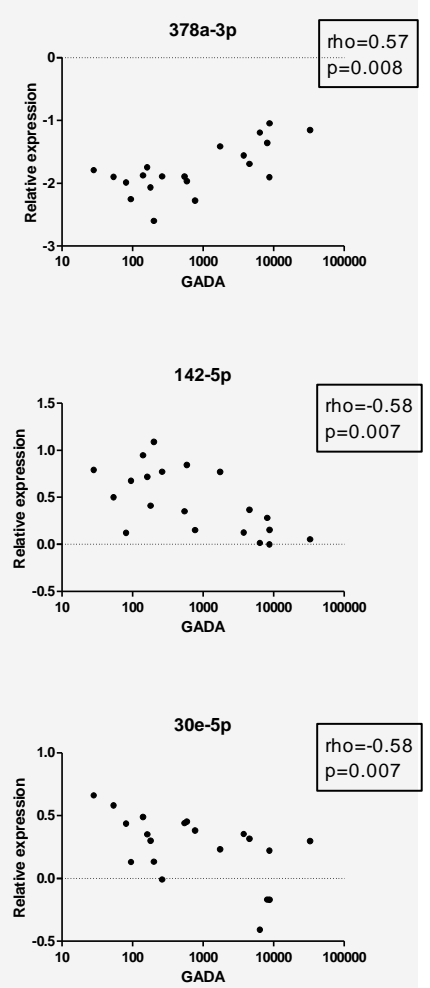

Figure 21. Correlation of miRNA expression to islet autoantibodies within the high-risk group. A) GADA, B) IA2A, C) IAA and D) ZnT8A(Trp). X-axes are presented in $\log 10$, and only correlations with $\mathrm{p}<0.01$ have been included.
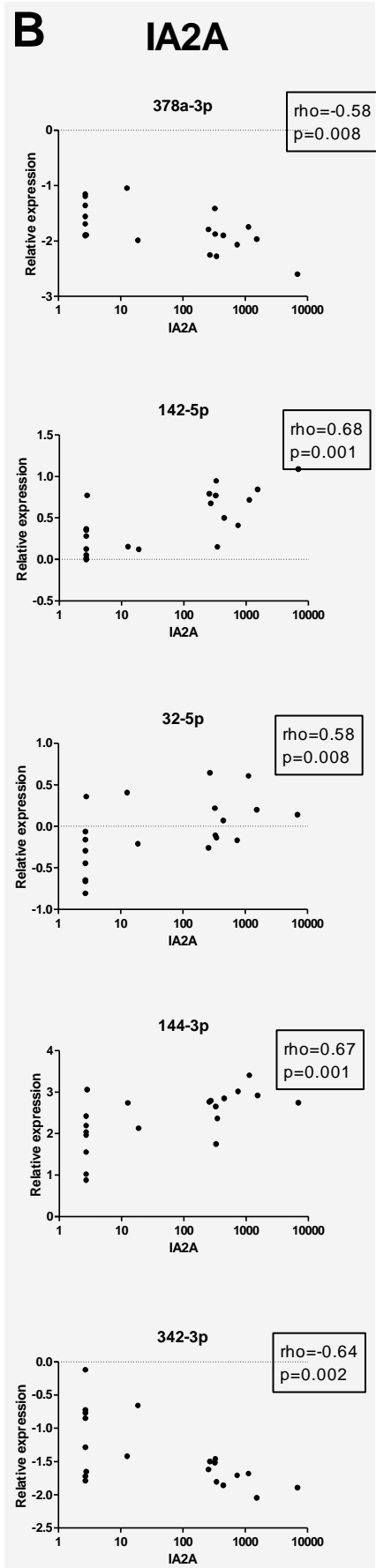

C ZnT8A(Trp)
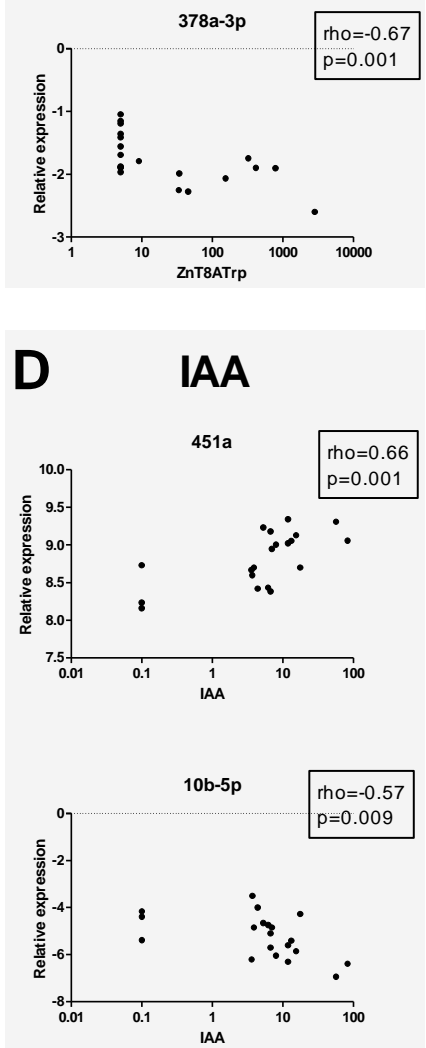
autoantigens correlated significantly to titers of islet autoantibodies. Additional evidence for a role of miR-342 in T1D is given by a study showing decreased levels in Treg from diabetic patients [172]. Furthermore, a study assessing miRNA expression in PBMC from patients with different forms of diabetes reported downregulation of miR-342-3p in T1D compared to T2D [224].

For the other miRNA-autoantibody associations observed by us, we could not find evidence supporting a direct link, as for miR-342-3p. Rather, it could be hypothesized that some of the observed associations arise from underlying connections between glucose homeostasis and the ongoing islet autoimmunity. For instance, miR-144, positively associated to IA2A in our study, has been demonstrated to impair insulin signaling and was linearly upregulated with increasing glycemic status when comparing subjects with normoglycemia, impaired fasting glucose or T2D [234]. The associations between autoantibody titers and miR-378a-3p were also interesting, as numerous studies have demonstrated a role of miR-378 in metabolic processes [235], e.g. as a regulator of mitochondrial metabolism and systemic energy homeostasis [236]. Notably, the expression of miR-378a-3p correlated negatively to IA2A and ZnT8A(Trp), but positively to GADA. The shared association of miR-378a-3p with IA2A and ZnT8A is in line with the correlation between IA2A- and ZnT8A titers that we found in samples from the same individuals, which in turn is in agreement with previous reports on high overlap between IA2A and ZnT8A in T1D [196]. Furthermore, finding miRNAs correlating with opposite directions to GADA and IA2A, like miR-378a-3p and miR-142-5p, mirrors our observation of an inverse relation between GADA- and IA2A titers. It has been shown that miR-142-5p acts as a negative regulator of T- and B cell activity in CD4+ T cells from SLE patients, together with miR-142-3p [237]. Another miRNA that also correlated with autoantibody titers in our study was miR-144, and both miR-142-5p and miR-144 have been reported as dysregulated in PBMCs from patients with different forms of diabetes [224]. To our knowledge, there are no previous studies showing associations between islet autoantibodies and miRNA expression in serum from high-risk individuals or T1D patients. Connections between autoantibodies and miRNA levels in PBMC have however been demonstrated in T1D patients, with miR-146 being related to serum GADA levels [168], and miR-326 to GADA- and IA2A positivity [171]. In our study, serum levels of these two miRNAs were not associated to islet autoantibodies, most likely due to different miRNA expression patterns in serum and PBMC. 


\section{Serum miRNA profile could not predict onset of clinical disease in high-risk}

\section{individuals}

We tested the hypothesis that serum miRNA profile might predict the onset of clinical disease by comparing the relative expression of miRNAs between progressors and non-progressors. The comparison revealed no significant differences after correction for multiple comparisons. Seven miRNAs differed with uncorrected values (Figure 22A), and including these in a PCA provided a clear separation of the groups (Figure 22B). The altered expression of these miRNAs is however difficult to interpret since some of them deviated differently to what should be expected in relation to healthy individuals and patients with T1D.
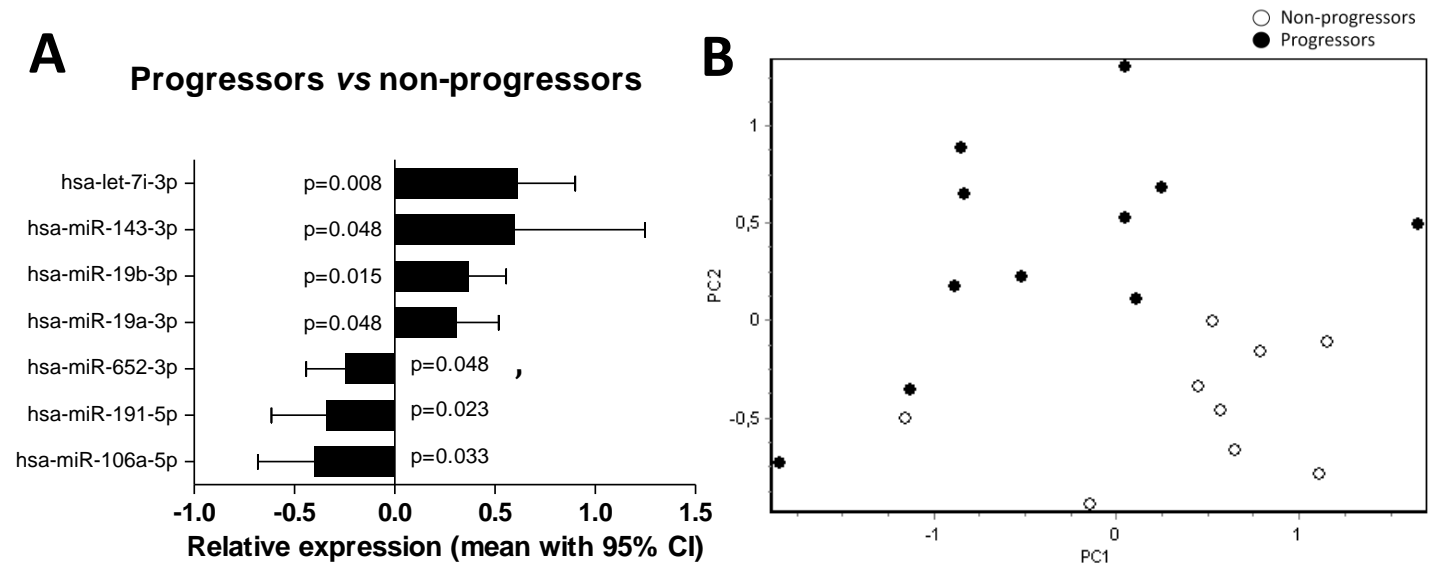

Figure 22. Relative expression of miRNAs in serum from high-risk children that developed diabetes (progressors, $n=11$ ) relative to those who did not (non-progressors, $n=9$ ) whose mean expression is set to 0 in the graph). Micro RNAs with uncorrected $\mathrm{p}<0.05$ are included in the figure, but differences were considered significant only at FDR-corrected p-value (q-value) <0.05. B) Principal component analysis (PCA) visualization (score plot) based on the seven miRNAs differing with uncorrected $\mathrm{p}<0.05$ between progressors (black circles) and non-progressors (empty circles).

\section{Deviating serum miRNA profile in new-onset T1D patients}

Recently diagnosed T1D patients showed a dramatically different miRNA profile compared both to the high-risk group and healthy controls, with 39 and 42 miRNAs differently expressed, respectively (Figure 23A-B). This was also seen in the PCA score plot, as T1D patients were clearly separated from the other two groups (Figure 23C). Considering that all the risk-children had ongoing autoimmunity and many also dysglycemia, we had expected to see more similarities between them and the newly diagnosed T1D patients. The high-risk individuals were however asymptomatic and from a clinical point of view still healthy. Thus, 

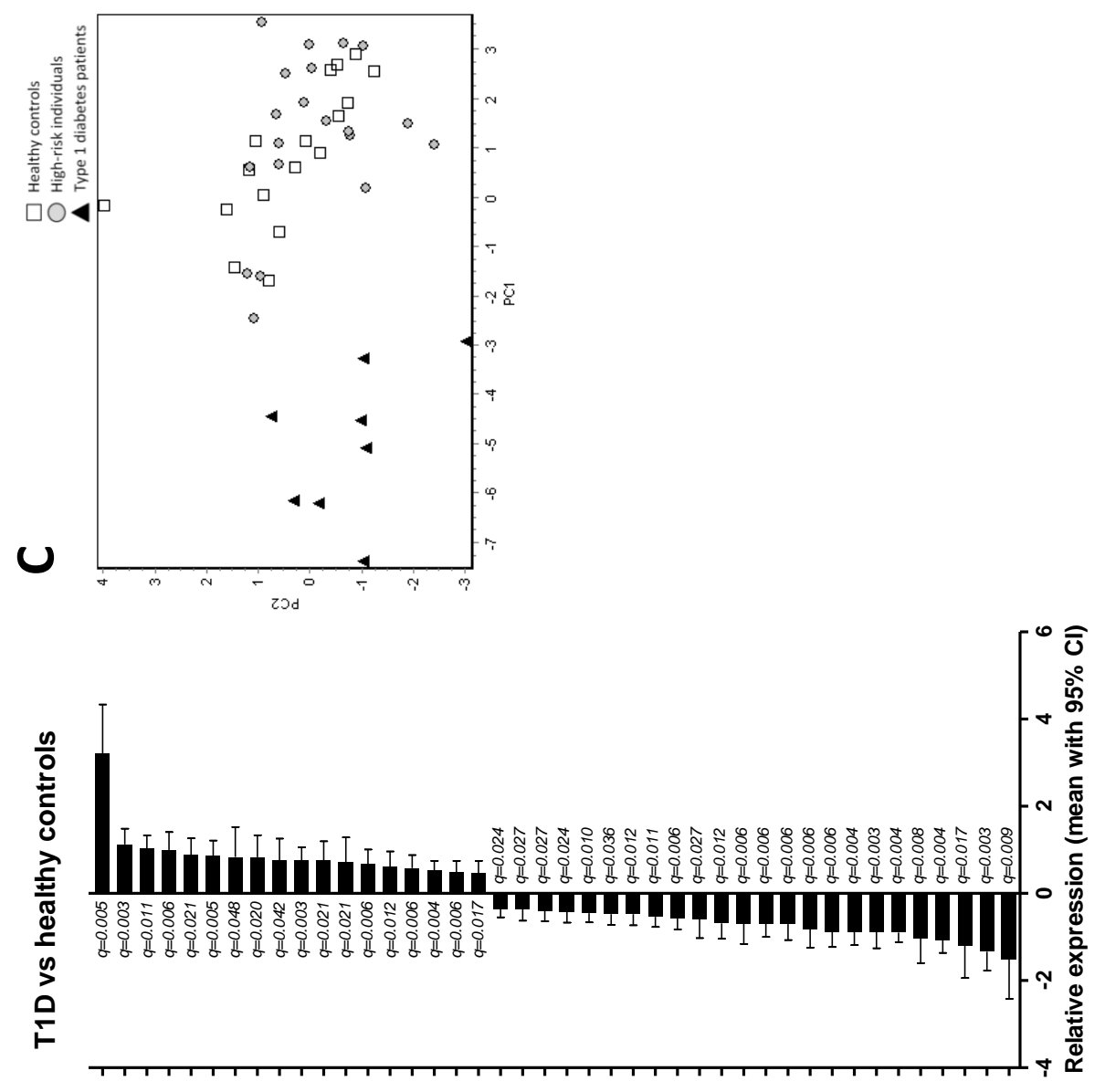

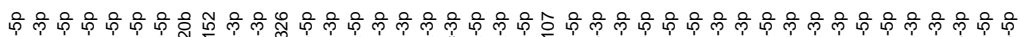

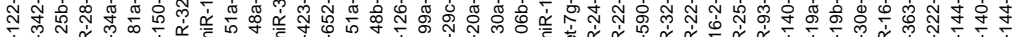

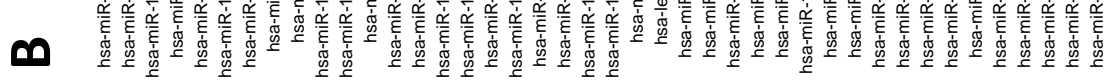

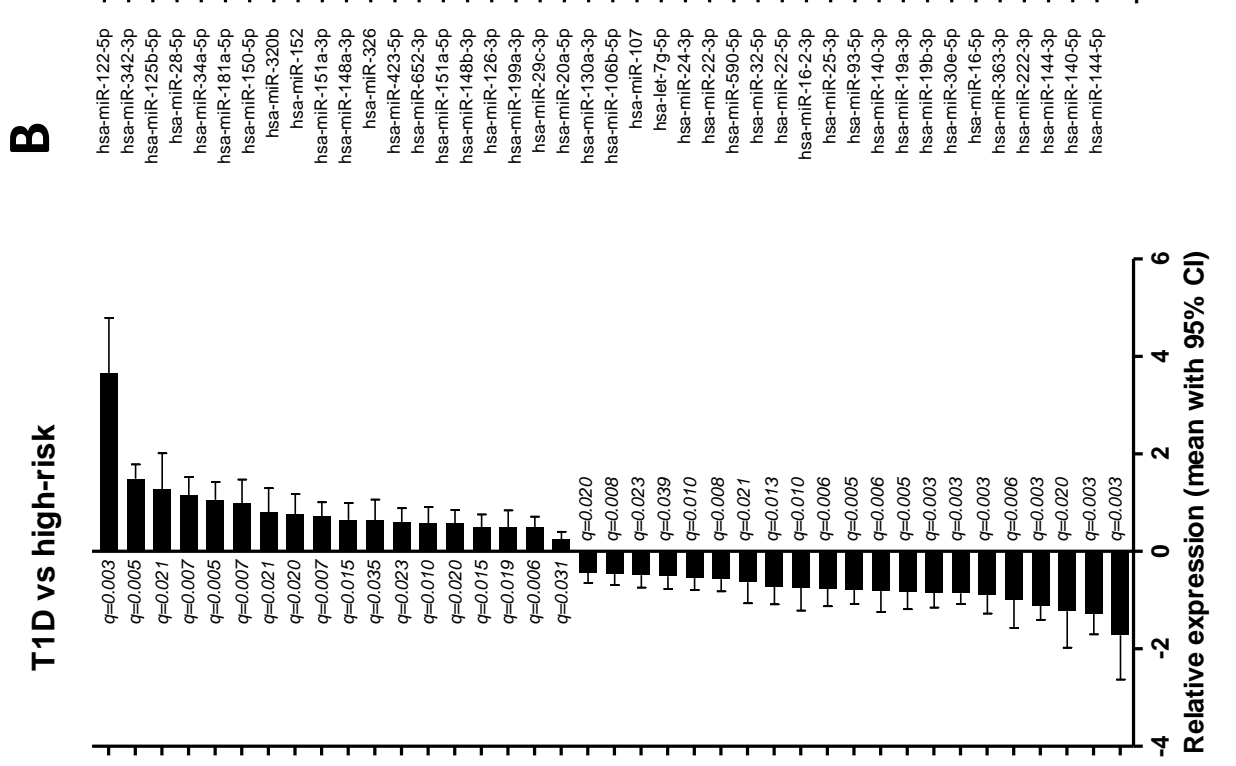

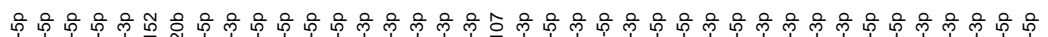

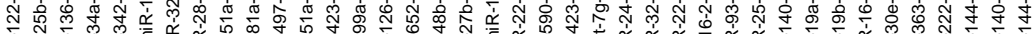

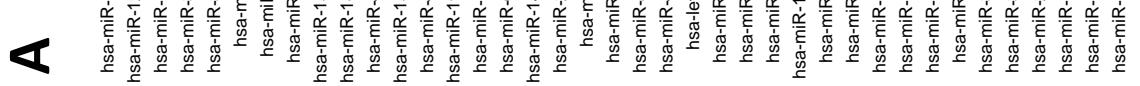


even though several miRNAs seemed related to dysregulated glucose homeostasis within the high-risk group, a reasonable explanation to why the high-risk individuals show much higher resemblance to healthy than to diabetic subjects is that the major metabolic disturbances occur very close to the diagnosis of manifest T1D.

Several of the miRNAs that were differently expressed in T1D are biologically relevant from a diabetes perspective [238-240] and for many (but not all) there are previous reports of dysregulation in the same expressional direction in T1D [174, 241]. The discrepancies observed might be explained by differences with regard to patient age and disease duration between the studied T1D cohorts. Even though many of the miRNAs differently expressed in the T1D group are interesting, we refrain from drawing further conclusions due to the small number of samples and the different sample storage conditions for this group. With this said, we do not believe that the storage at $-20^{\circ} \mathrm{C}$ instead of $-70^{\circ} \mathrm{C}$ for these samples had a major impact on the miRNA quality, given the remarkable stability of miRNA in extreme conditions, including repeated freeze-thaw [223]. The relative agreement between our results and data previously described by others support this [174, 241].

To conclude, we observed that several miRNAs appeared to be tightly associated to glucose homeostasis and islet autoantibodies among high-risk individuals, but no specific miRNA profile could distinguish them from healthy controls. Larger studies are needed to further assess the possibility of using circulating miRNAs as biomarkers of T1D risk, but our results suggest that their relevance as biomarkers of disease progression among individuals at risk seems to be limited. The possible associations of miRNA with glucose metabolism and autoantibodies might however be useful in the stratification of risk individuals. 


\section{The effect of physical activity on glucose homeostasis in healthy youth}

In a separate sub-study of ABIS, we wanted to assess the effects of physical activity on glucose homeostasis and weight status in healthy schoolchildren over time. Even moderately elevated BMI has a negative impact on metabolic profile and cardiovascular risk factors in children [242], and increased body weight among children has also been suggested as one factor possibly contributing not only to T2D but also to the increased incidence of T1D [68, $70,194]$. Low physical activity is associated with obesity and cardio-metabolic risk in children [243-246], and a central element in the accelerator hypothesis [70], the beta cell stress hypothesis [194] and the overload hypothesis [68] is that excessive activity of pancreatic beta cells, due to for example extra body weight, may cause or accelerate beta cell destruction. In this longitudinal study, physical activity was measured objectively by pedometers and estimated subjectively by questionnaires, and blood samples were drawn for assessment of glucose homeostasis.

\section{Physical activity was related to glucose homeostasis and anthropometric data in children}

The physical activity at eight years of age, assessed by the average number of daily steps, correlated to anthropometric measures like BMI and waist circumference, as well as to glucose homeostasis measured by C-peptide, HOMA2-IR and HOMA2-\%B, and this was even more evident at age 12 (Table 5).

Table 5. Variables correlated to the average number of daily steps.

\begin{tabular}{lllll}
\hline & Age 8 & & \multicolumn{2}{c}{ Age 12 } \\
\cline { 2 - 5 } & Pearson r & $\mathbf{p}$ & Pearson r \\
\hline BMI & -.185 & 0.019 & -.232 & 0.021 \\
Waist circumference & -.212 & 0.018 & -.328 & -.401 \\
C-peptide & -.224 & 0.029 & -.404 & $<0.001$ \\
HOMA2-IR & -.236 & 0.026 & -.271 & $<0.001$ \\
HOMA2-\%B & -.238 & 0.025 & 0.01 \\
\hline
\end{tabular}

Since BMI showed high correlations to waist circumference (Table 6), as expected, but also to measures related to glucose homeostasis (Table 6), the association between daily steps and C-peptide was assessed with adjustment for BMI (Table 7). We also included sex as a possible confounding factor. This showed that children taking more steps per day were less likely to have higher levels of fasting C-peptide at both ages, independent of sex and BMI (Table 7). At age 12 it was also shown that BMI Z-score was independently associated to fasting C-peptide (Table 7). 
Table 6. Variables correlated to BMI, other than average daily steps.

\begin{tabular}{|c|c|c|c|c|}
\hline & \multicolumn{2}{|l|}{ Age 8} & \multicolumn{2}{|l|}{ Age 12} \\
\hline & Pearson $r$ & $\mathrm{p}$ & Pearson $r$ & $\mathbf{p}$ \\
\hline Waist circumference & .797 & $<0.001$ & .857 & $<0.001$ \\
\hline HOMA2-IR & .208 & 0.046 & .335 & 0.001 \\
\hline C-peptide & & n.s & .334 & 0.001 \\
\hline HOMA2-\%B & & $n . s$ & .224 & 0.031 \\
\hline
\end{tabular}

n.s. = not significant

Table 7. Linear regression model with fasting C-peptide $(\mathrm{nmol} / \mathrm{l})$ as dependent variable at age $8(\mathrm{n}=88)$ and age $12(\mathrm{n}=88)$.

\begin{tabular}{llll}
\hline Age 8 & $\mathbf{P}$ & Adjusted Beta & $\mathbf{9 5 \%} \mathbf{C l}$ \\
\hline BMI Z-score & n.s. & 0.05 & $-0.004-0.111$ \\
\hline F-glucose (nmol/I) & $n . s$. & -0.07 & $-0.161-0.029$ \\
Gender (M/F) & $n . s$. & 0.01 & $-0.085-0.107$ \\
\hline Steps per day* & 0.021 & -0.02 & $-0.037--0.003$ \\
\hline Age 12 & $\mathbf{P}$ & Adjusted Beta & $\mathbf{9 5 \%}$ Cl \\
\hline BMI Z-score & 0.029 & 0.04 & $0.005-0.081$ \\
F-glucose (nmol/I) & $n . s$. & 0.04 & $-0.038-0.118$ \\
Gender (M/F) & $n . s$. & 0.05 & $-0.015-0.120$ \\
Steps per day* & 0.034 & -0.01 & $-0.014-0.127$
\end{tabular}

n.s. = not significant

* Steps per day divided with 1000 .

We also observed that children with a physical activity level reaching the BMI-referenced step recommendations [247] indeed had lower C-peptide, HOMA2-IR, HOMA2-\%B and waist circumference than those who did not (Figure 24).

A

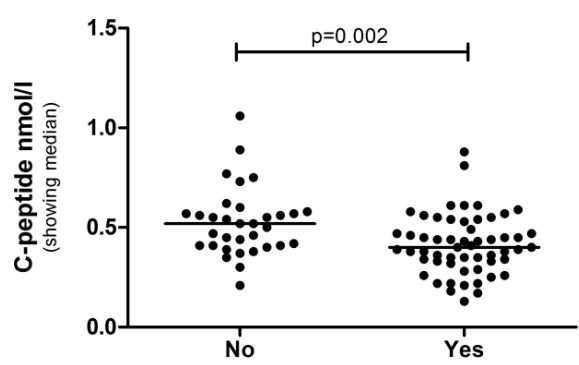

Reaching minimum step recommendation?
B

\begin{tabular}{lccc}
\multicolumn{4}{c}{ Reaching minimum step recommendations? } \\
Median values & No & Yes & p \\
\hline HOMA2-IR & 1.2 & 0.9 & 0.002 \\
HOMA2-\%B & 82.6 & 69.3 & 0.03 \\
Waist $(\mathrm{cm})$ & 73 & 68 & 0.042
\end{tabular}

Figure 24. Levels of C-peptide (A) and HOMA2-IR, HOMA2-\%B and waist circumference (B) in children reaching the minimum recommendation of daily steps, or not, at age 12 . The groups were compared by MannWhitney U-test. 
Together, these results show that low physical activity, already in school age, is related to increased beta cell load (indicated by elevated C-peptide) and insulin resistance. Although similar observations have been made before [248], an important finding was that associations seen at age 8 tended to remain or even become more pronounced with increasing age. Our results support and strengthen previous studies showing that a sedentary life style is associated with cardio-metabolic risk [249]. Physical inactivity with its effect on insulin resistance is known to be important for development of $\mathrm{T} 2 \mathrm{D}$, but might also play a role in the development of T1D. As suggested by the mentioned beta cell stress- and accelerator hypotheses, any factor contributing to beta cell stress, like physical inactivity, may lead not only to increased insulin secretion but also to increased presentation of autoantigens [250] and posttranslational modification of islet autoantigens, which in recent years has been implicated to have a role in T1D pathogenesis [251]. Thus, an additional factor that may contribute to the increasing incidence of T1D in children is our modern, sedentary life style.

\section{The effects of physical activity on glucose homeostasis were most pronounced in}

\section{boys}

When comparing boys and girls, we found that boys were physically more active than girls, both at age 8 and 12 (Table 8), which is consistent with previous findings [252]. Due to the quite large difference between genders, all analyses were repeated in girls and boys separately. This revealed that none of the significant associations to average daily steps seen at age 8 in the entire group could be confirmed in the separate analyses, possibly due to the smaller groups. At age 12, however, we observed that the physical activity of boys was clearly associated both to measures of glucose homeostasis and anthropometric data (Table 9), while no associations to daily steps were seen for girls. In addition, boys reaching the recommended amount of steps had significantly lower C-peptide (Figure 25A), HOMA2-IR, HOMA2-\%B and waist circumference (Figure 25B), just as seen in the group as a whole. For the girls, there was no difference when comparing those who reached recommendation and those who did not, at any age. 
Table 8. Group characteristics in the longitudinal pedometer study, at age 8 and 12, with comparisons between boys and girls, and paired comparisons over time.

\begin{tabular}{|c|c|c|c|c|c|}
\hline & \multirow[t]{2}{*}{ Sex } & \multirow{2}{*}{$\begin{array}{l}\text { Age } 8 \\
\text { Mean (n) }\end{array}$} & \multirow{2}{*}{$\begin{array}{l}\text { Age } 12 \\
\text { Mean (n) }\end{array}$} & \multicolumn{2}{|c|}{$\begin{array}{l}\text { Wilcoxon signed-rank } \\
\text { test } 8 \text { vs } 12 \text { years }\end{array}$} \\
\hline & & & & $n$ & $p$ \\
\hline \multirow[t]{2}{*}{ Steps per day } & -Girls & $15223(100)$ & $12853(50)$ & 50 & $<0.001$ \\
\hline & -Boys & 17067 (92) & $16154(51)$ & 45 & n.s. \\
\hline Boys vs girls, $p$ & & $<0.001$ & $<0.001$ & & \\
\hline \multirow[t]{2}{*}{ Body mass index $\left(\mathrm{kg} / \mathrm{m}^{2}\right)$} & -Girls & $16.5(83)$ & $18.6(49)$ & 49 & $<0.001$ \\
\hline & - Boys & $16.6(85)$ & $18.8(55)$ & 52 & $<0.001$ \\
\hline Boys vs girls, $p$ & & n.s. & n.s. & & \\
\hline \multirow[t]{2}{*}{ Waist circumference (cm) } & -Girls & $59.5(68)$ & $71.6(49)$ & 49 & $<0.001$ \\
\hline & -Boys & $60(62)$ & $71.1(55)$ & 52 & $<0.001$ \\
\hline Boys vs girls, $p$ & & n.s. & n.s. & & \\
\hline \multirow[t]{2}{*}{ Overweight/obese (\%) } & -Girls & $20(80)$ & $22.9(48)$ & 48 & n.s. ${ }^{b}$ \\
\hline & -Boys & $14.5(83)$ & $20(55)$ & 50 & n.s. ${ }^{b}$ \\
\hline Boys vs girls, $p$ & & n.s. ${ }^{a}$ & n.s. ${ }^{a}$ & & \\
\hline \multirow[t]{2}{*}{ Fasting C-peptide (nmol/l) } & -Girls & $0.37(52)$ & $0.5(43)$ & 35 & 0.007 \\
\hline & -Boys & $0.34(47)$ & $0.43(50)$ & 39 & 0.004 \\
\hline Boys vs girls, $p$ & & n.s. & n.s. & & \\
\hline \multirow[t]{2}{*}{ HOMA2-IR } & -Girls & $0.79(47)$ & $1.15(43)$ & 31 & 0.002 \\
\hline & -Boys & $0.74(45)$ & $0.98(50)$ & 38 & 0.001 \\
\hline Boys vs girls, $p$ & & n.s. & n.s. & & \\
\hline \multirow[t]{2}{*}{ HOMA2-\%B } & -Girls & $96.5(47)$ & $82.1(43)$ & 31 & n.s. \\
\hline & -Boys & $86.5(45)$ & $72.5(50)$ & 38 & n.s. \\
\hline Boys vs girls, $p$ & & n.s. & n.s. & & \\
\hline \multirow[t]{2}{*}{ F-glucose (mmol/l) } & -Girls & $4.6(60)$ & $5.1(45)$ & 41 & $<0.001$ \\
\hline & -Boys & $4.7(54)$ & $5.1(51)$ & 46 & $<0.001$ \\
\hline Boys vs girls, $p$ & & n.s. & n.s. & & \\
\hline \multirow[t]{2}{*}{ HbA1c (Mono-S \%) } & -Girls & $3.79(58)$ & N/A & & N/A \\
\hline & -Boys & $3.78(56)$ & N/A & & N/A \\
\hline Boys vs girls, $p$ & & n.s. & N/A & & \\
\hline
\end{tabular}

Boys and girls compared by Mann-Whitney U-test n.s. = not significant, N/A = not available

${ }^{\text {a }}$ proportions compared by Fisher's exact test

${ }^{\mathrm{b}}$ paired proportions compared by McNemar test

Thus it seems like boys, who in general were more physically active than girls, have more pronounced effects from physical activity on beta cell-load and insulin resistance. This has been observed previously, in an Australian study that also found an effect of physical activity on insulin resistance [253], but only in boys. The lack of effects from physical activity in the girls may be explained by the fact that some of them were on their way into puberty at age 12 , rendering them more insulin resistant. In addition, girls repeatedly showed a more narrow range of daily steps and lower levels of physical activity than boys, and it could be speculated that a certain threshold of activity needs to be reached before metabolic benefits are gained, in particular during puberty.

Table 9. Variables correlated to the average number of daily steps in boys at age 12 .

\begin{tabular}{lcc} 
Boys & \multicolumn{2}{c}{ Age 12 } \\
Variables correlated to steps & rho & $\mathrm{p}$ \\
\hline C-peptide & -.516 & $<0.001$ \\
HOMA2-IR & -.502 & $<0.001$ \\
HOMA2-\%B & -.327 & 0.027 \\
Waist & -.403 & 0.004
\end{tabular}


A

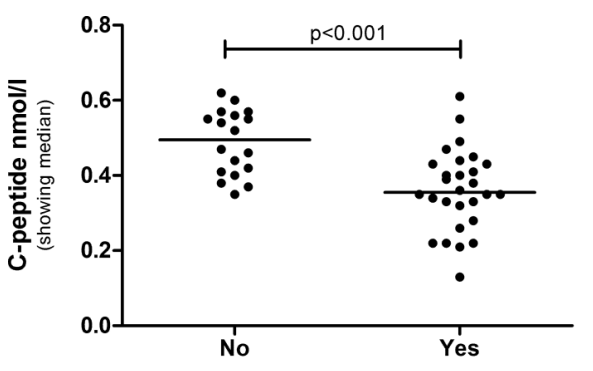

Reaching minimum step recommendation?
Reaching minimum step recommendations?

\begin{tabular}{lccc} 
Median values & No & Yes & $\mathrm{p}$ \\
\hline HOMA2-IR & 1.15 & 0.8 & $<0.001$ \\
HOMA2-\%B & 77.4 & 66.1 & 0.013 \\
Waist $(\mathrm{cm})$ & 76 & 67 & 0.015
\end{tabular}

Figure 25. Levels of C-peptide (A) and HOMA2-IR, HOMA2-\%B and waist circumference (B) in boys reaching the minimum recommendation of daily steps, or not, at age 12 . The groups were compared by MannWhitney U-test.

\section{Associations between anthropometric data and measures of glucose homeostasis}

In agreement with the analyses performed on the entire group, there were some associations between anthropometric data and measures of glucose homeostasis when girls and boys were analyzed separately (Table 10). These associations were not seen consistently over time, except for the relation between BMI and waist circumference that was observed at age 8 and 12 in boys (rho=.801, p<0.001, and rho=.751, $\mathrm{p}<0.001$, respectively), and in girls (Table 10, right). In boys at age 12, we also saw that f-glucose was correlated to C-peptide (rho $=.368$, $\mathrm{p}=0.009$ ) and HOMA2-IR (rho=.430, p=0.002). In girls, waist circumference was also correlated to C-peptide and HOMA2-IR at age 12 (Table10, right).

Table 10. Associations between anthropometric data and measures of glucose homeostasis in boys and girls separately. To the left, variables correlating to BMI and waist circumference in boys at age 8 . To the right, variables correlating to waist circumference in girls at both ages.

\begin{tabular}{|c|c|c|c|}
\hline Boys, age 8 & C-peptide & HOMA2-IR & HOMA2-\%B \\
\hline BMI & $.357(0.014)$ & $.335(0.025)$ & $.309(0.039)$ \\
\hline Waist & $.407(0.005)$ & $.388(0.008)$ & $.362(0.015)$ \\
\hline
\end{tabular}

\begin{tabular}{lcccc} 
Girls & \multicolumn{2}{c}{ Age 8 } & \multicolumn{2}{c}{ Age 12 } \\
Waist $x$ & rho & $\mathrm{p}$ & rho & $\mathrm{p}$ \\
\hline BMI & \multirow{2}{*}{.719} & $<0.001$ & .821 & $<0.001$ \\
C-peptide & & & .337 & 0.027 \\
HOMA2-IR & & & .327 & 0.032
\end{tabular}

\section{Analysis of longitudinal data}

When assessing changes over time, we observed that the average number of daily steps decreased significantly with age in girls (Table 8), and the boys had a non-significant decrease in steps from 8 to 12 years. This is in accordance with previously assessed physical activity patterns in youth [254]. In girls, there was no correlation between the step values at 
age 8 and 12, while they correlated significantly in boys (Table 11), indicating that their individual level of physical activity was more stable over time. BMI, waist circumference, Cpeptide, HOMA2-IR and f-glucose all increased with age in boys and girls (Table 8), and especially BMI and waist circumference showed high stability over time (Table 11), as previously shown [255].

Table 11. Correlation of individual values over time, from 8 to 12 years, assessed by Spearman's rho.

\begin{tabular}{lllc} 
& & \multicolumn{2}{c}{ Correlation 8 to $\mathbf{1 2}$ years } \\
& & rho & p \\
\hline \multirow{2}{*}{ BMI } & Girls & .815 & $<0.001$ \\
& Boys & .866 & $<0.001$ \\
\multirow{3}{*}{ Waist } & Girls & 703 & $<0.001$ \\
& Boys & .731 & $<0.001$ \\
\multirow{3}{*}{ Steps } & Girls & n.s. & n.s. \\
& Boys & .418 & 0.004 \\
f-glucose & Girls & n.s. & n.s. \\
& Boys & .486 & $<0.001$
\end{tabular}

When dividing the children into groups based on their change in physical activity from age 8 to 12 , it was seen that those who decreased their physical activity over time got significantly higher C-peptide (Figure 26A) and HOMA2-IR ( $\mathrm{p}=0.041$ ). When analyzing boys and girls separately, these differences could only be seen in boys (Figure 26B), with HOMA2-IR showing borderline significance $(\mathrm{p}=0.059)$.
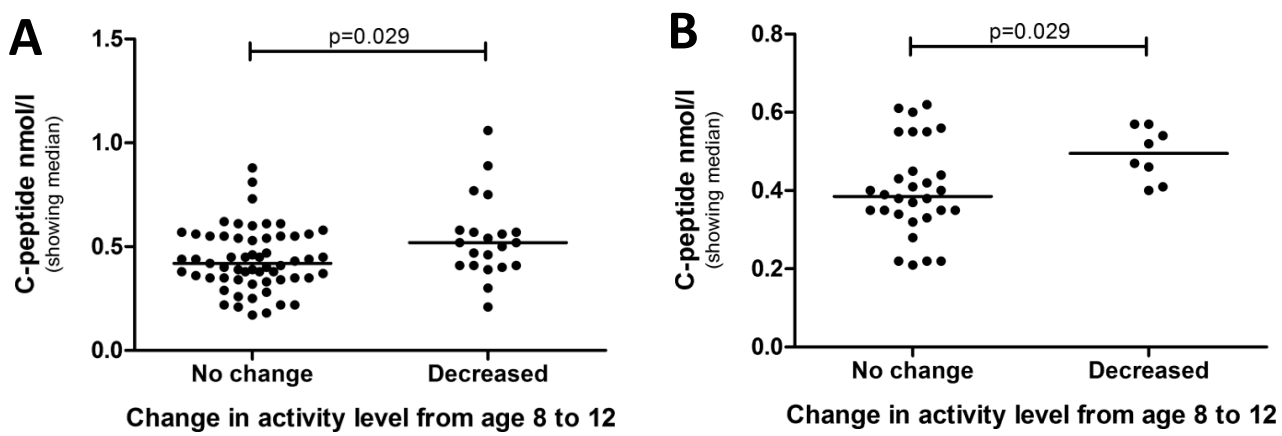

Figure 26. C-peptide level in children that maintained or decreased their physical activity over time. First showing all children together (A), then boys only (B). The groups were compared by Mann-Whitney U-test. 


\section{Weak associations between objective and subjective measures of physical activity}

In our study, as a complement to objective measurement by pedometers, parents and children answered questions regarding physical activity/sedentary behavior. We found no associations at either time point between the objectively measured activity data and questionnaire data pertaining to physical activity or sedentary behavior, when analyzing boys and girls together. In boys however, some consistency was seen, as a negative association between recorded average daily steps and daily leisure time hours in front of TV/video/DVD on school days reported by the child (rho=-.416, $\mathrm{p}=0.006$ ) was observed at age 12 . Furthermore, a negative association was revealed between parent-reported daily hours spent outdoors on schooldays and HOMA2-\%B at age 8 (rho=-.442, p=0.004). Although the relations between subjective and objective variables were sporadic and only seen in boys, they did point in the expected directions. Both body measures and laboratory values however showed better agreement to objectively measured activity level than to questionnaire data.

To conclude, it seems like the level of physical activity is related to insulin resistance and beta cell-stress in healthy youth. Furthermore, a decrease in physical activity already in school-age is associated with increased insulin resistance and load on the insulin producing beta cells, which might be of importance for development of both type 1-and 2 diabetes. Physical activity should be promoted for schoolchildren. 


\section{CONCLUDING REMARKS}

The knowledge about the period preceding onset of T1D has expanded greatly in the past years, much thanks to results from several studies addressing the natural history of the disease. The collective picture demonstrates a heterogeneous disease process, to date best characterized by determination of disease-related risk genes, autoantibody profiles and further risk staging by assessment of glucose homeostasis. Importantly, much of what we know about the pre-diabetic period comes from studies on first- or second-degree relatives of T1D patients. Even though they have increased disease risk, they may not be representative for T1D patients at large, who infrequently have familial disease. For this reason, studies performed in risk-cohorts from the general population are warranted. In our prospective follow-up of children positive for multiple islet autoantibodies, selected from the ABIS cohort and representing the general Swedish child population, we have studied different aspects of the pre-diabetic period. In contrast to many other risk-cohorts, the participants were identified through autoantibody screening regardless of genetic background. They were very homogenous in terms of age, with an age span of only two years, and the reference groups consisting of healthy children without increased risk and newly diagnosed T1D patients were well-matched to the risk-group.

Our results provide support for the use of IA2- and ZnT8 autoantibodies as discriminators for T1D progression in autoantibody-positive children, while presence of dysglycemia was not a useful predictor of clinical disease in this cohort. Disturbed glucose metabolism was however observed a long time before diagnosis in many of the progressors, in line with previous studies. Interestingly, this difficulty to maintain glucose homeostasis was seen despite a simultaneously increased insulin secretion prior to diagnosis, supporting that insulin resistance may be an important disease accelerator. Our data may thus support suggestions to take action against insulin resistance in individuals at increased risk, pharmacologically or by other interventions, in an attempt to delay disease development. This could not only be directly beneficial for the individual but could also prolong the window of opportunity to intervene in the immune-mediated disease process.

Even though risk stratification strategies have improved, earlier and more specific biomarkers would be valuable for screening and identification of risk subjects. Extensive efforts have been made in this research area for more than 30 years, but results from early studies have been limited by methodological constraints such as the demand for large sample volumes to 
detect the presence a very limited number of analytes. In the work behind this thesis we strove to identify biomarkers of risk using more modern methodologies like multiplex RTqPCR arrays, enabling simultaneous quantification of a broad range of targets in relatively small sample volumes. Assessing the expression of immune-related genes in PBMC from the high-risk individuals revealed no major differences in relation to healthy children, but rather that the expression seemed related to residual beta cell function. The only two genes that differed between the high-risk group and controls were TNF and CD45, but whether their expression can be of any use in disease prediction or risk stratification need to be confirmed. Perhaps our results primarily reflected an effect of onset-preceding metabolic changes on gene expression profile in peripheral immune cells, whereas it seems difficult to reveal clear associations to immune imbalances through this method. While the results from serum miRNA analysis also showed high resemblance between the expression in risk-individuals and healthy children, it was noteworthy that glucose homeostasis was highly reflected by miRNA expression among individuals at risk. That clear association has to our knowledge not been observed before, but the clinical relevance of this finding needs to be further elucidated. Several miRNAs were seemingly related to islet autoantibody titers as well. Such associations have been implicated by previous studies, but the relationships may be complex due to the fact that autoantibodies are coupled to other factors like HLA-genotype and age.

The healthy children used as a reference group were part of a separate study assessing the effects of physical activity, measured by pedometers, on glucose homeostasis. Insulin production and insulin resistance seemed to be significantly modulated by the degree of physical activity in healthy youth, especially in boys, highlighting the fact that low physical activity is a problem. The postulated role of insulin resistance at some stage during T1D development suggests that low physical activity may have consequences beyond the increasing incidence of T2D and cardiovascular disease. However, the relationship between low physical activity and increased insulin resistance may not necessarily be valid for individuals at increased risk of T1D, since these children may well suffer from metabolic abnormalities that disrupt the normal regulation of insulin sensitivity and resistance. It is therefore not certain whether they would respond in the same way to increased physical activity.

Although studying this particular cohort of young individuals with high risk for T1D provided interesting findings, it also illustrated the difficulties in identifying deviations during the pre-diabetic period that are not related to the already failing glucose homeostasis, 
which probably has a significant effect on many tissues and organs in the body. So far, sufficiently strong and reproducible blood-based signatures of pre-diabetes have not been identified in the "omic" areas of research. Such studies are however still in their infancy, and two important things will likely bring the field forward in the coming years: new larger international risk-cohorts and advances in molecular biology techniques. Hopefully, this will provide new insights into the pathogenesis of T1D and identify early changes that associate with progression to clinical disease. 


\section{ACKNOWLEDGEMENTS}

I would like to express my sincerest gratitude to all who have made contributions and all who have supported me during the work leading up to this thesis.

All the participating families in ABIS, especially children and parents in the high-risk follow-up and the children in the pedometer study.

My main supervisor, Rosaura Casas, for giving me a chance to do my thesis project in your group, for always being inspiring, and for supporting me, believing in me and helping me to grow.

My co-supervisor, Johnny Ludvigsson, for sharing your tremendous enthusiasm for research and your extensive knowledge in the field.

My past room-mates and co-authors Stina Axelsson Chéramy, Mikael Chéramy and Mikael Pihl, for introducing me to research, type 1 diabetes and being a $\mathrm{PhD}$ student. Thanks for all the good times - in the lab, in the office and in conferences. A special thanks to Stina, for taking me on as a student and being an excellent supervisor!

Ingela Johansson and Gosia Smolinska Konefal, for all the laboratory and technical support, all your help with samples and analyses, and for always being able to answer my questions regarding ABIS, autoantibodies, machines, freezers etc. And also for great company!

My present group-fellows and room-mates who brighten up my days, Hugo Barcenilla, Beatriz Tavira Iglesis and Louise Magnusson. Bea, for being a great friend, feeding me with sugar and giving me a hug whenever needed. Hugo, for good times in the office and long hours in the lab, expanding quadrillions of $\mathrm{T}$ cells and crying/laughing over failed suppression experiments. Louise, for being an excellent master student and now $\mathrm{PhD}$ student, for always caring for everyone around, and making sure that we all meet at fika.

My former group-member and present collaborator Camilla Skoglund, for coming up with the idea to the miRNA-project, for nice chats and good collaboration.

My former office-mates, Anna Kivling, Kristina Warstedt, Chamilly Evaldsson, Sri

Ramulu Elluru and Saubashya Sur, for good company and nice talks about research and life.

Everyone involved in ABIS high-risk follow-up, Ulrica Swartling, our fantastic research nurse Iris Franzén and Lena Berglert. Thank you for good collaboration and nice trips all over Sydöstra Sverige to collect blood samples.

Everyone involved in ABIS pedometer study, especially Karina Huus, Anders Raustorp, Ulla Ludvigsson, Tomas Faresjö, Emma Ong-Pålsson and all the helpful school nurses.

The research nurses at the pediatric clinic, Ann-Marie Sandström and Eva Isaksson, for being very helpful when I have needed it. 
Everyone who worked at the Division of Pediatrics during my years there, especially Ammi Fornander, Maria Hjorth, Anna Rydén, and an extra thanks to Anne Lahdenperä who introduced me to qPCR.

Thanks to all present and former colleagues at KEF for providing a nice atmosphere at work!

For all the administrative assistance, Ann-Christine Gilmore-Ellis, Madeleine Örlin, Humlan Svensson and Chatarina Malm.

Forum Scientium, the multidisciplinary graduate school at Linköping University, for providing a chance to see so much beyond my own field of research.

Åsa Schippert and Anette Molbaek at Core Facility, for always being extremely helpful with the methods I have used, and Florence Sjögren for sharing your expertise in flow cytometry and always answering my English grammar queries.

Ida Eriksson and Björn Ingelsson for nice dinners, lunches, gaming nights and excursions.

Och sist, men defintivt inte minst:

Josefine, Jessica och Therese med familjer. Tack för alla middagar, fester och allmänt häng! Ett särskilt tack till Jossan för alla pass och alla tidiga morgonpromenader, saknar dom!

"Högtidsgänget”, inkl Frida, Björn, Ante, Johanna, Jocke, Karin, Ols och Linnea. Tack för alla midsomrar, nyår, valborg, halloween etc. genom åren!

Mina kära, kära vänner Emma Olsson och Emma Ong-Pålsson. Är så glad att ni finns i mitt liv, vad skulle jag göra utan er?

Svärmor Jayne och svärfar Örjan. Vilken tur att just jag fick de bästa svärföräldrarna! Tack för att ni båda finns där och hjälper oss med vad vi än kan tänkas behöva hjälp med!

Alla mina fina släktingar (både mina egna och alla som "kommer på köpet”), som bryr er och finns där för mig, särskilt alla Åkermannar i och kring Snuggan!

Lillebror Gabriel, min fina svägerska Sara och bästa lilla Albert, min hängivna hejarklack. Tack för all pepp och allt stöd! Åh vad jag önskar att jag fick se er lite oftare!

Lillebror Hampus, tack för din eviga pepp och ditt stora intresse för vad jag gör! Fortfarande imponerad av hur envist du tragglade dig igenom min första publikation, och frågade mig vad allt betydde via sms tills du fattade det mesta.

Mamma och pappa, tack för ert ändlösa stöd och er kärlek!

Kalle och Fred, tack för att ni finns i mitt liv och delar min vardag! 
This thesis was supported by grants from the Juvenile Diabetes Research Foundation (JDRF), the Swedish Research Council (Vetenskapsrådet, K2005-72X-11242-11A), the Swedish Child Diabetes Foundation (Barndiabetesfonden), the Medical Research Council of Southeast Sweden (Forskningsrådet i sydöstra sverige, FORSS), Östgöta Brandstodsbolag, the Novo Nordisk Foundation and ALF Grants, Region Östergötland. 


\section{REFERENCES}

1. Alberti, K.G. and P.Z. Zimmet, Definition, diagnosis and classification of diabetes mellitus and its complications. Part 1: diagnosis and classification of diabetes mellitus provisional report of a WHO consultation. Diabetic medicine : a journal of the British Diabetic Association, 1998. 15(7): p. 539-53.

2. (2) Classification and diagnosis of diabetes. Diabetes Care, 2015. 38 Suppl: p. S8-S16.

3. Diagnosis and classification of diabetes mellitus. Diabetes Care, 2014. 37 Suppl 1: p. S81-90.

4. Secrest, A.M., et al., Cause-specific mortality trends in a large population-based cohort with long-standing childhood-onset type 1 diabetes. Diabetes, 2010. 59(12): p. 3216-22.

5. Dahlquist, G. and B. Kallen, Mortality in childhood-onset type 1 diabetes: a population-based study. Diabetes Care, 2005. 28(10): p. 2384-7.

6. Skrivarhaug, T., et al., Long-term mortality in a nationwide cohort of childhood-onset type 1 diabetic patients in Norway. Diabetologia, 2006. 49(2): p. 298-305.

7. Laing, S.P., et al., The British Diabetic Association Cohort Study, I: all-cause mortality in patients with insulin-treated diabetes mellitus. Diabetic medicine : a journal of the British Diabetic Association, 1999. 16(6): p. 459-65.

8. Nordwall, M., et al., Declining incidence of severe retinopathy and persisting decrease of nephropathy in an unselected population of Type 1 diabetes-the Linkoping Diabetes Complications Study. Diabetologia, 2004. 47(7): p. 1266-72.

9. Bojestig, M., et al., Declining incidence of nephropathy in insulin-dependent diabetes mellitus. The New England journal of medicine, 1994. 330(1): p. 15-8.

10. Harding, J.L., et al., Age-Specific Trends From 2000-2011 in All-Cause and Cause-Specific Mortality in Type 1 and Type 2 Diabetes: A Cohort Study of More Than One Million People. Diabetes Care, 2016. 39(6): p. 1018-26.

11. Patterson, C.C., et al., Early mortality in EURODIAB population-based cohorts of type 1 diabetes diagnosed in childhood since 1989. Diabetologia, 2007. 50(12): p. 2439-42.

12. Sandahl, K., et al., Increased mortality in a Danish cohort of young people with Type 1 diabetes mellitus followed for 24 years. Diabetic medicine : a journal of the British Diabetic Association, 2016.

13. The effect of intensive treatment of diabetes on the development and progression of longterm complications in insulin-dependent diabetes mellitus. The Diabetes Control and Complications Trial Research Group. The New England journal of medicine, 1993. 329(14): p. 977-86.

14. Nathan, D.M., et al., Intensive diabetes treatment and cardiovascular disease in patients with type 1 diabetes. The New England journal of medicine, 2005. 353(25): p. 2643-53.

15. Nordwall, M., et al., Good glycemic control remains crucial in prevention of late diabetic complications--the Linkoping Diabetes Complications Study. Pediatric diabetes, 2009. 10(3): p. 168-76.

16. Nordwall, M., et al., Impact of HbA1c, followed from onset of type 1 diabetes, on the development of severe retinopathy and nephropathy: the VISS Study (Vascular Diabetic Complications in Southeast Sweden). Diabetes Care, 2015. 38(2): p. 308-15.

17. Standards of medical care in diabetes--2014. Diabetes Care, 2014. 37 Suppl 1: p. S14-80.

18. Orchard, T.J., et al., Association between 7 years of intensive treatment of type 1 diabetes and long-term mortality. JAMA, 2015. 313(1): p. 45-53.

19. Lind, M., et al., Glycemic control and excess mortality in type 1 diabetes. The New England journal of medicine, 2014. 371(21): p. 1972-82.

20. Beck, R.W., et al., The T1D Exchange clinic registry. The Journal of clinical endocrinology and metabolism, 2012. 97(12): p. 4383-9.

21. Incidence and trends of childhood Type 1 diabetes worldwide 1990-1999. Diabetic medicine : a journal of the British Diabetic Association, 2006. 23(8): p. 857-66. 
22. Berhan, Y., et al., Thirty years of prospective nationwide incidence of childhood type 1 diabetes: the accelerating increase by time tends to level off in Sweden. Diabetes, 2011. 60(2): p. 577-81.

23. Patterson, C.C., et al., Trends in childhood type 1 diabetes incidence in Europe during 19892008: evidence of non-uniformity over time in rates of increase. Diabetologia, 2012. 55(8): p. 2142-7.

24. Dahlquist, G. and L. Mustonen, Analysis of 20 years of prospective registration of childhood onset diabetes time trends and birth cohort effects. Swedish Childhood Diabetes Study Group. Acta paediatrica, 2000. 89(10): p. 1231-7.

25. Pundziute-Lycka, A., et al., The incidence of Type I diabetes has not increased but shifted to a younger age at diagnosis in the 0-34 years group in Sweden 1983-1998. Diabetologia, 2002. 45(6): p. 783-91.

26. Dahlquist, G.G., L. Nystrom, and C.C. Patterson, Incidence of type 1 diabetes in Sweden among individuals aged 0-34 years, 1983-2007: an analysis of time trends. Diabetes Care, 2011. 34(8): p. 1754-9.

27. Rawshani, A., et al., The incidence of diabetes among 0-34 year olds in Sweden: new data and better methods. Diabetologia, 2014. 57(7): p. 1375-81.

28. Kaprio, J., et al., Concordance for type 1 (insulin-dependent) and type 2 (non-insulindependent) diabetes mellitus in a population-based cohort of twins in Finland. Diabetologia, 1992. 35(11): p. 1060-7.

29. Kyvik, K.O., A. Green, and H. Beck-Nielsen, Concordance rates of insulin dependent diabetes mellitus: a population based study of young Danish twins. BMJ, 1995. 311(7010): p. 913-7.

30. Pociot, F. and A. Lernmark, Genetic risk factors for type 1 diabetes. Lancet, 2016. 387(10035): p. 2331-9.

31. Gough, S.C. and M.J. Simmonds, The HLA Region and Autoimmune Disease: Associations and Mechanisms of Action. Current genomics, 2007. 8(7): p. 453-65.

32. Ilonen, J., et al., Estimation of genetic risk for type 1 diabetes. American journal of medical genetics, 2002. 115(1): p. 30-6.

33. Sanjeevi, C.B., et al., Polymorphic amino acid variations in HLA-DQ are associated with systematic physical property changes and occurrence of IDDM. Members of the Swedish Childhood Diabetes Study. Diabetes, 1995. 44(1): p. 125-31.

34. Noble, J.A. and A.M. Valdes, Genetics of the HLA region in the prediction of type 1 diabetes. Current diabetes reports, 2011. 11(6): p. 533-42.

35. Pugliese, A., et al., HLA-DRB1*15:01-DQA1*01:02-DQB1*06:02 Haplotype Protects Autoantibody-Positive Relatives From Type 1 Diabetes Throughout the Stages of Disease Progression. Diabetes, 2016. 65(4): p. 1109-19.

36. Polychronakos, C. and Q. Li, Understanding type 1 diabetes through genetics: advances and prospects. Nature reviews. Genetics, 2011. 12(11): p. 781-92.

37. Bodansky, H.J., et al., Evidence for an environmental effect in the aetiology of insulin dependent diabetes in a transmigratory population. BMJ, 1992. 304(6833): p. 1020-2.

38. Feltbower, R.G., et al., Trends in the incidence of childhood diabetes in south Asians and other children in Bradford, UK. Diabetic medicine : a journal of the British Diabetic Association, 2002. 19(2): p. 162-6.

39. Delli, A.J., et al., Type 1 diabetes patients born to immigrants to Sweden increase their native diabetes risk and differ from Swedish patients in HLA types and islet autoantibodies. Pediatric diabetes, 2010. 11(8): p. 513-20.

40. Ilonen, J., et al., Patterns of beta-cell autoantibody appearance and genetic associations during the first years of life. Diabetes, 2013. 62(10): p. 3636-40.

41. Soderstrom, U., J. Aman, and A. Hjern, Being born in Sweden increases the risk for type 1 diabetes - a study of migration of children to Sweden as a natural experiment. Acta paediatrica, 2012. 101(1): p. 73-7. 
42. Hermann, R., et al., Temporal changes in the frequencies of HLA genotypes in patients with Type 1 diabetes--indication of an increased environmental pressure? Diabetologia, 2003. 46(3): p. 420-5.

43. Rewers, M. and J. Ludvigsson, Environmental risk factors for type 1 diabetes. Lancet, 2016. 387(10035): p. 2340-8.

44. Kondrashova, A. and H. Hyoty, Role of viruses and other microbes in the pathogenesis of type 1 diabetes. International reviews of immunology, 2014. 33(4): p. 284-95.

45. Coppieters, K.T., T. Boettler, and M. von Herrath, Virus infections in type 1 diabetes. Cold Spring Harbor perspectives in medicine, 2012. 2(1): p. a007682.

46. Krogvold, L., et al., Detection of a low-grade enteroviral infection in the islets of langerhans of living patients newly diagnosed with type 1 diabetes. Diabetes, 2015. 64(5): p. 1682-7.

47. Yeung, W.C., W.D. Rawlinson, and M.E. Craig, Enterovirus infection and type 1 diabetes mellitus: systematic review and meta-analysis of observational molecular studies. BMJ, 2011. 342: p. d35.

48. Stene, L.C., et al., Enterovirus infection and progression from islet autoimmunity to type 1 diabetes: the Diabetes and Autoimmunity Study in the Young (DAISY). Diabetes, 2010. 59(12): p. 3174-80.

49. Salminen, K., et al., Enterovirus infections are associated with the induction of beta-cell autoimmunity in a prospective birth cohort study. Journal of medical virology, 2003. 69(1): p. 91-8.

50. Grieco, F.A., et al., Immunology in the clinic review series; focus on type 1 diabetes and viruses: how viral infections modulate beta cell function. Clinical and experimental immunology, 2012. 168(1): p. 24-9.

51. Strachan, D.P., Hay fever, hygiene, and household size. BMJ, 1989. 299(6710): p. 1259-60.

52. Bach, J.F., The effect of infections on susceptibility to autoimmune and allergic diseases. The New England journal of medicine, 2002. 347(12): p. 911-20.

53. Knip, M. and H. Siljander, The role of the intestinal microbiota in type 1 diabetes mellitus. Nature reviews. Endocrinology, 2016. 12(3): p. 154-67.

54. Kostic, A.D., et al., The dynamics of the human infant gut microbiome in development and in progression toward type 1 diabetes. Cell host \& microbe, 2015. 17(2): p. 260-73.

55. Borch-Johnsen, K., et al., Relation between breast-feeding and incidence rates of insulindependent diabetes mellitus. A hypothesis. Lancet, 1984. 2(8411): p. 1083-6.

56. Cardwell, C.R., et al., Breast-feeding and childhood-onset type 1 diabetes: a pooled analysis of individual participant data from 43 observational studies. Diabetes Care, 2012. 35(11): p. 2215-25.

57. Frederiksen, B., et al., Infant exposures and development of type 1 diabetes mellitus: The Diabetes Autoimmunity Study in the Young (DAISY). JAMA pediatrics, 2013. 167(9): p. 80815.

58. Norris, J.M., et al., Timing of initial cereal exposure in infancy and risk of islet autoimmunity. JAMA, 2003. 290(13): p. 1713-20.

59. Nucci, A.M., S.M. Virtanen, and D.J. Becker, Infant Feeding and Timing of Complementary Foods in the Development of Type 1 Diabetes. Current diabetes reports, 2015. 15(9): p. 62.

60. Van Belle, T.L., C. Gysemans, and C. Mathieu, Vitamin D and diabetes: the odd couple. Trends in endocrinology and metabolism: TEM, 2013. 24(11): p. 561-8.

61. Dahlquist, G., S.S. Bennich, and B. Kallen, Intrauterine growth pattern and risk of childhood onset insulin dependent (type I) diabetes: population based case-control study. BMJ, 1996. 313(7066): p. 1174-7.

62. Stene, L.C., et al., Birth weight and childhood onset type 1 diabetes: population based cohort study. BMJ, 2001. 322(7291): p. 889-92.

63. Larsson, H.E., et al., Diabetes-associated HLA genotypes affect birthweight in the general population. Diabetologia, 2005. 48(8): p. 1484-91. 
64. Couper, J.J., et al., Weight gain in early life predicts risk of islet autoimmunity in children with a first-degree relative with type 1 diabetes. Diabetes Care, 2009. 32(1): p. 94-9.

65. Johansson, C., U. Samuelsson, and J. Ludvigsson, A high weight gain early in life is associated with an increased risk of type 1 (insulin-dependent) diabetes mellitus. Diabetologia, 1994. 37(1): p. 91-4.

66. Rapid early growth is associated with increased risk of childhood type 1 diabetes in various European populations. Diabetes Care, 2002. 25(10): p. 1755-60.

67. Knerr, I., et al., The 'accelerator hypothesis': relationship between weight, height, body mass index and age at diagnosis in a large cohort of 9,248 German and Austrian children with type 1 diabetes mellitus. Diabetologia, 2005. 48(12): p. 2501-4.

68. Dahlquist, G., Can we slow the rising incidence of childhood-onset autoimmune diabetes? The overload hypothesis. Diabetologia, 2006. 49(1): p. 20-4.

69. Ludvigsson, J., Why diabetes incidence increases--a unifying theory. Annals of the New York Academy of Sciences, 2006. 1079: p. 374-82.

70. Wilkin, T.J., The accelerator hypothesis: weight gain as the missing link between Type I and Type II diabetes. Diabetologia, 2001. 44(7): p. 914-22.

71. Sepa, A., et al., Psychological stress may induce diabetes-related autoimmunity in infancy. Diabetes Care, 2005. 28(2): p. 290-5.

72. Sepa, A., A. Frodi, and J. Ludvigsson, Mothers' experiences of serious life events increase the risk of diabetes-related autoimmunity in their children. Diabetes Care, 2005. 28(10): p. 23949.

73. Nygren, M., et al., Experience of a serious life event increases the risk for childhood type 1 diabetes: the ABIS population-based prospective cohort study. Diabetologia, 2015. 58(6): p. 1188-97.

74. Marre, M.L., E.A. James, and J.D. Piganelli, beta cell ER stress and the implications for immunogenicity in type 1 diabetes. Frontiers in cell and developmental biology, 2015. 3: $p$. 67.

75. Krogvold, L., et al., Pancreatic biopsy by minimal tail resection in live adult patients at the onset of type 1 diabetes: experiences from the DiViD study. Diabetologia, 2014. 57(4): p. 8413.

76. Gepts, W., Pathologic anatomy of the pancreas in juvenile diabetes mellitus. Diabetes, 1965. 14(10): p. 619-33.

77. Richardson, S.J., et al., Immunopathology of the human pancreas in type-I diabetes. Seminars in immunopathology, 2011. 33(1): p. 9-21.

78. Willcox, A., et al., Analysis of islet inflammation in human type 1 diabetes. Clinical and experimental immunology, 2009. 155(2): p. 173-81.

79. Waldron-Lynch, F. and K.C. Herold, Immunomodulatory therapy to preserve pancreatic betacell function in type 1 diabetes. Nature reviews. Drug discovery, 2011. 10(6): p. 439-52.

80. Thomas, H.E., J.A. Trapani, and T.W. Kay, The role of perforin and granzymes in diabetes. Cell death and differentiation, 2010. 17(4): p. 577-85.

81. Coppieters, K.T., et al., Demonstration of islet-autoreactive CD8 T cells in insulitic lesions from recent onset and long-term type 1 diabetes patients. The Journal of experimental medicine, 2012. 209(1): p. 51-60.

82. Affymetrix Panomics. 2014-09-22]; Available from: http://www.panomics.com/index.php?id=product 64.

83. Mosmann, T.R., et al., Two types of murine helper T cell clone. I. Definition according to profiles of lymphokine activities and secreted proteins. Journal of immunology, 1986. 136(7): p. 2348-57.

84. Zhu, J., H. Yamane, and W.E. Paul, Differentiation of effector CD4 T cell populations (*). Annual review of immunology, 2010. 28: p. 445-89. 
85. Bedoya, S.K., et al., Th17 Cells in Immunity and Autoimmunity. Clinical \& developmental immunology, 2013. 2013: p. 986789.

86. Walker, L.S. and M. von Herrath, CD4 T cell differentiation in type 1 diabetes. Clinical and experimental immunology, 2016. 183(1): p. 16-29.

87. Wing, K. and S. Sakaguchi, Regulatory $T$ cells exert checks and balances on self tolerance and autoimmunity. Nature immunology, 2010. 11(1): p. 7-13.

88. Gitelman, S.E. and J.A. Bluestone, Regulatory $T$ cell therapy for type 1 diabetes: May the force be with you. Journal of autoimmunity, 2016. 71: p. 78-87.

89. Benoist, C. and D. Mathis, Treg cells, life history, and diversity. Cold Spring Harbor perspectives in biology, 2012. 4(9): p. a007021.

90. Mason, G.M., et al., Phenotypic Complexity of the Human Regulatory T Cell Compartment Revealed by Mass Cytometry. Journal of immunology, 2015. 195(5): p. 2030-7.

91. Kuhn, C., et al., Regulatory mechanisms of immune tolerance in type 1 diabetes and their failures. Journal of autoimmunity, 2016. 71: p. 69-77.

92. Pihoker, C., et al., Autoantibodies in diabetes. Diabetes, 2005. 54 Suppl 2: p. S52-61.

93. Wong, F.S., et al., Investigation of the role of B-cells in type 1 diabetes in the NOD mouse. Diabetes, 2004. 53(10): p. 2581-7.

94. Pescovitz, M.D., et al., Rituximab, B-lymphocyte depletion, and preservation of beta-cell function. The New England journal of medicine, 2009. 361(22): p. 2143-52.

95. Wong, F.S. and L. Wen, $B$ cells in autoimmune diabetes. The review of diabetic studies : RDS, 2005. 2(3): p. 121-35.

96. Berthelot, J.M., et al., Regulatory B cells play a key role in immune system balance. Joint, bone, spine : revue du rhumatisme, 2013. 80(1): p. 18-22.

97. Blair, P.A., et al., CD19(+)CD24(hi)CD38(hi) B cells exhibit regulatory capacity in healthy individuals but are functionally impaired in systemic Lupus Erythematosus patients. Immunity, 2010. 32(1): p. 129-40.

98. Habib, T., et al., Altered B cell homeostasis is associated with type I diabetes and carriers of the PTPN22 allelic variant. Journal of immunology, 2012. 188(1): p. 487-96.

99. Bottazzo, G.F., A. Florin-Christensen, and D. Doniach, Islet-cell antibodies in diabetes mellitus with autoimmune polyendocrine deficiencies. Lancet, 1974. 2(7892): p. 1279-83.

100. MacCuish, A.C., et al., Antibodies to pancreatic islet cells in insulin-dependent diabetics with coexistent autoimmune disease. Lancet, 1974. 2(7896): p. 1529-31.

101. Baekkeskov, S., et al., Identification of the 64K autoantigen in insulin-dependent diabetes as the GABA-synthesizing enzyme glutamic acid decarboxylase. Nature, 1990. 347(6289): p. 151-6.

102. Rabin, D.U., et al., Cloning and expression of IDDM-specific human autoantigens. Diabetes, 1992. 41(2): p. 183-6.

103. Wenzlau, J.M., et al., The cation efflux transporter ZnT8 (S/c30A8) is a major autoantigen in human type 1 diabetes. Proc Natl Acad Sci U S A, 2007. 104(43): p. 17040-5.

104. Palmer, J.P., et al., Insulin antibodies in insulin-dependent diabetics before insulin treatment. Science, 1983. 222(4630): p. 1337-9.

105. Lampasona, V. and D. Liberati, Islet Autoantibodies. Current diabetes reports, 2016. 16(6): p. 53.

106. Jasinski, J.M. and G.S. Eisenbarth, Insulin as a primary autoantigen for type 1 A diabetes. Clinical \& developmental immunology, 2005. 12(3): p. 181-6.

107. Potter, K.N. and T.J. Wilkin, The molecular specificity of insulin autoantibodies. Diabetes/metabolism research and reviews, 2000. 16(5): p. 338-53.

108. Winter, W.E. and D. Pittman. The clinical application of islet autoantibody testing for the diagnosis of autoimmune diabetes. 2013 2016-10-10]; Available from: http://www.mloonline.com/the-clinical-application-of-islet-autoantibody-testing-for-the-diagnosis-ofautoimmune-diabetes.php 
109. Baekkeskov, S., et al., Autoantibodies in newly diagnosed diabetic children immunoprecipitate human pancreatic islet cell proteins. Nature, 1982. 298(5870): p. 167-9.

110. Leslie, R.D., M.A. Atkinson, and A.L. Notkins, Autoantigens IA-2 and GAD in Type I (insulindependent) diabetes. Diabetologia, 1999. 42(1): p. 3-14.

111. Lu, J., et al., Identification of a second transmembrane protein tyrosine phosphatase, IA2 beta, as an autoantigen in insulin-dependent diabetes mellitus: precursor of the 37-kDa tryptic fragment. Proceedings of the National Academy of Sciences of the United States of America, 1996. 93(6): p. 2307-11.

112. McLaughlin, K.A., et al., Identification of Tetraspanin-7 as a Target of Autoantibodies in Type 1 Diabetes. Diabetes, 2016. 65(6): p. 1690-8.

113. Krischer, J.P., et al., The 6 year incidence of diabetes-associated autoantibodies in genetically at-risk children: the TEDDY study. Diabetologia, 2015. 58(5): p. 980-7.

114. Ziegler, A.G. and E. Bonifacio, Age-related islet autoantibody incidence in offspring of patients with type 1 diabetes. Diabetologia, 2012. 55(7): p. 1937-43.

115. Parikka, V., et al., Early seroconversion and rapidly increasing autoantibody concentrations predict prepubertal manifestation of type 1 diabetes in children at genetic risk. Diabetologia, 2012. 55(7): p. 1926-36.

116. Insel, R.A., et al., Staging presymptomatic type 1 diabetes: a scientific statement of JDRF, the Endocrine Society, and the American Diabetes Association. Diabetes Care, 2015. 38(10): p. 1964-74.

117. Skyler, J.S., Prevention and reversal of type 1 diabetes--past challenges and future opportunities. Diabetes Care, 2015. 38(6): p. 997-1007.

118. Steffes, M.W., et al., Beta-cell function and the development of diabetes-related complications in the diabetes control and complications trial. Diabetes Care, 2003. 26(3): p. 832-6.

119. Ludvigsson, J., et al., C-peptide in juvenile diabetics beyond the postinitial remission period. Relation to clinical manifestations at onset of diabetes, remission and diabetic control. Acta paediatrica Scandinavica, 1977. 66(2): p. 177-84.

120. Knip, M., et al., Hydrolyzed infant formula and early beta-cell autoimmunity: a randomized clinical trial. JAMA, 2014. 311(22): p. 2279-87.

121. Ludvigsson, J., et al., Plasmapheresis in the initial treatment of insulin-dependent diabetes mellitus in children. British medical journal, 1983. 286(6360): p. 176-8.

122. Chatenoud, L., K. Warncke, and A.G. Ziegler, Clinical immunologic interventions for the treatment of type 1 diabetes. Cold Spring Harbor perspectives in medicine, 2012. 2(8).

123. Sherry, N., et al., Teplizumab for treatment of type 1 diabetes (Protege study): 1-year results from a randomised, placebo-controlled trial. Lancet, 2011. 378(9790): p. 487-97.

124. Pescovitz, M.D., et al., B-lymphocyte depletion with rituximab and beta-cell function: twoyear results. Diabetes Care, 2014. 37(2): p. 453-9.

125. Ludvigsson, J., et al., GAD treatment and insulin secretion in recent-onset type 1 diabetes. $\mathrm{N}$ Engl J Med, 2008. 359(18): p. 1909-20.

126. Ludvigsson, J., et al., GAD65 antigen therapy in recently diagnosed type 1 diabetes mellitus. N Engl J Med. 366(5): p. 433-42.

127. Andersson, C., et al., Glucose tolerance and beta-cell function in islet autoantibody-positive children recruited to a secondary prevention study. Pediatric Diabetes, 2013. 14(5): p. 341349.

128. Effects of insulin in relatives of patients with type 1 diabetes mellitus. N Engl J Med, 2002. 346(22): p. 1685-91.

129. Skyler, J.S., et al., Effects of oral insulin in relatives of patients with type 1 diabetes: The Diabetes Prevention Trial--Type 1. Diabetes Care, 2005. 28(5): p. 1068-76.

130. Bluestone, J.A., et al., Type 1 diabetes immunotherapy using polyclonal regulatory $T$ cells. Science translational medicine, 2015. 7(315): p. 315ra189. 
131. Yi, T. and S.U. Song, Immunomodulatory properties of mesenchymal stem cells and their therapeutic applications. Arch Pharm Res. 35(2): p. 213-21.

132. Le Blanc, K. and O. Ringden, Immunomodulation by mesenchymal stem cells and clinical experience. J Intern Med, 2007. 262(5): p. 509-25.

133. Carlsson, P.O., et al., Preserved beta-cell function in type 1 diabetes by mesenchymal stromal cells. Diabetes, 2015. 64(2): p. 587-92.

134. Eisenbarth, G.S., Type I diabetes mellitus. A chronic autoimmune disease. The New England journal of medicine, 1986. 314(21): p. 1360-8.

135. Atkinson, M.A., G.S. Eisenbarth, and A.W. Michels, Type 1 diabetes. Lancet, 2014. 383(9911): p. 69-82.

136. Herold, K.C., et al., beta cell death and dysfunction during type 1 diabetes development in atrisk individuals. The Journal of clinical investigation, 2015. 125(3): p. 1163-73.

137. Ludvigsson, J. and L.G. Heding, beta-cell function in children with diabetes. Diabetes, 1978. 27 Suppl 1: p. 230-4.

138. Keenan, H.A., et al., Residual insulin production and pancreatic ss-cell turnover after 50 years of diabetes: Joslin Medalist Study. Diabetes, 2010. 59(11): p. 2846-53.

139. Jones, A.G. and A.T. Hattersley, The clinical utility of C-peptide measurement in the care of patients with diabetes. Diabetic medicine : a journal of the British Diabetic Association, 2013. 30(7): p. 803-17.

140. Sacks, D.B., A1C versus glucose testing: a comparison. Diabetes Care, 2011. 34(2): p. 518-23.

141. Mahon, J.L., et al., The TrialNet Natural History Study of the Development of Type 1 Diabetes: objectives, design, and initial results. Pediatric diabetes, 2009. 10(2): p. 97-104.

142. Familial risk of type I diabetes in European children. The Eurodiab Ace Study Group and The Eurodiab Ace Substudy 2 Study Group. Diabetologia, 1998. 41(10): p. 1151-6.

143. The Environmental Determinants of Diabetes in the Young (TEDDY) study: study design. Pediatric diabetes, 2007. 8(5): p. 286-98.

144. Kupila, A., et al., Feasibility of genetic and immunological prediction of type I diabetes in a population-based birth cohort. Diabetologia, 2001. 44(3): p. 290-7.

145. Ziegler, A.G., et al., Seroconversion to multiple islet autoantibodies and risk of progression to diabetes in children. JAMA : the journal of the American Medical Association, 2013. 309(23): p. 2473-9.

146. De Grijse, J., et al., Predictive power of screening for antibodies against insulinomaassociated protein 2 beta (IA-2beta) and zinc transporter-8 to select first-degree relatives of type 1 diabetic patients with risk of rapid progression to clinical onset of the disease: implications for prevention trials. Diabetologia, 2010. 53(3): p. 517-24.

147. Gorus, F.K., et al., Screening for insulinoma antigen 2 and zinc transporter 8 autoantibodies: a cost-effective and age-independent strategy to identify rapid progressors to clinical onset among relatives of type 1 diabetic patients. Clinical and experimental immunology, 2013. 171(1): p. 82-90.

148. Sosenko, J.M., et al., Incident dysglycemia and progression to type 1 diabetes among participants in the Diabetes Prevention Trial-Type 1. Diabetes Care, 2009. 32(9): p. 1603-7.

149. Krischer, J.P., The use of intermediate endpoints in the design of type 1 diabetes prevention trials. Diabetologia, 2013. 56(9): p. 1919-24.

150. Veijola, R., et al., Dysregulation of glucose metabolism in preclinical type 1 diabetes. Pediatric diabetes, 2016. 17 Suppl 22: p. 25-30.

151. Fourlanos, S., et al., Insulin resistance is a risk factor for progression to type 1 diabetes. Diabetologia, 2004. 47(10): p. 1661-7.

152. Xu, P., et al., Role of insulin resistance in predicting progression to type 1 diabetes. Diabetes Care, 2007. 30(9): p. 2314-20. 
153. Raab, J., et al., Capillary blood islet autoantibody screening for identifying pre-type 1 diabetes in the general population: design and initial results of the Fr1da study. BMJ open, 2016. 6(5): p. e011144.

154. Roep, B.O. and M. Peakman, Antigen targets of type 1 diabetes autoimmunity. Cold Spring Harbor perspectives in medicine, 2012. 2(4): p. a007781.

155. Pascual, V., D. Chaussabel, and J. Banchereau, A genomic approach to human autoimmune diseases. Annu Rev Immunol, 2009. 28: p. 535-71.

156. Ferreira, R.C., et al., A type I interferon transcriptional signature precedes autoimmunity in children genetically at risk for type 1 diabetes. Diabetes, 2014. 63(7): p. 2538-50.

157. Kallionpaa, H., et al., Innate immune activity is detected prior to seroconversion in children with HLA-conferred type 1 diabetes susceptibility. Diabetes, 2014. 63(7): p. 2402-14.

158. Reynier, F., et al., Specific gene expression signature associated with development of autoimmune type-I diabetes using whole-blood microarray analysis. Genes and immunity, 2010. 11(3): p. 269-78.

159. Elo, L.L., et al., Early suppression of immune response pathways characterizes children with prediabetes in genome-wide gene expression profiling. J Autoimmun. 35(1): p. 70-6.

160. Jin, Y., et al., Risk of type 1 diabetes progression in islet autoantibody-positive children can be further stratified using expression patterns of multiple genes implicated in peripheral blood lymphocyte activation and function. Diabetes, 2014. 63(7): p. 2506-15.

161. Moulder, R., et al., Serum proteomes distinguish children developing type 1 diabetes in a cohort with HLA-conferred susceptibility. Diabetes, 2015. 64(6): p. 2265-78.

162. Wang, X., et al., Identification of a molecular signature in human type 1 diabetes mellitus using serum and functional genomics. J Immunol, 2008. 180(3): p. 1929-37.

163. Lee, R.C., R.L. Feinbaum, and V. Ambros, The C. elegans heterochronic gene lin-4 encodes small RNAs with antisense complementarity to lin-14. Cell, 1993. 75(5): p. 843-54.

164. Holley, C.L. and V.K. Topkara, An introduction to small non-coding RNAs: miRNA and snoRNA. Cardiovasc Drugs Ther, 2011. 25(2): p. 151-9.

165. Mo, M.H., et al., Cell-free Circulating miRNA Biomarkers in Cancer. J Cancer, 2012. 3: p. 43248.

166. Pauley, K.M., S. Cha, and E.K. Chan, MicroRNA in autoimmunity and autoimmune diseases. J Autoimmun, 2009. 32(3-4): p. 189-94.

167. Miska, E.A., How microRNAs control cell division, differentiation and death. Current opinion in genetics \& development, 2005. 15(5): p. 563-8.

168. Yang, M., et al., Decreased miR-146 expression in peripheral blood mononuclear cells is correlated with ongoing islet autoimmunity in type 1 diabetes patients 1 miR-146. Journal of diabetes, 2015. 7(2): p. 158-65.

169. Takahashi, P., et al., MicroRNA expression profiling and functional annotation analysis of their targets in patients with type 1 diabetes mellitus. Gene, 2014. 539(2): p. 213-23.

170. Salas-Perez, F., et al., MicroRNAs miR-21a and miR-93 are down regulated in peripheral blood mononuclear cells (PBMCs) from patients with type 1 diabetes. Immunobiology, 2013. 218(5): p. 733-7.

171. Sebastiani, G., et al., Increased expression of microRNA miR-326 in type 1 diabetic patients with ongoing islet autoimmunity. Diabetes/metabolism research and reviews, 2011. 27(8): p. 862-6.

172. Hezova, R., et al., microRNA-342, microRNA-191 and microRNA-510 are differentially expressed in T regulatory cells of type 1 diabetic patients. Cellular immunology, 2010. 260(2): p. 70-4.

173. Roggli, E., et al., Changes in microRNA expression contribute to pancreatic beta-cell dysfunction in prediabetic NOD mice. Diabetes, 2012. 61(7): p. 1742-51.

174. Nielsen, L.B., et al., Circulating levels of microRNA from children with newly diagnosed type 1 diabetes and healthy controls: evidence that miR-25 associates to residual beta-cell function 
and glycaemic control during disease progression. Experimental diabetes research, 2012. 2012: p. 896362.

175. Bonifacio, E., Predicting type 1 diabetes using biomarkers. Diabetes Care, 2015. 38(6): p. 98996.

176. Ludvigsson, J., M. Ludvigsson, and A. Sepa, Screening for prediabetes in the general child population: maternal attitude to participation. Pediatr Diabetes, 2001. 2(4): p. 170-4.

177. World Health Organization, Definition and diagnosis of diabetes mellitus and intermediate hyperglycemia: report of a WHO/IDF consultation., 2006: Geneva, Switzerland.

178. Matthews, D.R., et al., Homeostasis model assessment: insulin resistance and beta-cell function from fasting plasma glucose and insulin concentrations in man. Diabetologia, 1985. 28(7): p. 412-9.

179. Levy, J.C., D.R. Matthews, and M.P. Hermans, Correct homeostasis model assessment (HOMA) evaluation uses the computer program. Diabetes Care, 1998. 21(12): p. 2191-2.

180. Grubin, C.E., et al., A novel radioligand binding assay to determine diagnostic accuracy of isoform-specific glutamic acid decarboxylase antibodies in childhood IDDM. Diabetologia, 1994. 37(4): p. 344-50.

181. Vaziri-Sani, F., et al., A novel triple mix radiobinding assay for the three ZnT8 (ZnT8-RWQ) autoantibody variants in children with newly diagnosed diabetes. J Immunol Methods, 2011. 371(1-2): p. 25-37.

182. Williams, A.J., et al., A novel micro-assay for insulin autoantibodies. J Autoimmun, 1997. 10(5): p. 473-8.

183. Holmberg, H., et al., Higher prevalence of autoantibodies to insulin and GAD65 in Swedish compared to Lithuanian children with type 1 diabetes. Diabetes Res Clin Pract, 2006. 72(3): p. 308-14.

184. Lavant, E.H., et al., A new PCR-SSP method for HLA DR-DQ risk assessment for celiac disease. Clinica chimica acta; international journal of clinical chemistry, 2011. 412(9-10): p. 782-4.

185. Lavant, E.H. and J.A. Carlson, A new automated human leukocyte antigen genotyping strategy to identify $D R-D Q$ risk alleles for celiac disease and type 1 diabetes mellitus. Clin Chem Lab Med, 2009. 47(12): p. 1489-95.

186. Gullstrand, C., et al., Progression to type 1 diabetes and autoantibody positivity in relation to HLA-risk genotypes in children participating in the ABIS study. Pediatr Diabetes, 2008. 9(3 Pt 1): p. 182-90.

187. Helminen, O., et al., OGTT and random plasma glucose in the prediction of type 1 diabetes and time to diagnosis. Diabetologia, 2015. 58(8): p. 1787-96.

188. Hekkala, A., et al., Family history of diabetes and distribution of class II HLA genotypes in children with newly diagnosed type 1 diabetes: effect on diabetic ketoacidosis. European journal of endocrinology / European Federation of Endocrine Societies, 2011. 165(5): p. 8137.

189. Andersen, C.L., J.L. Jensen, and T.F. Orntoft, Normalization of real-time quantitative reverse transcription-PCR data: a model-based variance estimation approach to identify genes suited for normalization, applied to bladder and colon cancer data sets. Cancer Res, 2004. 64(15): p. 5245-50.

190. Exiqon. Locked Nucleic Acid (LNA $\left.{ }^{T M}\right)$ Technology 2016 2016-10-10]; Available from: http://www.exiqon.com/Ina-technology.

191. Sallis, J.F. and B.E. Saelens, Assessment of physical activity by self-report: status, limitations, and future directions. Res Q Exerc Sport, 2000. 71(2 Suppl): p. S1-14.

192. Atkin, A.J., et al., Methods of Measurement in epidemiology: Sedentary Behaviour. International journal of epidemiology, 2012. 41(5): p. 1460-1471.

193. Yeung, K.Y. and W.L. Ruzzo, Principal component analysis for clustering gene expression data. Bioinformatics, 2001. 17(9): p. 763-74. 
194. Ludvigsson, J., Why diabetes incidence increases--a unifying theory. Ann N Y Acad Sci, 2006. 1079: p. 374-82.

195. Elding Larsson, H., C. Larsson, and A. Lernmark, Baseline heterogeneity in glucose metabolism marks the risk for type 1 diabetes and complicates secondary prevention. Acta diabetologica, 2015. 52(3): p. 473-81.

196. Brorsson, C., et al., Correlations between islet autoantibody specificity and the SLC3OA8 genotype with HLA-DQB1 and metabolic control in new onset type 1 diabetes. Autoimmunity, 2011. 44(2): p. 107-14.

197. Graham, J., et al., Genetic effects on age-dependent onset and islet cell autoantibody markers in type 1 diabetes. Diabetes, 2002. 51(5): p. 1346-55.

198. Lundgren, M., et al., Reduced morbidity at diagnosis and improved glycemic control in children previously enrolled in DiPis follow-up. Pediatric diabetes, 2014. 15(7): p. 494-501.

199. Elding Larsson, H., et al., Children followed in the TEDDY study are diagnosed with type 1 diabetes at an early stage of disease. Pediatric diabetes, 2014. 15(2): p. 118-26.

200. Baughcum, A.E., et al., Maternal efforts to prevent type 1 diabetes in at-risk children. Diabetes Care, 2005. 28(4): p. 916-21.

201. Azar, S.T., et al., Type I (insulin-dependent) diabetes is a Th1-and Th2-mediated autoimmune disease. Clinical and diagnostic laboratory immunology, 1999. 6(3): p. 306-10.

202. Mallone, R., V. Brezar, and C. Boitard, T cell recognition of autoantigens in human type 1 diabetes: clinical perspectives. Clin Dev Immunol, 2011. 2011: p. 513210.

203. Lindley, S., et al., Defective suppressor function in CD4(+)CD25(+) T-cells from patients with type 1 diabetes. Diabetes, 2005. 54(1): p. 92-9.

204. Brusko, T.M., et al., Functional defects and the influence of age on the frequency of CD4+ CD25+ T-cells in type 1 diabetes. Diabetes, 2005. 54(5): p. 1407-14.

205. Cope, A.P., Regulation of autoimmunity by proinflammatory cytokines. Curr Opin Immunol, 1998. 10(6): p. 669-76.

206. Tchilian, E.Z. and P.C. Beverley, Altered CD45 expression and disease. Trends Immunol, 2006. 27(3): p. 146-53.

207. Han, D., et al., Immune profiling by multiple gene expression analysis in patients at-risk and with type 1 diabetes. Clin Immunol, 2011. 139(3): p. 290-301.

208. Huck, S., et al., Expression of B cell receptor-associated signaling molecules in human lupus. Autoimmunity, 2001. 33(3): p. 213-24.

209. Wood, J.P., et al., CD45 exon 4 point mutation does not confer susceptibility to type 1 diabetes mellitus or Graves' disease. Eur J Immunogenet, 2002. 29(1): p. 73-4.

210. Thude, $\mathrm{H}$., et al., A transmembrane protein-tyrosine phosphatase receptor type $C$ (CD45) exon $A$ point mutation ( $77 \mathrm{C}$ to $\mathrm{G}$ ) is not associated with the development of type 1 diabetes mellitus in a German population. Eur J Immunogenet, 2004. 31(6): p. 245-7.

211. Hanifi-Moghaddam, P., et al., Altered chemokine levels in individuals at risk of Type 1 diabetes mellitus. Diabet Med, 2006. 23(2): p. 156-63.

212. Lohmann, T., et al., Reduced expression of Th1-associated chemokine receptors on peripheral blood lymphocytes at diagnosis of type 1 diabetes. Diabetes, 2002. 51(8): p. 2474-80.

213. Pfleger, C., et al., Relation of circulating concentrations of chemokine receptor CCR5 ligands to C-peptide, proinsulin and HbA1c and disease progression in type 1 diabetes. Clin Immunol, 2008. 128(1): p. 57-65.

214. Zhernakova, A., et al., Genetic variants of RANTES are associated with serum RANTES level and protection for type 1 diabetes. Genes Immun, 2006. 7(7): p. 544-9.

215. Sabbah, E., et al., Diabetes-associated autoantibodies in relation to clinical characteristics and natural course in children with newly diagnosed type 1 diabetes. The Childhood Diabetes In Finland Study Group. J Clin Endocrinol Metab, 1999. 84(5): p. 1534-9.

216. Sosenko, J.M., et al., Patterns of metabolic progression to type 1 diabetes in the Diabetes Prevention Trial-Type 1. Diabetes Care, 2006. 29(3): p. 643-9. 
217. Veljkovic, J. and U. Hansen, Lineage-specific and ubiquitous biological roles of the mammalian transcription factor LSF. Gene, 2004. 343(1): p. 23-40.

218. Seavey, M.M. and P. Dobrzanski, The many faces of Janus kinase. Biochem Pharmacol, 2012. 83(9): p. 1136-45.

219. Appleman, L.J., et al., CD28 costimulation mediates $T$ cell expansion via IL-2-independent and IL-2-dependent regulation of cell cycle progression. J Immunol, 2000. 164(1): p. 144-51.

220. Kornete, M. and C.A. Piccirillo, Critical co-stimulatory pathways in the stability of Foxp3+ Treg cell homeostasis in Type I diabetes. Autoimmunity reviews, 2011. 11(2): p. 104-11.

221. Salomon, B. and J.A. Bluestone, Complexities of CD28/B7: CTLA-4 costimulatory pathways in autoimmunity and transplantation. Annu Rev Immunol, 2001. 19: p. 225-52.

222. Kaizer, E.C., et al., Gene expression in peripheral blood mononuclear cells from children with diabetes. J Clin Endocrinol Metab, 2007. 92(9): p. 3705-11.

223. Chen, X., et al., Characterization of microRNAs in serum: a novel class of biomarkers for diagnosis of cancer and other diseases. Cell research, 2008. 18(10): p. 997-1006.

224. Collares, C.V., et al., Identifying common and specific microRNAs expressed in peripheral blood mononuclear cell of type 1 , type 2 , and gestational diabetes mellitus patients. BMC research notes, 2013. 6: p. 491.

225. Frost, R.J. and E.N. Olson, Control of glucose homeostasis and insulin sensitivity by the Let-7 family of microRNAs. Proceedings of the National Academy of Sciences of the United States of America, 2011. 108(52): p. 21075-80.

226. Dooley, J., et al., The microRNA-29 Family Dictates the Balance Between Homeostatic and Pathological Glucose Handling in Diabetes and Obesity. Diabetes, 2016. 65(1): p. 53-61.

227. Zhou, R., et al., Mitochondria-related miR-151a-5p reduces cellular ATP production by targeting CYTB in asthenozoospermia. Scientific reports, 2015. 5: p. 17743.

228. Nielsen, S., et al., The miRNA plasma signature in response to acute aerobic exercise and endurance training. PLoS One, 2014. 9(2): p. e87308.

229. Zhang, Y., et al., MicroRNA-106b induces mitochondrial dysfunction and insulin resistance in C2C12 myotubes by targeting mitofusin-2. Molecular and cellular endocrinology, 2013. 381(1-2): p. 230-40.

230. Gallagher, I.J., et al., Integration of microRNA changes in vivo identifies novel molecular features of muscle insulin resistance in type 2 diabetes. Genome medicine, 2010. 2(2): p. 9.

231. Abuhatzira, L., et al., Multiple microRNAs within the $14 q 32$ cluster target the mRNAs of major type 1 diabetes autoantigens IA-2, IA-2beta, and GAD65. FASEB journal : official publication of the Federation of American Societies for Experimental Biology, 2015. 29(10): p. 4374-83.

232. Bjork, E., et al., Glucose regulation of the autoantigen GAD65 in human pancreatic islets. The Journal of clinical endocrinology and metabolism, 1992. 75(6): p. 1574-6.

233. Mandemakers, W., et al., Co-regulation of intragenic microRNA miR-153 and its host gene la2 beta: identification of miR-153 target genes with functions related to IA-2beta in pancreas and brain. Diabetologia, 2013. 56(7): p. 1547-56.

234. Karolina, D.S., et al., MicroRNA 144 impairs insulin signaling by inhibiting the expression of insulin receptor substrate 1 in type 2 diabetes mellitus. PLoS One, 2011. 6(8): p. e22839.

235. Krist, B., et al., The Role of miR-378a in Metabolism, Angiogenesis, and Muscle Biology. International journal of endocrinology, 2015. 2015: p. 281756.

236. Carrer, M., et al., Control of mitochondrial metabolism and systemic energy homeostasis by microRNAs 378 and 378*. Proceedings of the National Academy of Sciences of the United States of America, 2012. 109(38): p. 15330-5.

237. Ding, S., et al., Decreased microRNA-142-3p/5p expression causes CD4+ T cell activation and B cell hyperstimulation in systemic lupus erythematosus. Arthritis and rheumatism, 2012. 64(9): p. 2953-63.

238. Roggli, E., et al., Involvement of microRNAs in the cytotoxic effects exerted by proinflammatory cytokines on pancreatic beta-cells. Diabetes, 2010. 59(4): p. 978-86. 
239. Melkman-Zehavi, T., et al., miRNAs control insulin content in pancreatic beta-cells via downregulation of transcriptional repressors. The EMBO journal, 2011. 30(5): p. 835-45.

240. Foley, N.H. and L.A. O'Neill, miR-107: a toll-like receptor-regulated miRNA dysregulated in obesity and type II diabetes. Journal of leukocyte biology, 2012. 92(3): p. 521-7.

241. Sebastiani, G., I. Spagnuolo, and A. Patti, MicroRNA expression fingerprint in serum of type 1 diabetic patients. Diabetologia, 2012. 55: p. S48.

242. Larsson, C., O. Hernell, and T. Lind, Moderately elevated body mass index is associated with metabolic variables and cardiovascular risk factors in Swedish children. Acta paediatrica, 2011. 100(1): p. 102-8.

243. Danielsen, Y.S., et al., The relationship between life-style and cardio-metabolic risk indicators in children: the importance of screen time. Acta paediatrica, 2011. 100(2): p. 253-9.

244. Hjorth, M.F., et al., Low physical activity level and short sleep duration are associated with an increased cardio-metabolic risk profile: a longitudinal study in 8-11 year old Danish children. PLoS One, 2014. 9(8): p. e104677.

245. Flodmark, C.E., et al., New insights into the field of children and adolescents' obesity: the European perspective. International journal of obesity and related metabolic disorders : journal of the International Association for the Study of Obesity, 2004. 28(10): p. 1189-96.

246. Wilkin, T.J., et al., The relative contributions of birth weight, weight change, and current weight to insulin resistance in contemporary 5-year-olds: the EarlyBird Study. Diabetes, 2002. 51(12): p. 3468-72.

247. Tudor-Locke, C., et al., BMI-referenced standards for recommended pedometer-determined steps/day in children. Prev Med, 2004. 38(6): p. 857-64.

248. Guinhouya, B.C., et al., Evidence of the influence of physical activity on the metabolic syndrome and/or on insulin resistance in pediatric populations: a systematic review. International journal of pediatric obesity : IJPO : an official journal of the International Association for the Study of Obesity, 2011. 6(5-6): p. 361-88.

249. Ekelund, U., et al., Moderate to vigorous physical activity and sedentary time and cardiometabolic risk factors in children and adolescents. Jama, 2012. 307(7): p. 704-712.

250. Bjork, E., et al., Expression of the $64 \mathrm{kDa} /$ glutamic acid decarboxylase rat islet cell autoantigen is influenced by the rate of insulin secretion. Diabetologia, 1992. 35(5): p. 490-3.

251. McLaughlin, R.J., et al., Where, How, and When: Positioning Posttranslational Modification Within Type 1 Diabetes Pathogenesis. Current diabetes reports, 2016. 16(7): p. 63.

252. Raustorp, A., R.P. Pangrazi, and A. Stahle, Physical activity level and body mass index among schoolchildren in south-eastern Sweden. Acta paediatrica, 2004. 93(3): p. 400-4.

253. Telford, R.D., et al., Effects of changes in adiposity and physical activity on preadolescent insulin resistance: the Australian LOOK longitudinal study. PLoS One, 2012. 7(10): p. e47438.

254. Beets, M.W., et al., Pedometer-measured physical activity patterns of youth: a 13-country review. American journal of preventive medicine, 2010. 38(2): p. 208-16.

255. Whitaker, R.C., et al., Predicting obesity in young adulthood from childhood and parental obesity. The New England journal of medicine, 1997. 337(13): p. 869-73. 



\section{Papers}

The articles associated with this thesis have been removed for copyright reasons. For more details about these see:

http://urn.kb.se/resolve?urn=urn:nbn:se:liu:diva- 132171 